
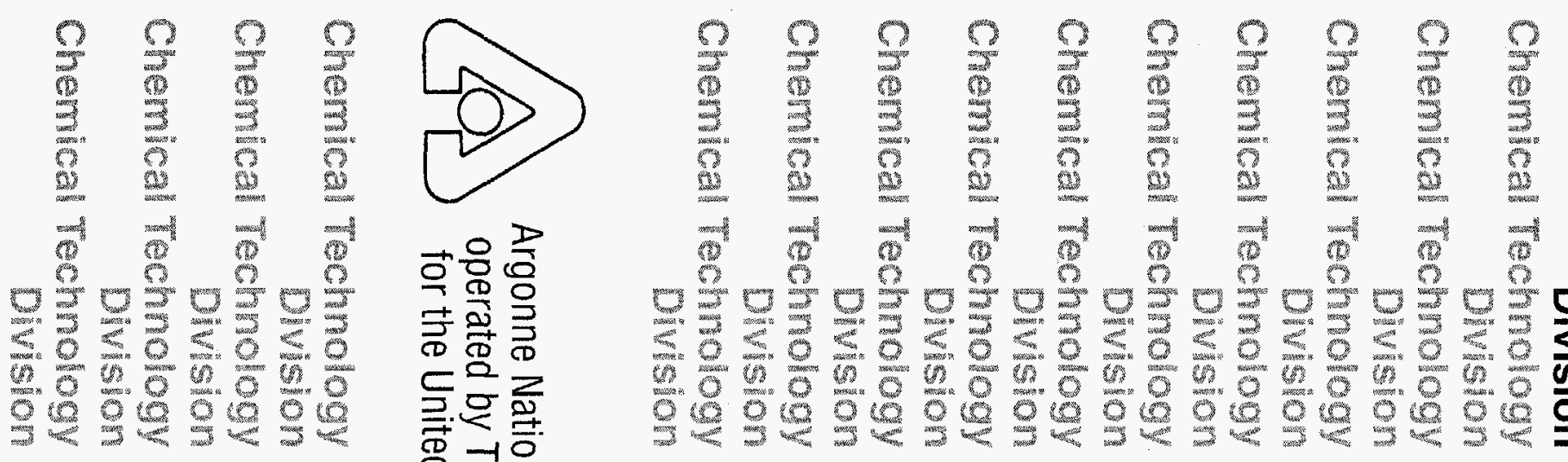

들유류.

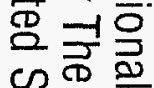

爱气呂

官

声家.

욜을

䙲

丞

우융 공

罢

产

夏

8 崩

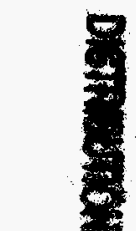

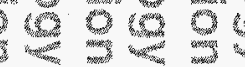

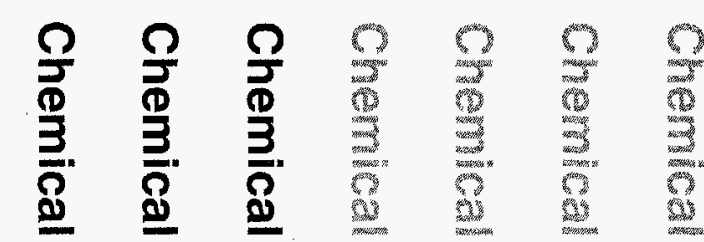

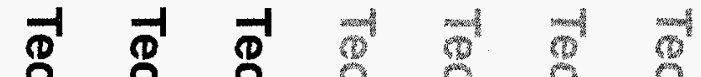

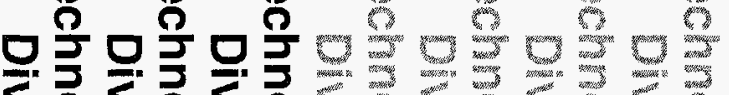

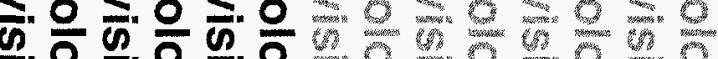

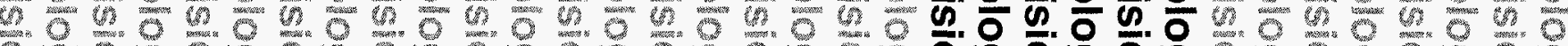
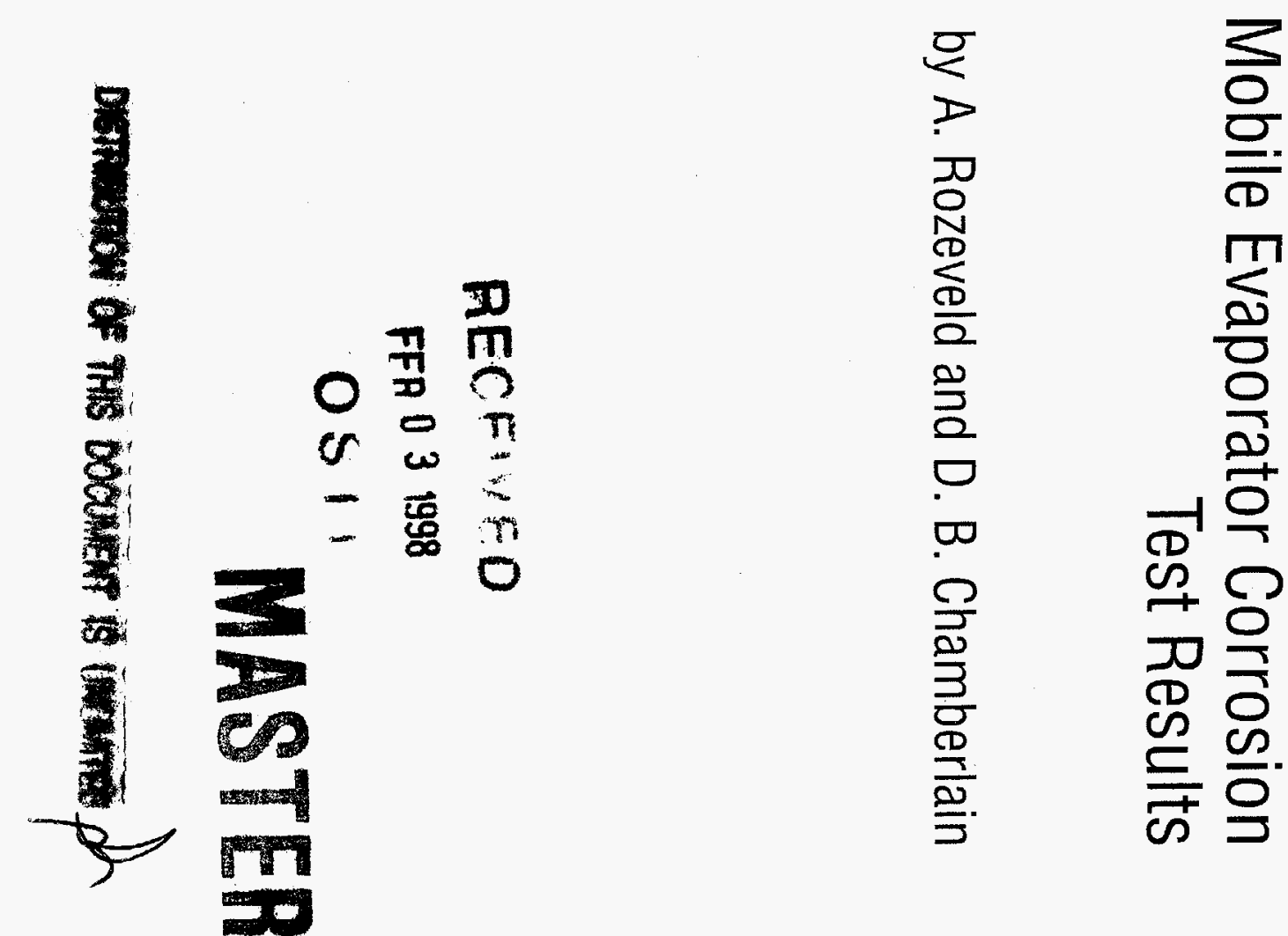
Argonne National Laboratory, with facilities in the states of Illinois and Idaho, is owned by the United States government, and operated by The University of Chicago under the provisions of a contract with the Department of Energy.

\section{DISCLAIMER}

This report was prepared as an account of work sponsored by an agency of the United States Government. Neither the United States Government nor any agency thereof, nor any of their employees, makes any warranty, express or implied, or assumes any legal liability or responsibility for the accuracy, completeness, or usefulness of any information, apparatus, product, or process disclosed, or represents that its use would not infringe privately owned rights. Reference herein to any specific commercial product, process, or service by trade name, trademark, manufacturer, or otherwise, does not necessarily constitute or imply its endorsement, recommendation, or favoring by the United States Government or any agency thereof. The views and opinions of authors expressed herein do not necessarily state or reflect those of the United States Government or any agency thereof.

Reproduced from the best available copy.

Available to DOE and DOE contractors from the

Office of Scientific and Technical Information

P.O. Box 62

Oak Ridge, TN 37831

Prices available from (423) 576-8401

Available to the public from the

National Technical Information Service

U.S. Department of Commerce

5285 Port Royal Road

Springfield, VA 22161 


\section{DISCLAIMER}

Portions of this document may be illegible electronic image products. Images are produced from the best available original document. 
Distribution Category:

Radioactive Waste Tank

Remediation

(UC-2030)

ANL-97/2

\section{ARGONNE NATIONAL LABORATORY \\ 9700 South Cass Avenue \\ Argonne, IL 60439}

\section{MOBILE EVAPORATOR \\ CORROSION TEST RESULTS}

by

A. Rozeveld and D. B. Chamberlain

Chemical Technology Division

May 1997 


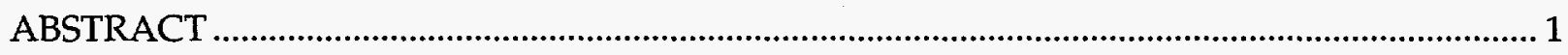

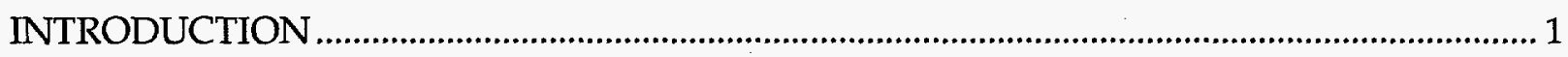

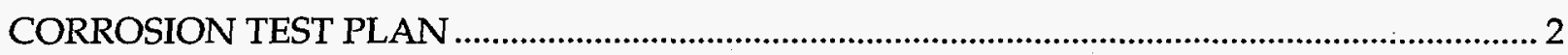

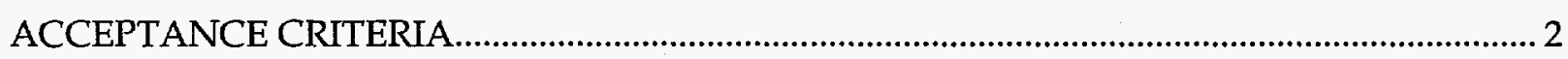

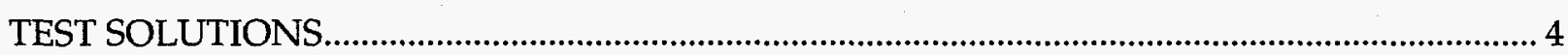

SELECTION OF CANDIDATE ALLOYS.............................................................................

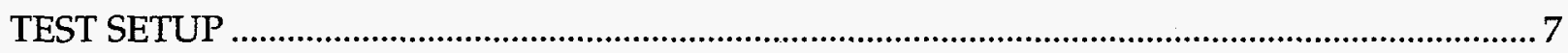

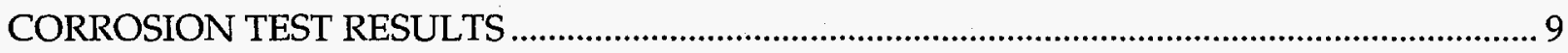

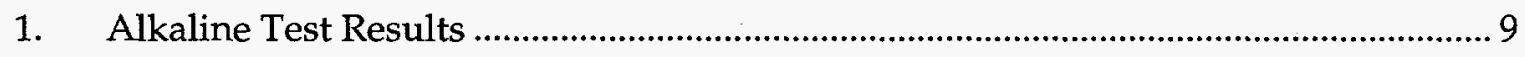

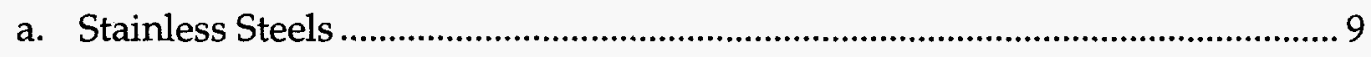

b. Nickel-Based Alloys..................................................................................................11

c. Titanium-Grade 2 2............................................................................................13

2. Nitric Acid Results .............................................................................................14

a. Type 304L Stainless Steel ...................................................................................14

b. Type 316L Stainless Steel ...................................................................................15

c. Type AL-6XN Stainless Steel ...........................................................................

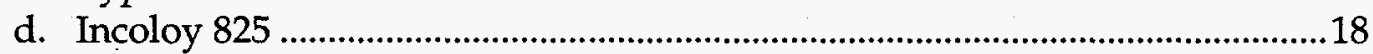

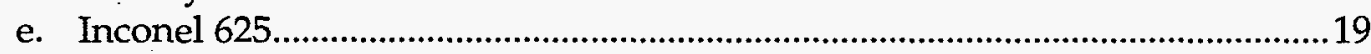

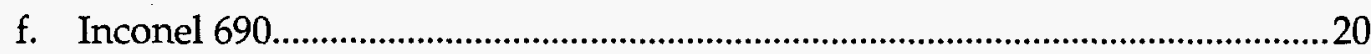

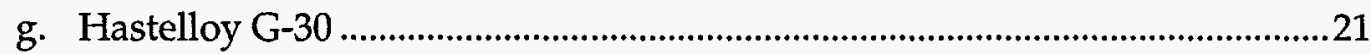

h. Titanium-Grade 2................................................................................................22

3. Electrochemical Testing...........................................................................................23

a. Linear Polarization Resistance Data......................................................................23

b. Cyclic Potentiodynamic Polarization Data ......................................................23

DISCUSSION 
TABLE OF CONTENTS (contd)

\section{Page}

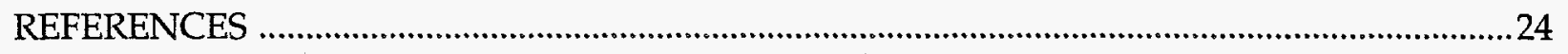

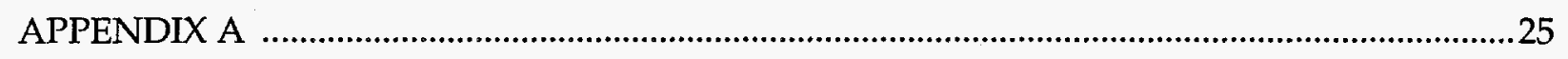

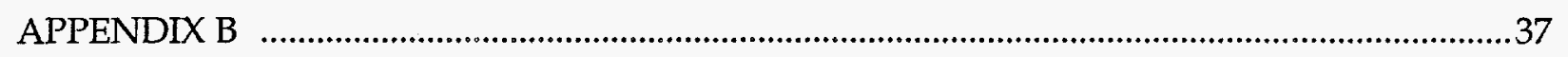

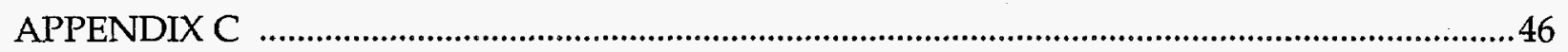


1. Corrosion Test Matrix 3

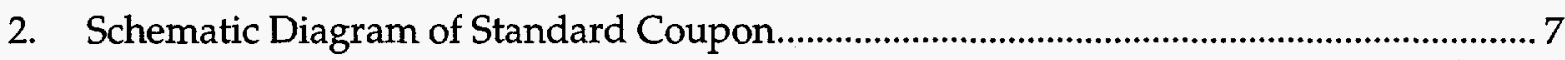

3. Schematic Diagram of Welded Coupon .......................................................................

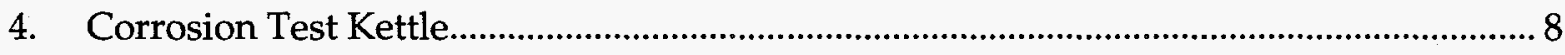

5. Schematic of the Multiple Crevice Assembly That Was Bolted to Corrosion Coupons for the Crevice Corrosion Experiments 9

6. Type 304L Stainless Steel with Severe, Uniform Intergranular Attack and Uniform Grain Loss 15

7. Type 316L Stainless Steel with Severe, Uniform Intergranular Attack and Uniform Grain Loss 16

8. Type Al-6XN Stainless Steel with Uniform Intergranular Attack and Intermittent Grain Loss

9. Incoloy 825 Nickel-Based Alloy Exhibiting Uniform Intergranular Attack with Some Grain Loss

10. Inconel 625 Nickel-Based Alloy with Uniform Intergranular Attack

11. Inconel 690 Nickel-Based Alloy Showing Light Intergranular Attack with Slight Grain Loss.

12. Hastelloy G-30 Nickel-Based Alloy with Light Etching 21

13. Grade 2 Titanium Exhibiting No Etching or Intergranular Attack .22 


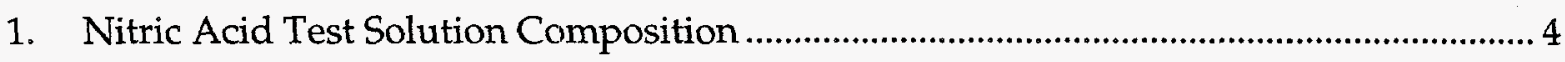

2. Sodium Hydroxide Test Solution Composition................................................................ 4

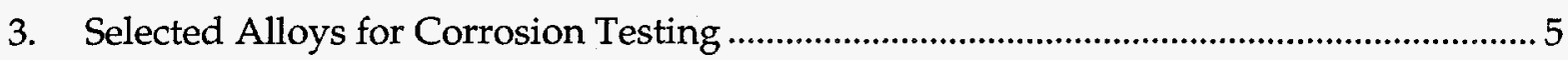

4. Chemical Composition of Selected Alloys .................................................................. 6

5. Type 304L Stainless Steel Corrosion Rates--Alkaline Solution .......................................10

6. Type 316L Stainless Steel Corrosion Rates--Alkaline Solution ......................................10

7. Type AL-6XN Stainless Steel Corrosion Rates--Alkaline Solution .................................11

8. Incoloy 825 Corrosion Rates--Alkaline Solution ........................................................ 11

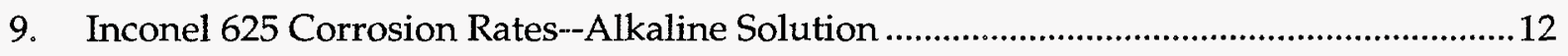

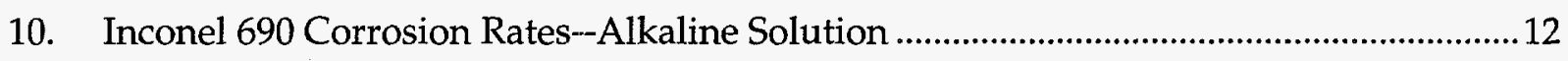

11. Hastelloy G-30 Corrosion Rates--Alkaline Solution ......................................................13

12. Titanium Grade 2 Corrosion Rates--Alkaline Solution ...............................................13

13. Type 304L Stainless Steel Corrosion Rates--Acidic Solution.........................................14

14. Type 316L Stainless Steel Corrosion Rates--Acidic Solution.........................................16

15. AL-6XN Stainless Steel Corrosion Rates--Acidic Solution ............................................17

16. Incoloy 825 Corrosion Rates--Acidic Solution...................................................... 18

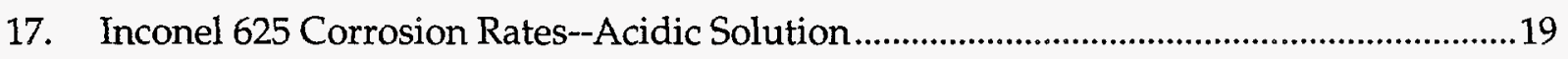

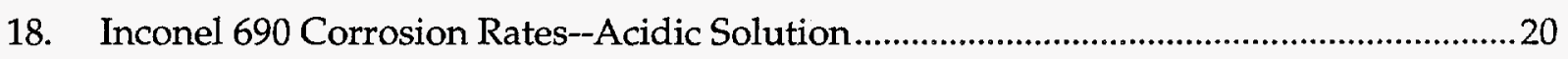

19. Hastelloy G-30 Corrosion Rates--Acidic Solution......................................................21

20. Titanium Grade 2 Corrosion Rates--Acidic Solution.....................................................22

21. Combined Nickel+Chromiurn Content of Selected Nickel-Based Alloys......................24 


\section{ACRONYMS}

ANL Argonne National Laboratory

ASTM American Society for Testing and Materials

CPU Compact Processing Unit

DOE Department of Energy

HAZ Heat Affected Zone

$\mathrm{mm} / \mathrm{y} \quad$ millimeters/year

mpy mils per year (i.e., 0.001 inches/year)

NACE National Association of Corrosion Engineers

ORNL Oak Ridge National Laboratory

SCC Stress Corrosion Cracking

SRS Savannah River Site

TWRS Tank Waste Remediation System

UST-ID Underground Storage Tank - Integrated Demonstration 


\title{
MOBILE EVAPORATOR CORROSION TEST RESULTS
}

by

\author{
A. Rozeveld and D. B. Chamberlain
}

\begin{abstract}
Laboratory corrosion tests were conducted on eight candidates to select a durable and cost-effective alloy for use in mobile evaporators to process radioactive waste solutions. Based on an extensive literature survey of corrosion data, three stainless steel alloys (304L, 316L, AL-6XN), four nickel-based alloys $(825,625,690, \mathrm{G}-30)$, and titanium were selected for testing. The corrosion tests included vapor phase, liquid junction (interface), liquid immersion, and crevice corrosion tests on plain and welded samples of candidate materials. Tests were conducted at $80^{\circ} \mathrm{C}$ for 45 days in two different test solutions: a nitric acid solution to simulate evaporator conditions during the processing of the cesium ion-exchange eluant and a highly alkaline sodium hydroxide solution to simulate the composition of Tank 241-AW-101 during evaporation.

All of the alloys exhibited excellent corrosion resistance in the alkaline test solution. Corrosion rates were very low and localized corrosion was not observed. Results from the nitric acid tests showed that only 316L stainless steel did not meet our performance criteria. The $316 \mathrm{~L}$ welded interface and crevice specimens had rates of 22.2 mpy and 21.8 mpy, respectively, which exceeds the maximum corrosion rate of 20 mpy. The other welded samples had about the same corrosion resistance as the plain samples. None of the welded samples showed preferential weld or heat-affected zone (HAZ) attack. Vapor corrosion was negligible for all alloys. All of the alloys except 316L exhibited either "satisfactory" (2-20 mpy) or "excellent" (<2 mpy) corrosion resistance as defined by National Association of Corrosion Engineers. However, many of the alloys experienced intergranular corrosion in the nitric acid test solution, which could indicate a susceptibility to stress corrosion cracking (SCC) in this environment.
\end{abstract}

\section{INTRODUCTION}

The program titled "UST-ID: Mobile Evaporator/Concentrator Technology Development" was funded by the Department of Energy (DOE) to develop a mobile evaporator/concentrator compact processing unit (CPU) originally intended for processing wastes from underground storage tanks at Hanford and potentially four other DOE sites. Changes in the project's mission were introduced when Westinghouse Hanford and DOE decided against the installation and testing of CPU-based processes. Because of this decision, the focus on evaporator CPU usage has shifted to the general DOE complex. As part of the development process, a durable and cost-effective alloy must be selected as the material of 
construction for the CPU. This report describes the selection and corrosion testing of eight candidate alloys and presents the test results from Stage 1 of the corrosion test plan.

\section{CORROSION TEST PLAN}

Corrosion testing was carried out at $\mathrm{CC}$ Technologies in Columbus, $\mathrm{OH}$, under American Society for Testing and Materials (ASTM) standards and guidelines. This company is a fully equipped, corrosion testing and research laboratory specializing in the evaluation of material properties, materials selection, corrosion, and corrosion control. The corrosion test plan is described briefly below.

The corrosion test plan consists of two stages. Stage 1, which is the subject of this report, included vapor phase, liquid junction (interface), liquid immersion, and crevice corrosion tests on plain and welded samples of candidate materials. Additional testing required includes tests for stress corrosion cracking (SCC) with specimens prepared per ASTM G30-90. Alloys that had corrosion rates of 20 mpy or less in Stage 1 should be tested for SCC. Stage 1 tests were completed at $80^{\circ} \mathrm{C}$ for 45 days in two different test solutions (described below). A slight vacuum (pressure of $660 \mathrm{mmHg}$ ) was maintained to simulate the conditions inside an evaporator. Figure 1 illustrates the test matrix for Stage 1. Tests on abraded specimens are being considered to evaluate the effect of the feed solids content on the corrosion resistance. Tests using irradiated specimens will not be conducted because the maximum concentration of radionuclides in the evaporator will be $2 \mathrm{Ci} / \mathrm{L}$, which will not affect corrosion rates [HARRISON].

\section{ACCEPTANCE CRITERIA}

Based upon the Stage 1 test results, acceptable alloys should have a general corrosion rate less than $0.53 \mathrm{~mm} / \mathrm{y}(20 \mathrm{mpy})$. The National Association of Corrosion Engineers (NACE) defines "excellent" corrosion resistance to be less than $0.053 \mathrm{~mm} / \mathrm{y}$ (2 mpy) and "satisfactory" performance to be less than $0.53 \mathrm{~mm} / \mathrm{y}$ ( $20 \mathrm{mpy})$; we have adopted these guidelines. If intergranular corrosion is evident in the samples, then SCC tests should be completed. These tests, however, are beyond the scope of this study. 


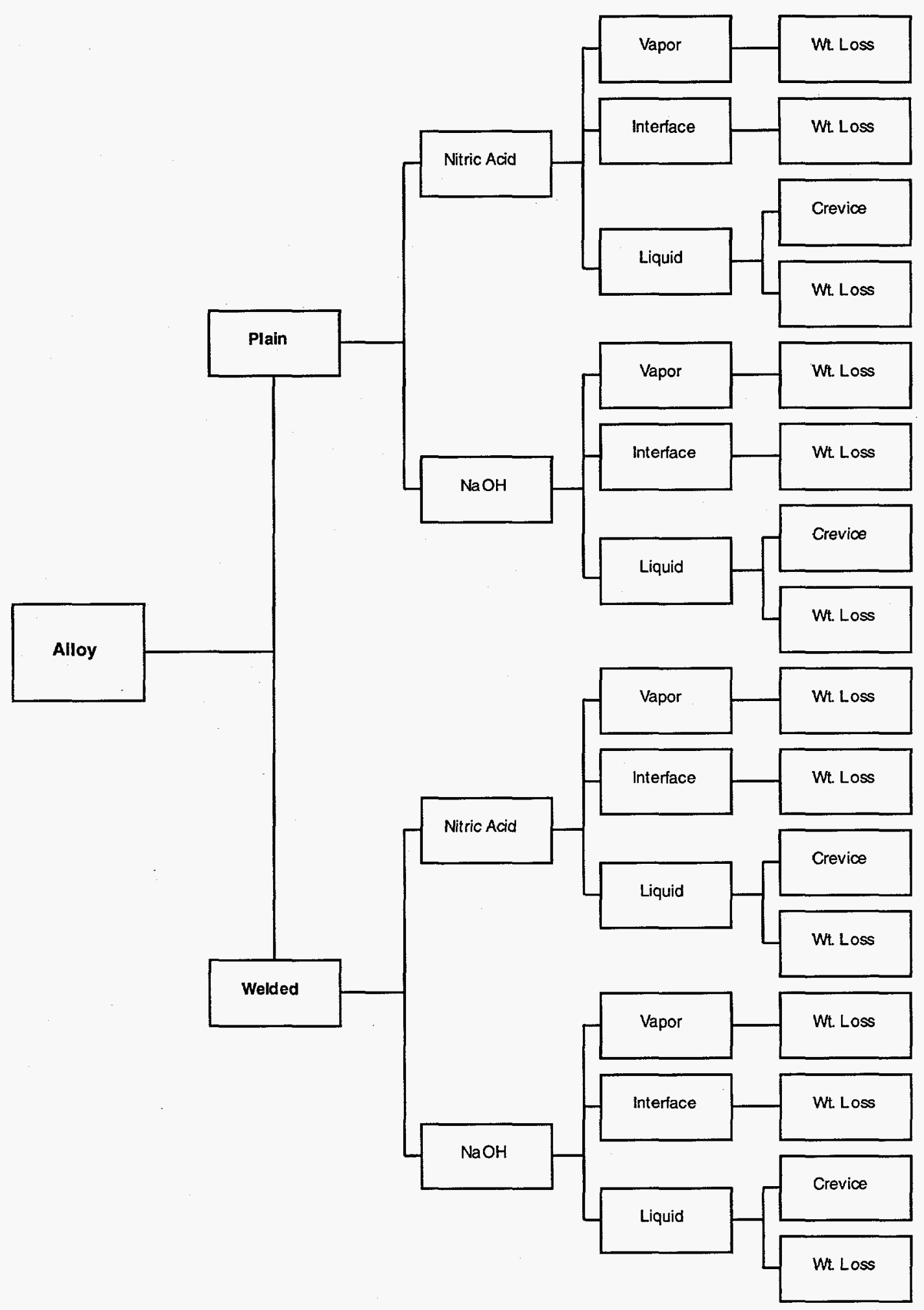

Fig. 1. Corrosion Test Matrix 


\section{TEST SOLUTIONS}

The evaporator CPU was originally intended to process (1) cesium-free tank waste from Hanford Tank 241-AW-101 and (2) cesium ion-exchange eluant. Although CPUs will no longer be installed and tested at Hanford, the recommended test solutions for the corrosion test plan were not changed for two reasons. First, the Tank Waste Remediation System (TWRS) program still includes a number of evaporators in their Case BETA Prime flowsheet [ORME]. These data will assist them to select materials for these units. Second, the simulated waste solutions being evaluated in this study are more corrosive than what we can expect at other sites. Thus, materials that pass our acceptance criteria would be appropriate for those sites. If SCC tests are done, solution compositions more specific to other sites may be evaluated.

Two solutions were selected for testing: (1) a nitric acid solution to simulate evaporator conditions during the processing of the cesium ion-exchange eluant and (2) a highly alkaline sodium hydroxide solution to simulate the composition of Tank 241-AW-101 during evaporation. The compositions of these solutions are shown in Tables 1 and 2, respectively [RICHMOND]. Since corrosion rates increase with increasing concentration and temperature for both nitric acid and sodium hydroxide solutions, the most concentrated compositions expected in the evaporator were chosen as test solutions.

Table 1. Nitric Acid Test Solution Composition

\begin{tabular}{cc}
\hline Constituent & Concentration, $\underline{\mathrm{M}}$ \\
\hline $\mathrm{H}^{+}$ & 15.9 \\
$\mathrm{Na}^{+}$ & 2.5 \\
$\mathrm{NO}_{3}^{-}$ & 18.4 \\
\hline
\end{tabular}

Table 2. Sodium Hydroxide Test Solution Composition

\begin{tabular}{lclc}
\hline $\begin{array}{c}\text { Cation } \\
\text { Constituent }\end{array}$ & $\begin{array}{c}\text { Concentration, } \\
\mathrm{M}\end{array}$ & $\begin{array}{c}\text { Anion } \\
\text { Constituent }\end{array}$ & $\begin{array}{c}\text { Concentration, } \\
\mathrm{M}\end{array}$ \\
\hline Aluminum & $9.5 \mathrm{E}-01$ & Chloride & $1.5 \mathrm{E}-01$ \\
Chromium & $3.1 \mathrm{E}-03$ & Hydroxide & $5.7 \mathrm{E}+00$ \\
Iron & $7.9 \mathrm{E}-04$ & Fluoride & $4.0 \mathrm{E}-03$ \\
Magnesium & $2.0 \mathrm{E}-03$ & Nitrite & $2.8 \mathrm{E}+00$ \\
Potassium & $1.1 \mathrm{E}+00$ & Nitrate & $3.8 \mathrm{E}+00$ \\
Sodium & $9.0 \mathrm{E}+00$ & Phosphate & $2.2 \mathrm{E}-02$ \\
Ammonia & $1.5 \mathrm{E}-02$ & Sulfate & $1.1 \mathrm{E}-02$ \\
& & Carbonate & $2.1 \mathrm{E}-01$ \\
\hline
\end{tabular}


During the processing of waste solutions containing fluoride and calcium ions, a $\mathrm{CaF}_{2-}$ containing scale may form on surfaces. If the system is flushed with nitric acid to remove the scale, a highly corrosive $\mathrm{HNO}_{3}-\mathrm{HF}$ solution may form. The material of construction selected for the system must have acceptable corrosion resistance to this acid mixture. Alternatively, it may be possible to reduce or eliminate the corrosivity of the fluoride solution by adding a complexant such as $\mathrm{Zr}$ or $\mathrm{Al}$ to the solution [CHEN]. We recommend that those alloys which exhibit acceptable corrosion resistance in Stage 1 be tested in an $\mathrm{HNO}_{3}-\mathrm{HF}$ environment.

\section{SELECTION OF CANDIDATE ALLOYS}

Based on an extensive literature survey of corrosion data, eight alloys were selected for corrosion testing in the two environments described above (15.9 $\underline{\mathrm{M}} \mathrm{HNO}_{3}$ and $\left.5 \underline{\mathrm{M}} \mathrm{NaOH}\right)$. The selection process will be discussed briefly here; a more detailed description can be found in Appendix A.

Three stainless steel (SS) alloys, four nickel-based alloys, and titanium were selected for testing; they are listed in Table 3. The chemical composition of each of the alloys is given in Table 4. Type 304L is a common evaporator construction material; 316L, 825 and 625 are also used [ANTHONY]. We included several alloys in our testing program to provide alternative materials for the CPU in case the stainless steels prove to be inadequate.

Table 3. Selected Alloys for Corrosion Testing

\begin{tabular}{cc}
\hline Alloy Type & Alloy Name \\
\hline Stainless steel & 304L, 316L, AL-6XN \\
Nickel-based alloy & $825,625,690$, G-30 \\
Titanium & Grade 2 \\
\hline
\end{tabular}

The 304L and 316L alloys are Ni-Cr low-carbon stainless steels; 316L SS also has $2.5 \%$ Mo for pitting resistance. The alloy AL-6XN is a "6-moly stainless." It contains higher levels of $\mathrm{Ni}$ and $\mathrm{Cr}$ than 304 or $316 \mathrm{~L}$ plus $\sim 6 \% \mathrm{Mo}$. In general, the higher the nickel and chromium content, the more corrosion resistant the alloy, so AL-6XN should be fairly resistant to our test solutions.

The nickel-based alloys 825, 625, 690 and G-30 also have higher $\mathrm{Ni}$ and $\mathrm{Cr}$ contents and are expected to perform as well as or better than the stainless steels in the acidic and alkaline test solutions. These four alloys have $\mathrm{Ni}+\mathrm{Cr}$ contents ranging from $63.5 \%$ to $87 \%$. Grade 2 titanium is commercially pure and is often used for heat-exchanger tubes in evaporators. 
Table 4. Chemical Composition of Selected Alloys

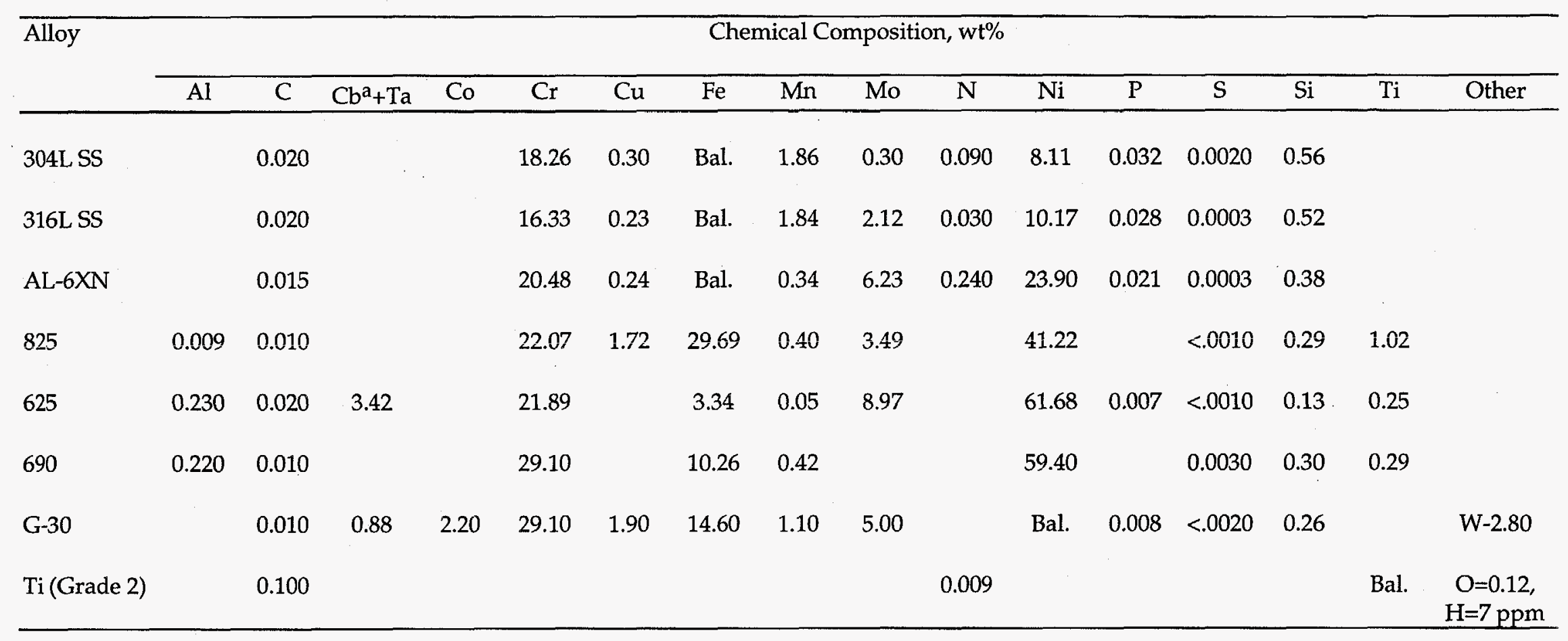

a Archaic usage for niobium $(\mathrm{Nb})$ is columbium $(\mathrm{Cb})$. 


\section{TEST SETUP}

Two plain and two welded specimens of each candidate alloy were tested in each solution at every condition. Samples of each alloy were from the same heat ${ }^{1}$ and oriented parallel to the rolling direction. They were prepared according to ASTM G1-90; the batch (or heat) sample surface finish was polished to 120 grit. Schematic diagrams of the standard and welded coupons are given in Figs. 2 and 3, respectively.

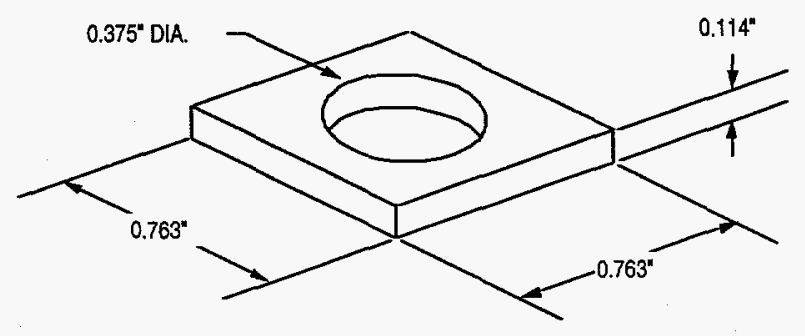

Fig. 2. Schematic Diagram of Standard Coupon

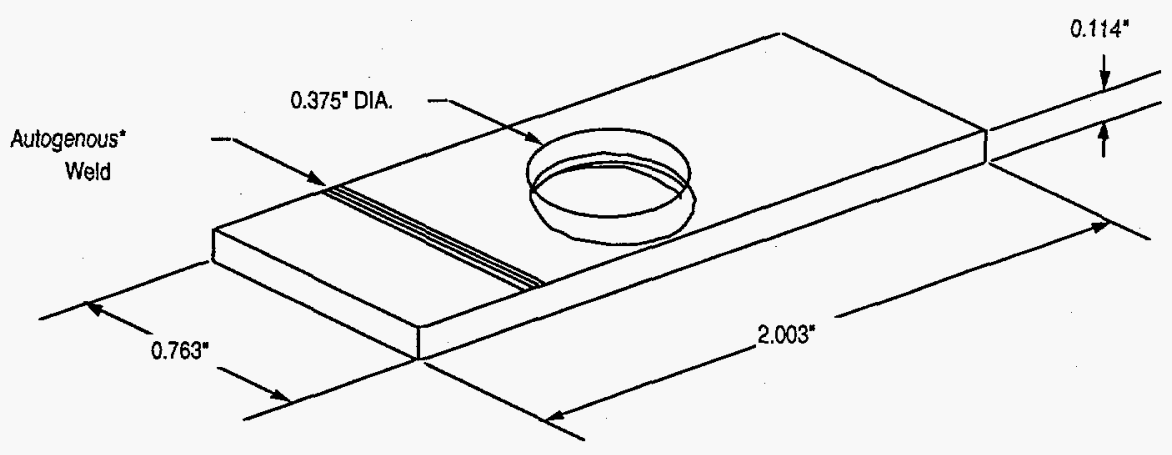

"Selt-welded.

Fig. 3. Schematic Diagram of Welded Coupon

Tests were performed in four-liter resin kettles equipped with a heating mantle and thermocouple (see Fig. 4). Samples were supported in the kettles by a rigid Teflon "tree" which has Hastelloy $\mathrm{C} 276$ hardware isolated from the samples by Teflon washers and tubes. Coupons were placed in three areas of the kettle: the vapor phase, the interface, and the liquid phase. The testing apparatus was adapted to allow for sampling of the test solutions, and thus for monitoring compositional variations, during the tests. Such variations could indicate a sudden change in the corrosion rate of the test specimen. Monitoring was completed by conducting periodic linear polarization resistance measurements. Changes in these readings would indicate a change in the solution chemistry. No change was seen during testing. Funding constraints prevented us from completing any solution analyses.

${ }^{1}$ Heat is defined as a batch of steel prepared and poured at the same time. 


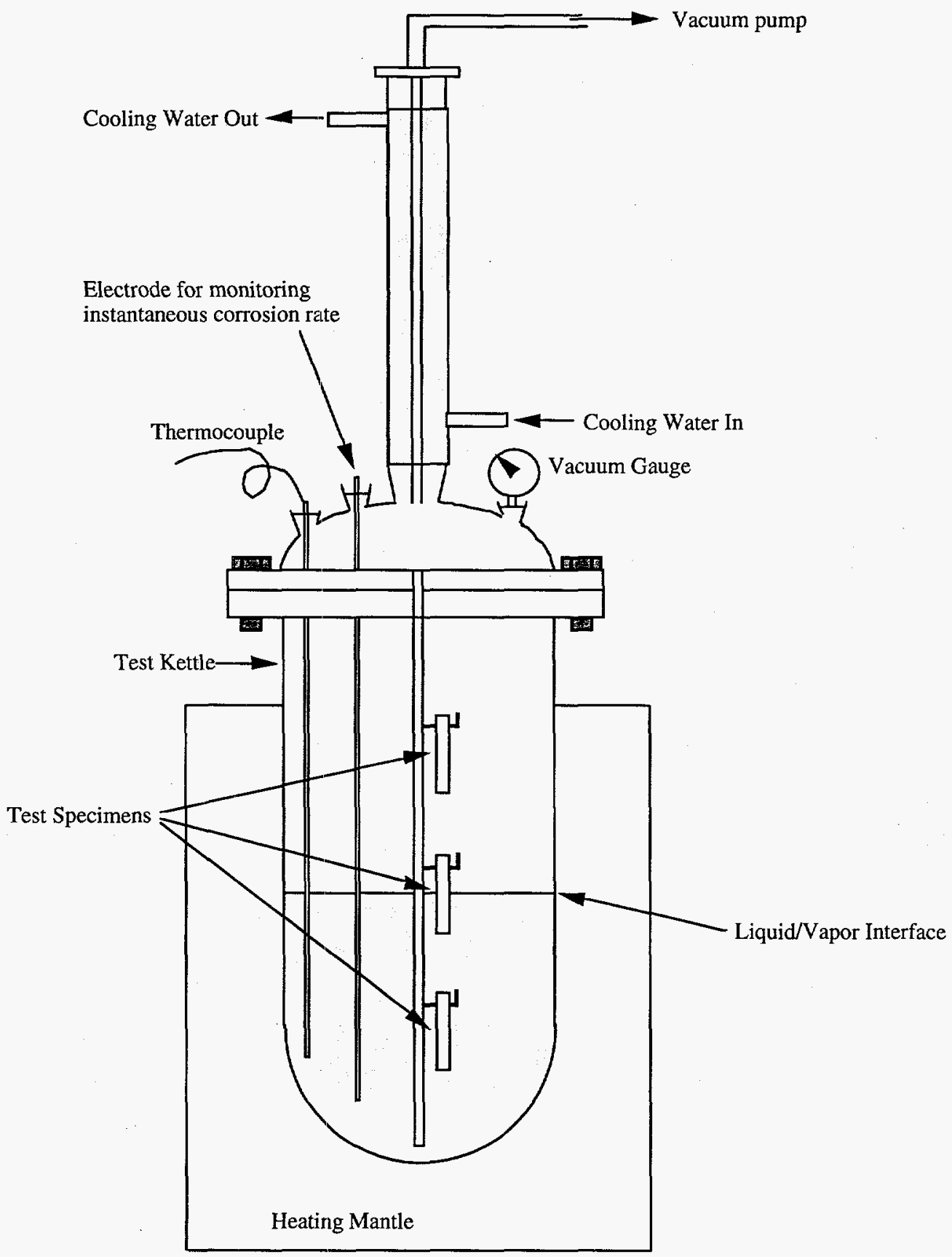

Fig. 4. Corrosion Test Kettle

The crevice corrosion samples were prepared according to standard procedure ASTM G78, with radically grooved Teflon crevice-formers bolted to either side of the test sample. A schematic of this assembly is shown in Fig. 5. These samples were located in the liquid phase in each kettle. 


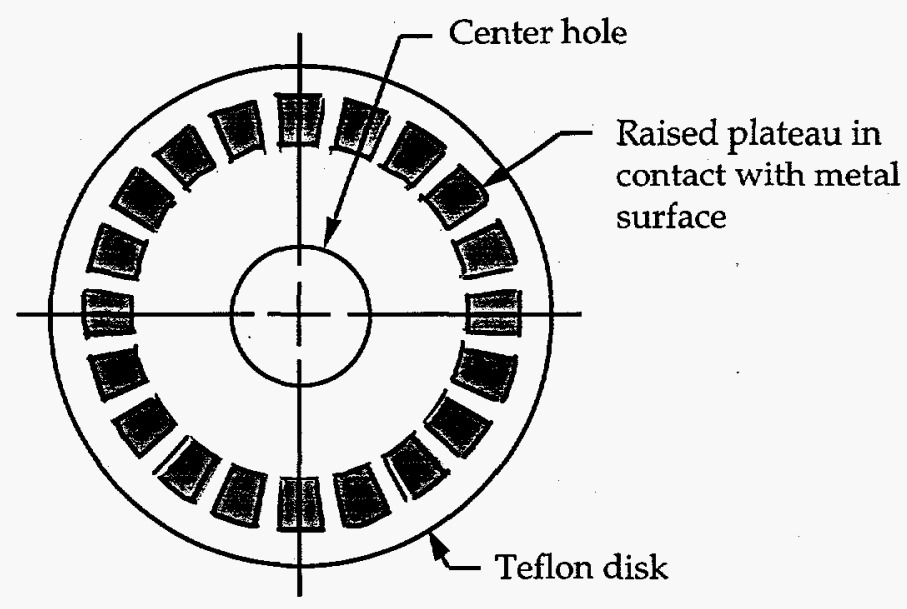

Fig. 5. Schematic of the Multiple Crevice Assembly That Was Bolted to Corrosion Coupons for the Crevice Corrosion Experiments

Tests were conducted at $80^{\circ} \mathrm{C}\left(176^{\circ} \mathrm{F}\right)$ and $660 \mathrm{mmHg}$ for 45 days. Evaluation of the samples after testing included mass loss measurements for corrosion rate calculations and examination for pitting, intergranular corrosion, weld attack, and crevice corrosion. Visual observations before cleaning included notation of staining, deposits, or corrosion products. Those samples which required it were mechanically cleaned to remove loose deposits by brushing the samples with a soft nylon brush under running warm water, then rinsing with deionized water and acetone. A weighed blank specimen of each material was included in the chemical cleaning operations to ensure that any weight loss associated with the cleaning process was accounted for in the weight-loss calculations.

Some problems associated with applying a vacuum to the test kettles were encountered during testing. The standard test kettles were not designed for operation with a vacuum, so they were modified during the setup for the alkaline solution tests to maintain a slight vacuum. However, the nitric acid test solution attacked some components of the modified kettles, contaminating the test solution. Rather than compromise the test results, the samples were cleaned (according to ASTM G1-90) and reweighed, a new nitric acid test solution was prepared, and the tests were restarted. Twice during the subsequent 45-day exposure, the vacuum was lost for a short time $(<24 \mathrm{hr})$ when the vacuum line was blocked by debris. These short-term deviations from vacuum should not affect the test results.

\section{CORROSION TEST RESULTS}

The corrosion rate data presented in this section are averages of the two specimens for each alloy and condition. The complete data set, including the weight measurements, is reported in Appendices B and C.

\section{1. $\quad$ Alkaline Test Results}

\section{a. Stainless Steels}

All of the stainless steel samples had very low corrosion rates ( $\leq 0.06 \mathrm{mpy}$, $\leq 0.0015 \mathrm{~mm} / \mathrm{y}$ ) in the alkaline solution (see Tables 5-7). Although some corrosion rate 
differences were seen in the liquid, vapor, and interface samples, the rates were very low and differences are probably not significant. No pitting, crevice, or preferential weld attack was found on any of the stainless steel samples. The 304L and 316L samples had some slight discoloration on the liquid phase and interface specimens beneath the crevice formers and the sample mounting hardware; no discoloration was observed on the AL-6XN samples.

Table 5. Type 304L Stainless Steel Corrosion Rates--Alkaline Solution ${ }^{\mathrm{a}}$

\begin{tabular}{lcc}
\hline Condition & \multicolumn{2}{c}{ Average Corrosion Rate } \\
\cline { 2 - 3 } & $\mathrm{mm} / \mathrm{y}$ & $\mathrm{mpy}$ \\
\hline Liquid--Wt. Loss & 0.0015 & 0.06 \\
Liquid--Crevice & 0.0008 & 0.03 \\
Interface--Wt. Loss & 0.0008 & 0.03 \\
Vapor--Wt. Loss & 0.0008 & 0.03 \\
Weld--Liquid--Wt. Loss & 0.0005 & 0.02 \\
Weld--Liquid--Crevice & 0.0005 & 0.02 \\
Weld--Interface--Wt. Loss & 0.0003 & 0.01 \\
Weld--Wt. Loss--Vapor & $0.00^{\mathrm{b}}$ & $0.00^{\mathrm{b}}$ \\
\hline
\end{tabular}

Test was completed at $80^{\circ} \mathrm{C}$ and $660 \mathrm{mmHg}$ for 45 days.

${ }^{b}$ An average corrosion rate of 0.00 indicates that the sample experienced no weight loss during testing.

Table 6. Type 316L Stainless Steel Corrosion Rates--Alkaline Solution ${ }^{\mathrm{a}}$

\begin{tabular}{lcc}
\hline Condition & \multicolumn{2}{c}{ Average Corrosion Rate } \\
\cline { 2 - 3 } & mpy & $\mathrm{mm} / \mathrm{y}$ \\
\hline Liquid--Wt. Loss & 0.0008 & 0.03 \\
Liquid--Crevice & 0.0010 & 0.04 \\
Interface--Wt. Loss & 0.0005 & 0.02 \\
Vapor--Wt. Loss & 0.0005 & 0.02 \\
Weld--Liquid--Wt. Loss & 0.0008 & 0.03 \\
Weld--Liquid--Crevice & 0.0008 & 0.03 \\
Weld--Interface--Wt. Loss & $0.00^{\mathrm{b}}$ & $0.00^{\mathrm{b}}$ \\
Weld--Wt. Loss--Vapor & 0.0003 & 0.01 \\
\hline
\end{tabular}

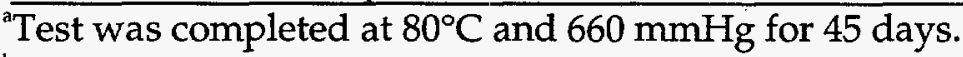

${ }^{\mathrm{b}}$ An average corrosion rate of 0.00 indicates that the sample experienced no weight loss during testing. 
Table 7. Type AL-6XN Stainless Steel Corrosion Rates--Alkaline Solution ${ }^{\mathrm{a}}$

\begin{tabular}{llc}
\hline Condition & \multicolumn{2}{c}{ Average Corrosion Rate } \\
\cline { 2 - 3 } & $\mathrm{mm} / \mathrm{y}$ & $\mathrm{mpy}$ \\
\hline Liquid--Wt. Loss & 0.0013 & 0.05 \\
Liquid--Crevice & 0.0010 & 0.04 \\
Interface--Wt. Loss & 0.0013 & 0.05 \\
Vapor--Wt. Loss & 0.0010 & 0.04 \\
Weld--Liquid--Wt. Loss & 0.0015 & 0.06 \\
Weld--Liquid--Crevice & 0.0010 & 0.04 \\
Weld--Interface--Wt. Loss & 0.0010 & 0.04 \\
Weld--Wt. Loss--Vapor & 0.0005 & 0.02 \\
\hline
\end{tabular}

${ }^{\mathrm{a}}$ Test was completed at $80^{\circ} \mathrm{C}$ and $660 \mathrm{mmHg}$ for 45 days.

\section{b. Nickel-Based Alloys}

None of the nickel-based alloys experienced pitting, crevice, or preferential weld attack. The 825 sample exhibited a very light etching during the visual inspection before cleaning, but the observed corrosion rates for all conditions of the alloy were quite low (see Tables 8-11). All of the nickel-based alloys had very low corrosion rates $[\leq 0.0008 \mathrm{~mm} / \mathrm{y}(\leq 0.07 \mathrm{mpy})]$ in the alkaline solution.

Table 8. Incoloy 825 Corrosion Rates--Alkaline Solution ${ }^{a}$

\begin{tabular}{lcc}
\hline \multirow{2}{*}{ Condition } & \multicolumn{2}{c}{ Average Corrosion Rate } \\
\cline { 2 - 3 } & $\mathrm{mm} / \mathrm{y}$ & $\mathrm{mpy}$ \\
\hline Liquid--Wt. Loss & 0.0005 & 0.02 \\
Liquid--Crevice & 0.0008 & 0.03 \\
Interface--Wt. Loss & 0.0005 & 0.02 \\
Vapor--Wt. Loss & 0.0005 & 0.02 \\
Weld--Liquid--Wt. Loss & 0.0003 & 0.01 \\
Weld--Liquid--Crevice & 0.0003 & 0.01 \\
Weld--Interface--Wt. Loss & $0.00^{\mathrm{b}}$ & $0.00^{\mathrm{b}}$ \\
Weld--Wt. Loss--Vapor & $0.00^{\mathrm{b}}$ & $0.00^{\mathrm{b}}$ \\
\hline
\end{tabular}

${ }^{a}$ Test was completed at $80^{\circ} \mathrm{C}$ and $660 \mathrm{mmHg}$ for 45 days.

${ }^{b}$ An average corrosion rate of 0.00 indicates that the sample experienced no weight loss during testing. 
Table 9. Inconel 625 Corrosion Rates--Alkaline Solution ${ }^{a}$

\begin{tabular}{llc}
\hline \multirow{2}{*}{ Condition } & \multicolumn{2}{c}{ Average Corrosion Rate } \\
\cline { 2 - 3 } & $\mathrm{mm} / \mathrm{y}$ & $\mathrm{mpy}$ \\
\hline Liquid--Wt. Loss & 0.0008 & 0.03 \\
Liquid--Crevice & 0.0010 & 0.04 \\
Interface--Wt. Loss & 0.0008 & 0.03 \\
Vapor--Wt. Loss & 0.0008 & 0.03 \\
Weld--Liquid--Wt. Loss & 0.0003 & 0.01 \\
Weld--Liquid--Crevice & 0.0003 & 0.01 \\
Weld--Interface--Wt. Loss & 0.0003 & 0.01 \\
Weld--Wt. Loss--Vapor & 0.0003 & 0.01 \\
\hline
\end{tabular}

${ }^{a}$ Test was completed at $80^{\circ} \mathrm{C}$ and $660 \mathrm{mmHg}$ for 45 days.

Table 10. Inconel 690 Corrosion Rates--Alkaline Solution ${ }^{a}$

\begin{tabular}{lcc}
\hline \multirow{2}{*}{ Condition } & \multicolumn{2}{c}{ Average Corrosion Rate } \\
\cline { 2 - 3 } & $\mathrm{mm} / \mathrm{y}$ & $\mathrm{mpy}$ \\
\hline Liquid--Wt. Loss & 0.0018 & 0.07 \\
Liquid--Crevice & 0.0015 & 0.06 \\
Interface--Wt. Loss & 0.0008 & 0.03 \\
Vapor--Wt. Loss & 0.0018 & 0.07 \\
Weld--Liquid--Wt. Loss & 0.0003 & 0.01 \\
Weld--Liquid--Crevice & $0.00^{\mathrm{b}}$ & $0.00^{\mathrm{b}}$ \\
Weld--Interface--Wt. Loss & $0.00^{\mathrm{b}}$ & $0.00^{\mathrm{b}}$ \\
Weld--Wt. Loss--Vapor & $0.00^{\mathrm{b}}$ & $0.00^{\mathrm{b}}$ \\
\hline
\end{tabular}

Test was completed at $80^{\circ} \mathrm{C}$ and $660 \mathrm{mmHg}$ for 45 days.

${ }^{\mathrm{b}} \mathrm{An}$ average corrosion rate of 0.00 indicates that the sample experienced no weight loss during testing. 
Table 11. Hastelloy G-30 Corrosion Rates--Alkaline Solution ${ }^{\mathrm{a}}$

\begin{tabular}{lcc}
\hline \multirow{2}{*}{ Condition } & \multicolumn{2}{c}{ Average Corrosion Rate } \\
\cline { 2 - 3 } & $\mathrm{mm} / \mathrm{y}$ & $\mathrm{mpy}$ \\
\hline Liquid--Wt. Loss & 0.0003 & 0.01 \\
Liquid--Crevice & 0.0005 & 0.02 \\
Interface--Wt. Loss & 0.0003 & 0.01 \\
Vapor--Wt. Loss & 0.0003 & 0.01 \\
Weld--Liquid--Wt. Loss & $0.00^{\mathrm{b}}$ & $0.00^{\mathrm{b}}$ \\
Weld--Liquid--Crevice & $0.00^{\mathrm{b}}$ & $0.00^{\mathrm{b}}$ \\
Weld--Interface--Wt. Loss & $0.00^{\mathrm{b}}$ & $0.00^{\mathrm{b}}$ \\
Weld--Wt. Loss--Vapor & $0.00^{\mathrm{b}}$ & $0.00^{\mathrm{b}}$ \\
\hline
\end{tabular}

${ }^{a}$ Test was completed at $80^{\circ} \mathrm{C}$ and $660 \mathrm{mmHg}$ for 45 days.

${ }^{\mathrm{b}} \mathrm{An}$ average corrosion rate of 0.00 indicates that the sample experienced no weight loss during testing.

\section{c. Titanium--Grade 2}

No pitting, crevice, or preferential weld attack was observed on the titanium samples. They were discolored with a blue-brown tint, which was darker on the liquid phase samples. The corrosion rates (see Table 12) for all of the titanium samples were very low $\leq 0.0038 \mathrm{~mm} / \mathrm{y}(\leq 0.15 \mathrm{mpy})$.

Table 12. Titanium Grade 2 Corrosion Rates--Alkaline Solution ${ }^{\mathrm{a}}$

\begin{tabular}{llc}
\hline \multirow{2}{*}{ Condition } & \multicolumn{2}{c}{ Average Corrosion Rate } \\
\cline { 2 - 3 } & $\mathrm{mm} / \mathrm{y}$ & $\mathrm{mpy}$ \\
\hline Liquid--Wt. Loss & 0.0023 & 0.09 \\
Liquid--Crevice & 0.0023 & 0.09 \\
Interface--Wt. Loss & 0.0031 & 0.12 \\
Vapor--Wt. Loss & 0.0018 & 0.07 \\
Weld--Liquid--Wt. Loss & 0.0026 & 0.10 \\
Weld--Liquid--Crevice & 0.0031 & 0.12 \\
Weld--Interface-Wt. Loss & 0.0038 & 0.15 \\
Weld-Wt. Loss--Vapor & 0.0015 & 0.06 \\
\hline
\end{tabular}

${ }^{\mathrm{a}}$ Test was completed at $80^{\circ} \mathrm{C}$ and $660 \mathrm{mmHg}$ for 45 days. 


\section{2. $\quad$ Nitric Acid Results}

\section{a. Type 304L Stainless Steel}

Corrosion rates for the $304 \mathrm{~L}$ stainless steel coupons are reported in Table 13. No pitting or crevice attack was observed for any of the samples. The samples exhibited a deep blue-black tinting that was impervious to standard cleaning methods. However, the luminescent appearance of the tinting indicated that it was a very thin film and would not affect the corrosion rate calculation. The tinting was heavier on samples exposed to the liquid phase and interface conditions. The 304L samples experienced severe uniform intergranular attack with uniform grain loss. In the welded coupons, the weld structures were revealed and exhibited intergranular attack, but no preferential attack of the weld or heataffected zone (HAZ) was found. The average corrosion rate for the liquid-phase samples was $0.138 \mathrm{~mm} / \mathrm{y}$ (5.4 mpy). A micrograph of the coupon surface, showing severe, uniform intergranular attack and uniform grain loss, is shown in Fig. 6.

Table 13. Type 304L Stainless Steel Corrosion Rates--Acidic Solution ${ }^{\mathrm{a}}$

\begin{tabular}{lcc}
\hline Condition & \multicolumn{2}{c}{ Average Corrosion Rate } \\
\cline { 2 - 3 } & $\mathrm{mm} / \mathrm{y}$ & $\mathrm{mpy}$ \\
\hline Liquid--Wt. Loss & 0.148 & 5.77 \\
Liquid--Crevice & 0.0842 & 3.29 \\
Interface--Wt. Loss & 0.119 & 4.65 \\
Vapor--Wt. Loss & 0.0026 & 0.10 \\
Weld--Liquid--Wt. Loss & 0.132 & 5.16 \\
Weld--Liquid--Crevice & 0.139 & 5.43 \\
Weld--Interface--Wt. Loss & 0.113 & 4.43 \\
Weld--Wt. Loss--Vapor & 0.0018 & 0.07 \\
\hline
\end{tabular}

${ }^{\mathrm{a}}$ Test was completed at $80^{\circ} \mathrm{C}$ and $660 \mathrm{mmHg}$ for 45 days. 


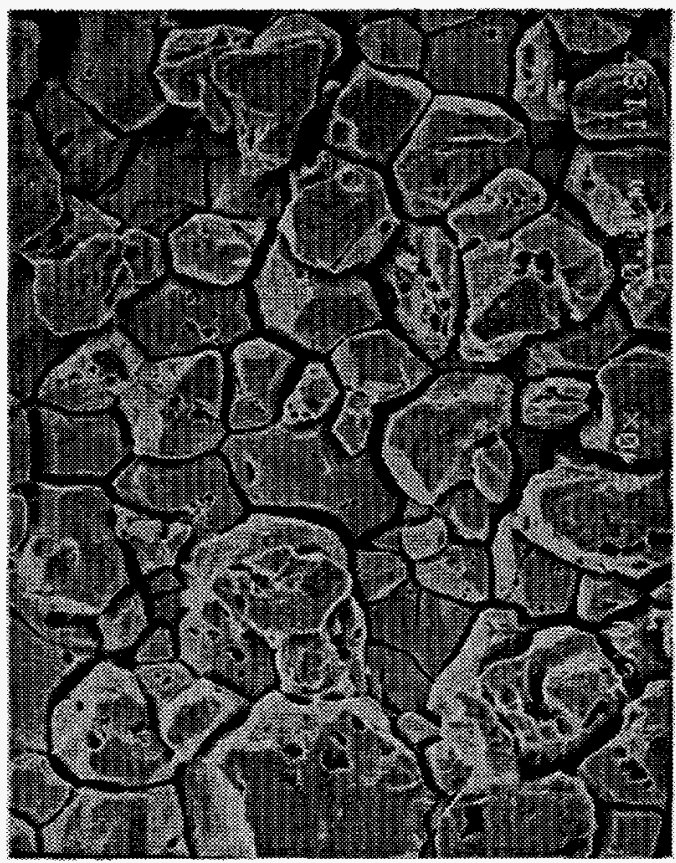

Fig. 6. Type 304L Stainless Steel with Severe, Uniform Intergranular Attack and Uniform Grain Loss. Micrograph of base metal at 500X. Coupon shown is a liquid-phase sample following 45-day immersion testing at $80^{\circ} \mathrm{C}$ and $660 \mathrm{mmHg}$.

\section{b. Type 316L Stainless Steel}

Results for the 316L samples were similar to those for the $304 \mathrm{~L}$ samples (see Table 14). Blue-brown tinting was observed on the samples; there was no evidence of pitting or crevice attack. The attack was again characterized as severe uniform intergranular corrosion with uniform grain loss. Weld structures were revealed, but no preferential attack occurred. The average corrosion rate for the 316L liquid-phase samples was $0.443 \mathrm{~mm} / \mathrm{y}$ (17.3 mpy). A micrograph of the coupon surface, showing severe, uniform intergranular attack and uniform grain loss, is shown in Fig. 7. 
Table 14. Type 316L Stainless Steel Corrosion Rates--Acidic Solution ${ }^{\mathrm{a}}$

\begin{tabular}{lcc}
\hline Condition & \multicolumn{2}{c}{ Average Corrosion Rate } \\
\cline { 2 - 3 } & $\mathrm{mm} / \mathrm{y}$ & $\mathrm{mpy}$ \\
\hline Liquid--Wt. Loss & 0.369 & 14.42 \\
Liquid--Crevice & 0.418 & 16.32 \\
Interface--Wt. Loss & 0.301 & 11.77 \\
Vapor--Wt. Loss & 0.0038 & 0.15 \\
Weld--Liquid--Wt. Loss & 0.426 & 16.65 \\
Weld--Liquid--Crevice & 0.557 & 21.75 \\
Weld--Interface--Wt. Loss & 0.569 & 22.24 \\
Weld--Wt. Loss--Vapor & 0.0023 & 0.09 \\
\hline aTestwas completet $80^{\circ} \mathrm{C}$ and $660 \mathrm{~mm}$
\end{tabular}

${ }^{a}$ Test was completed at $80^{\circ} \mathrm{C}$ and $660 \mathrm{mmHg}$ for 45 days.

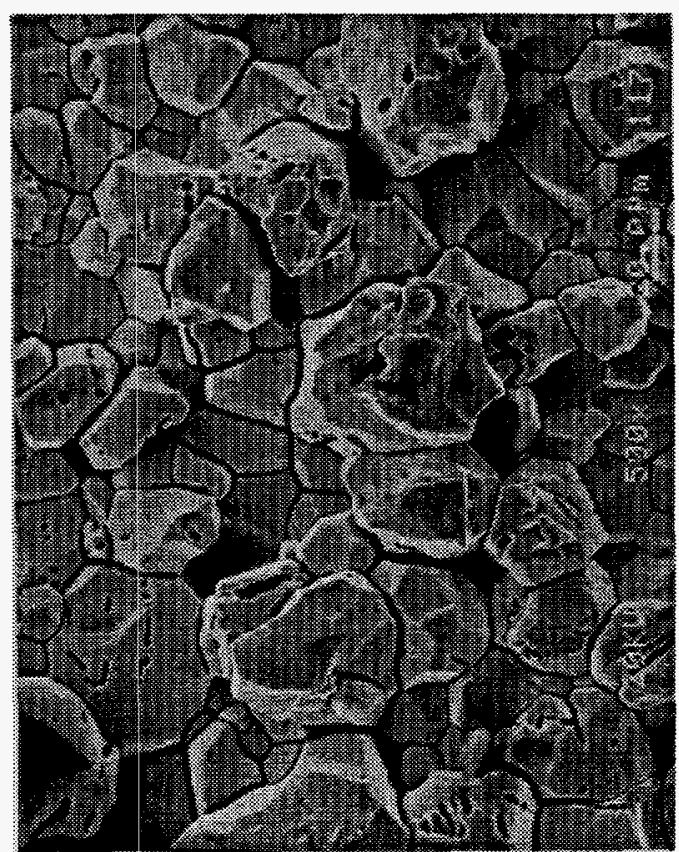

Fig. 7. Type 316L Stainless Steel with Severe, Uniform Intergranular Attack and Uniform Grain Loss. Micrograph of base metal at 500X. Coupon shown is a liquid-phase sample following 45-day immersion testing at $80^{\circ} \mathrm{C}$ and $660 \mathrm{mmHg}$. 
c. Type AL-6XN Stainless Steel

No discoloration, pitting, or crevice attack was visible on the AL-6XN samples. The samples exhibited uniform intergranular attack with intermittent grain loss, but was not as severe as that on $304 \mathrm{~L}$ and $316 \mathrm{~L}$. The weld structure was clearly revealed on the AL-6XN liquid phase and interface samples but just barely visible on the vapor-phase samples. No preferential weld attack was observed. The average corrosion rate for the AL-6XN liquid phase samples was $0.033 \mathrm{~mm} / \mathrm{y}(1.3 \mathrm{mpy})$ (see Table 15). A micrograph of the coupon surface showing uniform intergranular attack and intermittent grain loss is shown in Fig. 8.

Table 15. Type AL-6XN Stainless Steel Corrosion Rates--Acidic Solution ${ }^{\mathrm{a}}$

\begin{tabular}{lcc}
\hline Condition & \multicolumn{2}{c}{ Average Corrosion Rate } \\
\cline { 2 - 3 } & $\mathrm{mpy}$ & $\mathrm{mm} / \mathrm{y}$ \\
\hline Liquid--Wt. Loss & 0.032 & 1.26 \\
Liquid--Crevice & 0.053 & 2.05 \\
Interface--Wt. Loss & 0.054 & 2.13 \\
Vapor--Wt. Loss & 0.0026 & 0.10 \\
Weld--Liquid--Wt. Loss & 0.0276 & 1.08 \\
Weld--Liquid--Crevice & 0.0218 & 0.85 \\
Weld--Interface--Wt. Loss & 0.067 & 2.63 \\
Weld--Wt. Loss--Vapor & 0.0018 & 0.07 \\
\hline
\end{tabular}

${ }^{a}$ Test was completed at $80^{\circ} \mathrm{C}$ and $660 \mathrm{mmHg}$ for 45 days.

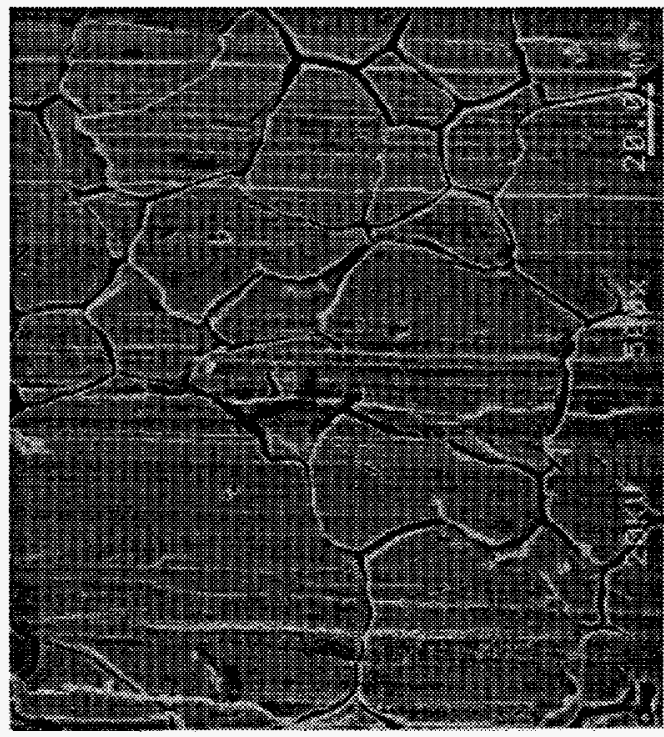

Fig. 8. Type Al-6XN Stainless Steel with Uniform Intergranular Attack and Intermittent Grain Loss. The horizontal scratches are from polishing during coupon preparation. Micrograph of base metal at 500X. Coupon shown is a liquid-phase sample following 45-day immersion testing at $80^{\circ} \mathrm{C}$ and $660 \mathrm{mmHg}$. 


\section{d. Incoloy 825}

No pitting, crevice, or preferential weld attack was observed on any of the samples, but they experienced uniform intergranular attack with some grain loss; the weld structures were revealed on the liquid-phase and interface samples. The average corrosion rate for the liquid-phase samples was $0.0009 \mathrm{~mm} / \mathrm{y}(3.6 \mathrm{mpy}$ ) (see Table 16). A micrograph of the coupon surface, showing uniform intergranular attack with some grain loss, is shown in Fig. 9.

Table 16. Incoloy 825 Corrosion Rates--Acidic Solution ${ }^{\mathrm{a}}$

\begin{tabular}{lcc}
\hline \multirow{2}{*}{ Condition } & \multicolumn{2}{c}{ Average Corrosion Rate } \\
\cline { 2 - 3 } & $\mathrm{mm} / \mathrm{y}$ & $\mathrm{mpy}$ \\
\hline Liquid--Wt. Loss & 0.115 & 4.48 \\
Liquid--Crevice & 0.117 & 4.58 \\
Interface--Wt. Loss & 0.047 & 1.84 \\
Vapor--Wt. Loss & 0.0008 & 0.03 \\
Weld--Liquid--Wt. Loss & 0.069 & 2.69 \\
Weld--Liquid--Crevice & 0.063 & 2.47 \\
Weld--Interface--Wt. Loss & 0.030 & 1.17 \\
Weld--Wt. Loss--Vapor & 0.0003 & 0.01 \\
\hline
\end{tabular}

${ }^{a}$ Test was completed at $80^{\circ} \mathrm{C}$ and $660 \mathrm{mmHg}$ for 45 days.

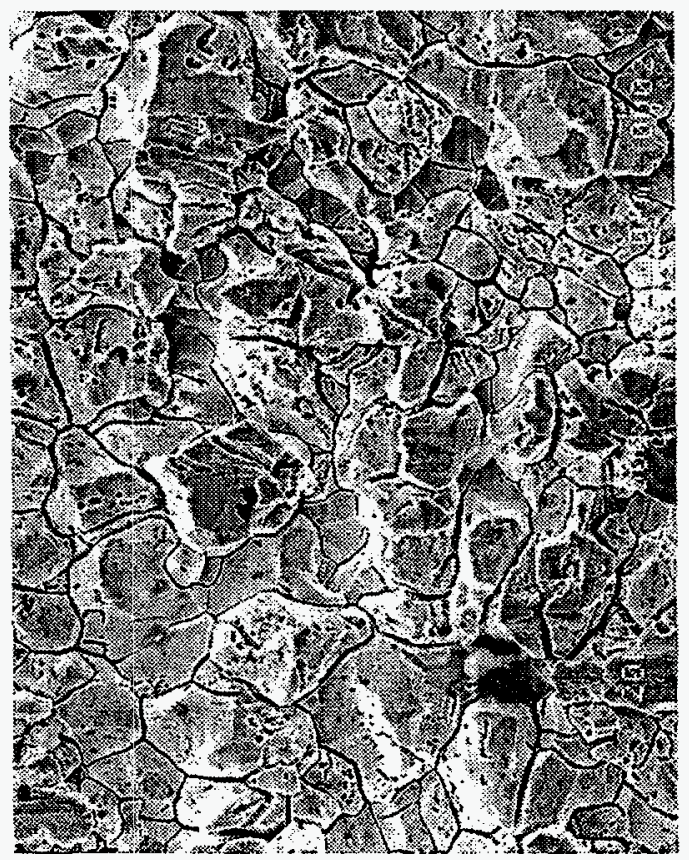

Fig. 9. Incoloy 825 Nickel-Based Alloy Exhibiting Uniform Intergranular Attack with Some Grain Loss. Micrograph of base metal at 460X. Coupon shown is a liquid-phase sample following 45-day immersion testing at $80^{\circ} \mathrm{C}$ and $660 \mathrm{mmHg}$. 
e. $\quad \underline{\text { Inconel } 625}$

No pitting, crevice, or preferential weld attack was observed on the samples. However, the weld structure was clearly revealed on the liquid phase and interface samples. The observed attack was uniform and intergranular with no grain loss. The corrosion rate for the liquid-phase specimens averaged $0.069 \mathrm{~mm} / \mathrm{y}(2.7 \mathrm{mpy}$ ) (see Table 17). A micrograph of the coupon surface, showing uniform intergranular attack, is shown in Fig. 10.

Table 17. Inconel 625 Corrosion Rates--Acidic Solution ${ }^{\mathrm{a}}$

\begin{tabular}{lcc}
\hline Condition & \multicolumn{2}{c}{ Average Corrosion Rate } \\
\cline { 2 - 3 } & $\mathrm{mm} / \mathrm{y}$ & $\mathrm{mpy}$ \\
\hline Liquid--Wt. Loss & 0.082 & 3.20 \\
Liquid--Crevice & 0.095 & 3.70 \\
Interface--Wt. Loss & 0.071 & 2.76 \\
Vapor--Wt. Loss & 0.0018 & 0.07 \\
Weld--Liquid--Wt. Loss & 0.056 & 2.18 \\
Weld--Liquid--Crevice & 0.039 & 1.52 \\
Weld--Interface--Wt. Loss & 0.068 & 2.65 \\
Weld--Wt. Loss--Vapor & 0.0018 & 0.07 \\
\hline
\end{tabular}

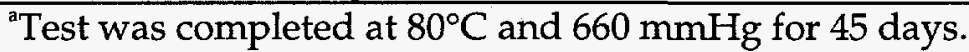

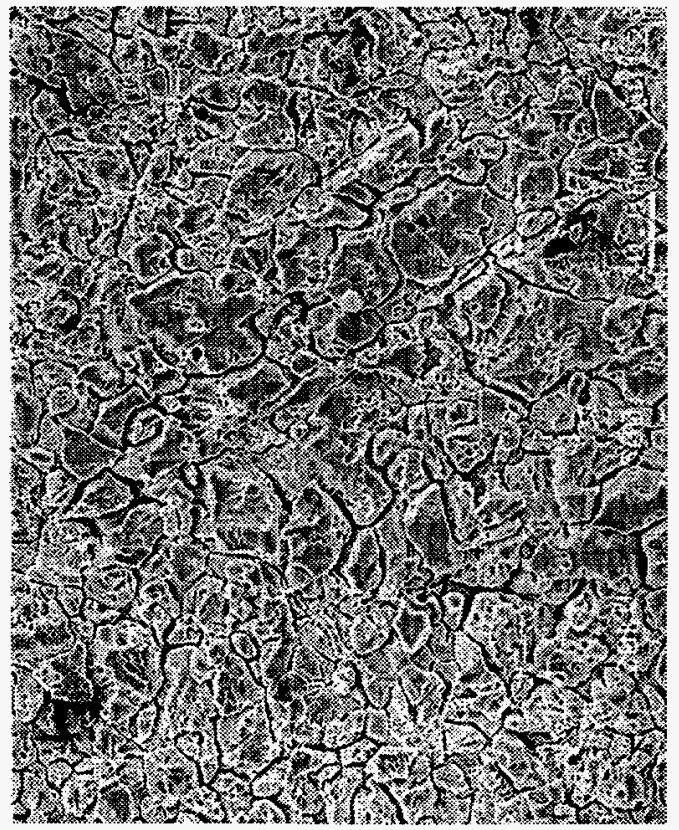

Fig. 10. Inconel 625 Nickel-Based Alloy with Uniform Intergranular Attack. Micrograph of base metal at 500X. Coupon shown is a liquid-phase sample following 45-day immersion testing at $80^{\circ} \mathrm{C}$ and $660 \mathrm{mmHg}$. 


\section{f. $\quad$ Inconel 690}

No pitting, crevice, or preferential weld attack was observed on the samples. The attack was characterized as light intergranular attack with slight grain loss. The weld structures were revealed on the liquid-phase and interface samples. These samples also showed a very light brown tinting and very slight etching on all exposed areas. The liquidphase samples had an average corrosion rate of $0.038 \mathrm{~mm} / \mathrm{y}(1.5 \mathrm{mpy})$ (see Table 18). A micrograph of the coupon surface, showing light intergranular attack with slight grain loss, is shown in Fig. 11.

Table 18. Inconel 690 Corrosion Rates--Acidic Solution ${ }^{\mathrm{a}}$

\begin{tabular}{lcc}
\hline Condition & \multicolumn{2}{c}{ Average Corrosion Rate } \\
\cline { 2 - 3 } & $\mathrm{mm} / \mathrm{y}$ & $\mathrm{mpy}$ \\
\hline Liquid--Wt. Loss & 0.043 & 1.67 \\
Liquid--Crevice & 0.039 & 1.51 \\
Interface--Wt. Loss & 0.017 & 0.65 \\
Vapor--Wt. Loss & 0.0008 & 0.03 \\
Weld--Liquid--Wt. Loss & 0.038 & 1.50 \\
Weld--Liquid--Crevice & 0.035 & 1.38 \\
Weld--Interface--Wt. Loss & 0.013 & 0.51 \\
Weld--Wt. Loss--Vapor & 0.0003 & 0.01 \\
\hline Test was completed at $80^{\circ} \mathrm{C}$ and $660 \mathrm{mmHg}$ for 45 days.
\end{tabular}

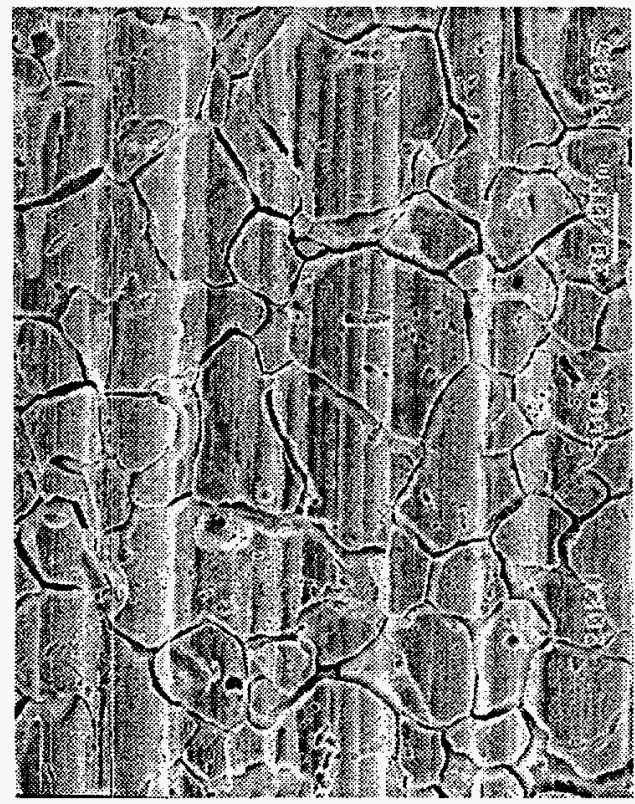

Fig. 11. Inconel 690 Nickel-Based Alloy Showing Light Intergranular Attack with Slight Grain Loss. The vertical scratches are from polishing during coupon preparation. Micrograph of base metal at $500 \mathrm{X}$. Coupon shown is a liquid-phase sample following 45-day immersion testing at $80^{\circ} \mathrm{C}$ and $660 \mathrm{mmHg}$. 


\section{g. $\quad$ Hastelloy G-30}

No pitting, crevice, or preferential weld attack was observed on the G-30 samples. They experienced light etching, which revealed the alloy's microstructure, but no significant intergranular attack was observed. Weld structures were visible on the liquid-phase and interface specimens. These specimens also had very light brown tinting on the exposed surfaces. The average corrosion rate for the liquid-phase samples was $0.019 \mathrm{~mm} / \mathrm{y}(0.76 \mathrm{mpy})$ (see Table 19). A micrograph of the coupon surface, showing light etching of the surface, is shown in Fig. 12.

Table 19. Hastelloy G-30 Corrosion Rates--Acidic Solution ${ }^{\mathrm{a}}$

\begin{tabular}{lcc}
\hline Condition & \multicolumn{2}{c}{ Average Corrosion Rate } \\
\cline { 2 - 3 } & $\mathrm{mm} / \mathrm{y}$ & $\mathrm{mpy}$ \\
\hline Liquid--Wt. Loss & 0.020 & 0.78 \\
Liquid--Crevice & 0.026 & 1.03 \\
Interface--Wt. Loss & 0.023 & 0.90 \\
Vapor--Wt. Loss & 0.001 & 0.04 \\
Weld--Liquid--Wt. Loss & 0.014 & 0.55 \\
Weld--Liquid--Crevice & 0.018 & 0.69 \\
Weld--Interface--Wt. Loss & 0.015 & 0.60 \\
Weld--Wt. Loss--Vapor & 0.0008 & 0.03 \\
\hline
\end{tabular}

${ }^{a}$ Test was completed at $80^{\circ} \mathrm{C}$ and $660 \mathrm{mmHg}$ for 45 days.

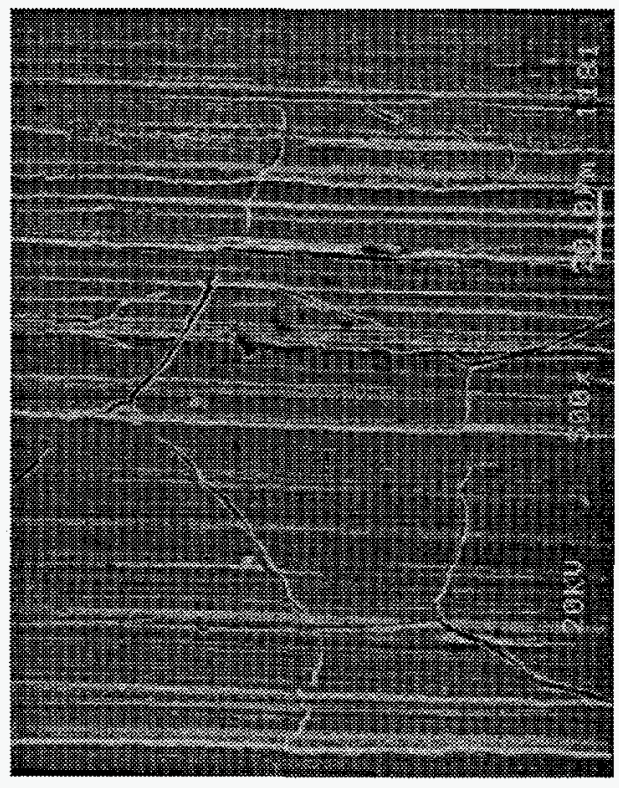

Fig. 12. Hastelloy G-30 Nickel-Based Alloy with Light Etching. Micrograph of base metal at $500 \mathrm{X}$. The horizontal scratches are from polishing during coupon preparation. Coupon shown is a liquid-phase sample following 45-day immersion testing at $80^{\circ} \mathrm{C}$ and $660 \mathrm{mmHg}$. 


\section{h. $\quad$ Titanium-Grade 2}

No pitting, crevice, or preferential weld attack was observed. The liquidphase and interface samples were tinted a very light blue-brown. No etching or intergranular attack was observed. The average corrosion rate for the liquid-phase samples was $0.0028 \mathrm{~mm} / \mathrm{y}$ (0.11 mpy) (see Table 20). A micrograph of the coupon surface, which exhibits no etching or intergranular attack, is shown in Fig. 13.

Table 20. Titanium Grade 2 Corrosion Rates--Acidic Solution ${ }^{\mathrm{a}}$

\begin{tabular}{lcc}
\hline Condition & \multicolumn{2}{c}{ Average Corrosion Rate } \\
\cline { 2 - 3 } & $\mathrm{mm} / \mathrm{y}$ & $\mathrm{mpy}$ \\
\hline Liquid--Wt. Loss & 0.010 & 0.40 \\
Liquid--Crevice & 0.0005 & 0.02 \\
Interface--Wt. Loss & 0.0005 & 0.02 \\
Vapor--Wt. Loss & 0.0008 & 0.03 \\
Weld--Liquid--Wt. Loss & 0.0005 & 0.02 \\
Weld--Liquid--Crevice & 0.0005 & 0.02 \\
Weld--Interface--Wt. Loss & 0.0013 & 0.05 \\
Weld--Wt. Loss--Vapor & 0.0008 & 0.03 \\
\hline
\end{tabular}

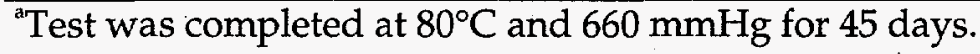

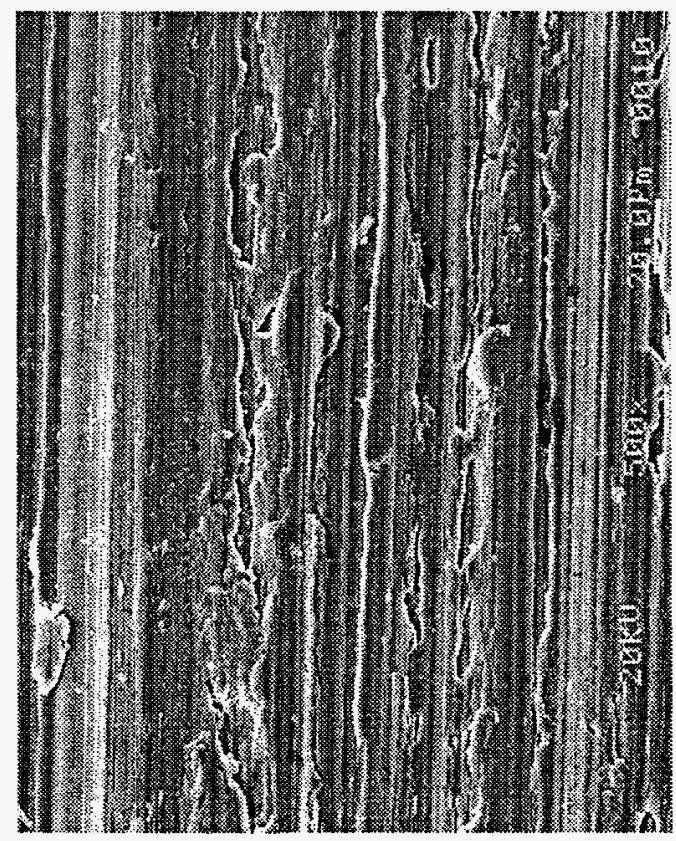

Fig. 13. Grade 2 Titanium Exhibiting No Etching or Intergranular Attack. Micrograph of base metal at $500 \mathrm{X}$. The vertical scratches are from polishing during coupon preparation. Coupon shown is a liquid-phase sample following 45 -day immersion testing at $80^{\circ} \mathrm{C}$ and $660 \mathrm{mmHg}$. 


\section{Electrochemical Testing}

\section{a. $\quad$ Linear Polarization Resistance Data}

The corrosion rate of $304 \mathrm{~L}$ in nitric acid solution did not exceed $0.11 \mathrm{~mm} / \mathrm{y}$ ( $4.2 \mathrm{mpy}$ ) after 96 hours of exposure, although initial rates were observed in excess of $1.28 \mathrm{~mm} / \mathrm{y}$ (50 mpy). (Stainless steels initially experience higher rates of corrosion before passivation occurs.) No effect of the vacuum losses was seen in the measured corrosion rate during the 45-day exposure. No effect of solution additions to the kettle (to maintain solution levels) was observed in the measured corrosion rates once the system returned to $80^{\circ} \mathrm{C}$ following the addition. The corrosion rate of $304 \mathrm{~L}$ in the alkaline test solution did not exceed 0.07 mpy after 48 hours of exposure. No effect on the rate was observed upon application of vacuum to the test kettle. Likewise, solution additions did not affect the measured corrosion rate once the temperature of the system returned to $80^{\circ} \mathrm{C}$ following the addition.

\section{b. Cyclic Potentiodynamic Polarization Data}

Cyclic potentiodynamic polarization (CPP) tests were performed by $\mathrm{CC}$ Technologies on the candidate alloys soon after the long-term exposure tests were started. They were conducted at $80^{\circ} \mathrm{C}$. The results were expected to predict those of the long-term tests, that is, whether the alloys would undergo pitting in the test solution. In this technique, the polarity and magnitude of the current flow between a specimen of the alloy and an inert counter electrode are measured as a function of electrochemical potential. The potential is scanned to a value that exceeds the pitting potential, then reversed and returned to the corrosion potential. The occurrence of hysteresis between the forward and reverse scans is generally indicative of pitting or crevice corrosion on the specimen during the test. These results are given in Appendix B. The results showed no pitting or crevice attack on any of the samples.

\section{DISCUSSION}

All of the alloys exhibited excellent corrosion resistance in the sodium hydroxide test solution. Corrosion rates were very low and localized corrosion was not observed.

Results for the nitric acid test solution showed that only 316L stainless steel did not meet our acceptance criteria. The $316 \mathrm{~L}$ welded interface and crevice specimens had rates of 0.59 $\mathrm{mm} / \mathrm{y}(22.2 \mathrm{mpy})$ and $0.58 \mathrm{~mm} / \mathrm{y}(21.8 \mathrm{mpy})$, respectively, which exceeds the maximum corrosion rate of $0.53 \mathrm{~mm} / \mathrm{y}(20 \mathrm{mpy})$. Except for 316L welded samples had about the same corrosion resistance as the plain samples. None of the welded samples showed preferential weld or HAZ attack. Vapor corrosion was negligible for all alloys. All of the alloys except 316L exhibited either "satisfactory" $(0.053-0.53 \mathrm{~mm} / \mathrm{y}, 2-20 \mathrm{mpy})$ or "excellent" $(<0.053 \mathrm{~mm} / \mathrm{y}, 2$ mpy) corrosion resistance as defined by National Association of Corrosion Engineers (NACE). However, many of the alloys experienced intergranular corrosion in the nitric acid test solution, which could indicate a susceptibility to SCC in this environment. Any of these alloys under consideration for use in a nitric acid solution should be tested for SCC beforehand in that solution.

The nickel-based alloys we tested have $(\mathrm{Ni}+\mathrm{Cr}$ ) contents ranging from $63.5 \%$ to $87 \%$ (see Table 21). Surprisingly, Hastelloy G-30 performed as well as or better than the rest of the nickel-based alloys, even though it has a $(\mathrm{Ni}+\mathrm{Cr})$ content of only $67 \%$. This behavior may reflect the presence of cobalt in the alloy, which is believed to increase the corrosion resistance of nickel-based alloys [BARKER]. In addition, only G-30 and titanium experienced no 
intergranular attack. As expected, the corrosion resistance of titanium in the nitric acid solution was excellent.

The results indicate that all of the alloys should undergo further testing for SCC in the sodium hydroxide solution. All of the alloys except 316L should be tested for SCC in the nitric acid test solution. The 316L stainless steel should not be considered for service in a nitric acid environment similar to the test solution.

Table 21. Combined Nickel+Chromium Content of Selected Nickel-Based Alloys

\begin{tabular}{c|cccc}
\cline { 2 - 5 } & \multicolumn{4}{|c}{ Alloy } \\
\cline { 2 - 5 } & 825 & 625 & 690 & G-30 \\
\hline General Type & Ni-Cr-Fe-Mo & Ni-Cr-Mo-Fe & Ni-Cr-Fe & Ni-Cr-Fe-Mo-Co-W \\
Ni+Cr wt $\%$ & 63.5 & 81 & 87 & 67.5 \\
\hline
\end{tabular}

\section{REFERENCES}

\section{ANTHONY}

D. Anthony, "Improved Evaporators for Radioactive Wastes," Chem. Eng. Progress, p. 58-63, July 1993.

\section{BARKER}

S. A. Barker and E. B. Schwenk, "Materials Evaluation for a Transuranic Processing Facility," WHC-SA-0963-FP (November 1990).

\section{CHEN}

L. Chen, personal communication (1994).

\section{HARRISON}

R. J. Harrison, AECL, Chalk River Laboratories, Chalk River, ON (Canada), personal communication (1994).

NACE

Corrosion Data Survey, Metals Section, NACE, 6th ed., p. 11, 1985.

ORME

R. Orme, Westinghouse Hanford Company, personal communication (1994).

RICHMOND

W. Richmond, "Conceptual Design Report: Cesium Demonstration Unit," EBASCO/BNFL Report E/B-SD-W236B-RPT-008-Rev OB (1994). 


\section{APPENDIX A}

\section{MATERIALS SELECTION}

\section{A. Selection of Process Solutions}

The evaporator/concentrator compact processing unit (CPU) was originally intended to process cesium-free tank waste from Hanford Tank 241-AW-101 and cesium ion-exchange eluant. Changes in the project's mission occurred when Westinghouse Hanford and DOE decided against installation and testing of CPU-based processes. Because of this decision, the focus on evaporator CPUs shifted to the Savannah River Site (SRS) and Oak Ridge National Laboratory (ORNL). However, the focus of materials selection and the recommended test solutions were not changed for several reasons. First, the Tank Waste Remediation System (TWRS) program still includes a number of evaporators in their Case BETA Prime flowsheet [ORME]. These corrosion data will assist in selecting materials for these units. Second, the waste solutions being evaluated generally appear to be more corrosive than what we can expect at other sites. Therefore, by testing various materials in both acidic and alkaline environments, corrosion data applicable to these sites is obtained.

The composition of the two waste solutions being evaluated for evaporation are reported in Tables A-1 and A-2. The test solutions will contain the major components of these process streams (see Tables A-3 and A-4). Since corrosion rates increase with concentration and temperature for both nitric acid and sodium hydroxide, the most concentrated compositions expected in the evaporator were chosen as test solutions. One criterion for a CPU-based process is to be able to process both acidic and alkaline solutions. Therefore, the material of construction must be resistant to corrosion in both environments. If a dedicated evaporator is used for one process stream, then this restrictive requirement can be relaxed. 
Table A-1. Chemical Composition of Tank 241-AW-101 a, b

\begin{tabular}{cccc}
\hline Constituent & Avg. Conc., $\underline{M}$ & Constituent & Avg. Conc., $\underline{\underline{M}}$ \\
\hline Aluminum & $1.03 \mathrm{E}+00$ & Sodium & $1.00 \mathrm{E}+01$ \\
Arsenic & $<1.33 \mathrm{E}-07$ & Titanium & $<9.88 \mathrm{E}-05$ \\
Barium & $<6.80 \mathrm{E}-05$ & Uranium & $9.39 \mathrm{E}-04$ \\
Bismuth & $<5.79 \mathrm{E}-04$ & Zinc & $<4.84 \mathrm{E}-03$ \\
Cadmium & $<1.08 \mathrm{E}-05$ & Zirconium & $<5.54 \mathrm{E}-04$ \\
Calcium & $8.26 \mathrm{E}-04$ & Ammonia & $1.45 \mathrm{E}-02$ \\
Chromium & $3.08 \mathrm{E}-03$ & Carbonate & $2.05 \mathrm{E}-01$ \\
Copper & $<3.81 \mathrm{E}-04$ & Chloride & $1.46 \mathrm{E}-01$ \\
Iron & $<7.86 \mathrm{E}-04$ & Cyanide & $1.03 \mathrm{E}-03$ \\
Lead & $<1.46 \mathrm{E}-03$ & Hydroxide & $5.07 \mathrm{E}+00$ \\
Magnesium & $2.15 \mathrm{E}-03$ & Fluoride & $<4.02 \mathrm{E}-03$ \\
Manganese & $4.76 \mathrm{E}-04$ & Nitrite & $2.19 \mathrm{E}+00$ \\
Mercury & $<7.8 \mathrm{E}-6$ & Nitrate & $3.46 \mathrm{E}+00$ \\
Molybdenum & $6.00 \mathrm{E}-04$ & Phosphate & $2.22 \mathrm{E}-02$ \\
Potassium & $1.07 \mathrm{E}+00$ & Sulfate & $1.07 \mathrm{E}-02$ \\
Selenium & $4.20 \mathrm{E}-07$ & TOC & 0.205 \\
Silicon & $<4.36 \mathrm{E}-03$ & & \\
Silver & $<3.10 \mathrm{E}-04$ & & \\
\hline
\end{tabular}

aComposition from [RICHMOND].

${ }^{b}$ Density $=1.56 \mathrm{~g} / \mathrm{cm}^{3} ; 43.6 \mathrm{wt}^{\mathrm{t}} \%$ water.

cTOC = Total Organic (oxidizable) Carbon, in mol/L.

Table A-2. HLW Stream Composition of the Cesium-Removal Ion-Exchange Eluanta,b

\begin{tabular}{cc}
\hline Constituent & Concentration, $\underline{\mathrm{M}}$ \\
\hline $\mathrm{Ca}^{+2}$ & $1.56 \mathrm{E}-04$ \\
$\mathrm{Cs}^{+}$ & $2.77 \mathrm{E}-05$ \\
$\mathrm{H}^{+}$ & $2.47 \mathrm{E}-01$ \\
$\mathrm{Na}^{+}$ & $4.30 \mathrm{E}-02$ \\
$\mathrm{NO}_{3}^{-}$ & $2.91 \mathrm{E}-01$ \\
$\mathrm{Sr}^{+2}$ & $1.46 \mathrm{E}-07$ \\
\hline
\end{tabular}

a98.1 wt \% water.

bAspen Model Prediction. 
Table A-3. Sodium Hydroxide Test Solution Composition

\begin{tabular}{lclc}
\hline Constituent & Concentration, $\underline{\mathrm{M}}$ & Constituent & Concentration, $\underline{\mathrm{M}}$ \\
\hline Aluminum & $9.5 \mathrm{E}-01$ & Chloride & $1.5 \mathrm{E}-01$ \\
Chromium & $3.1 \mathrm{E}-03$ & Hydroxide & $5.7 \mathrm{E}+00$ \\
Iron & $7.9 \mathrm{E}-04$ & Fluoride & $4.0 \mathrm{E}-03$ \\
Magnesium & $2.0 \mathrm{E}-03$ & Nitrite & $2.8 \mathrm{E}+00$ \\
Potassium & $1.1 \mathrm{E}+00$ & Nitrate & $3.8 \mathrm{E}+00$ \\
Sodium & $9.0 \mathrm{E}+00$ & Phosphate & $2.2 \mathrm{E}-02$ \\
Ammonia & $1.5 \mathrm{E}-02$ & Sulfate & $1.1 \mathrm{E}-02$ \\
& & Carbonate & $2.1 \mathrm{E}-01$ \\
\hline
\end{tabular}

Table A-4. Nitric Acid Test Solution Composition

\begin{tabular}{cc}
\hline Constituent & Concentration, $\underline{\mathrm{M}}$ \\
\hline $\mathrm{H}^{+}$ & 15.9 \\
$\mathrm{Na}^{+}$ & 2.5 \\
$\mathrm{NO}_{3}{ }^{-}$ & 18.4 \\
\hline
\end{tabular}

During the processing of waste solutions such as the one given in Table A-1, scale containing $\mathrm{CaF}_{2}$ may form in the evaporator/concentrator $\mathrm{CPU}$. If the $\mathrm{CPU}$ is flushed with nitric acid to remove the scale, a highly corrosive $\mathrm{HNO}_{3}-\mathrm{HF}$ solution may form. Thus, the material of construction which is selected must have acceptable corrosion resistance to the nitric-hydrofluoric acid mixture to which it may be exposed. Alternatively, complexing agents such as zirconium or aluminum can be added to the nitric acid cleaning solutions to complex the fluoride, reducing the corrosivity of the solution. Those alloys which exhibit acceptable corrosion resistance in Stage 1 should be tested in a nitric-hydrofluoric acid environment.

Acceptable corrosion rates have been suggested by the National Association of Corrosion Engineers for various applications [NACE]. They are listed in Table A-5.

Table A-5. NACE Corrosion Ratings

\begin{tabular}{ccc}
\hline $\begin{array}{c}\text { Corrosion Rate, } \\
\mathrm{mm} / \mathrm{y}(\mathrm{mpy})\end{array}$ & Rating & Applications \\
\hline & & \\
$0.051(<2)$ & excellent & very critical \\
$0.051-0.51(2-20)$ & satisfactory & critical \\
$0.51-1.28(20-50)$ & useful & non-critical \\
$1.28(>50)$ & poor & none \\
\hline
\end{tabular}


In industry, the "excellent" rating may extend up to $0.128 \mathrm{~mm} / \mathrm{y}$ (5 mpy) [ALLEGHENY CORP]. Meyer [MEYER] considered a rate of $0.51 \mathrm{~mm} / \mathrm{y}(20 \mathrm{mpy})$ to be the maximum allowable corrosion rate for nitric acid concentrators (evaporators). We considered alloys for testing that had rates of up to $1.28 \mathrm{~mm} / \mathrm{y}(50 \mathrm{mpy})$ in various standard test solutions.

\section{Selection of Candidate Materials}

Some general comments can be made concerning suitable alloys for nitric acid and sodium hydroxide environments; the following information was condensed from the Handbook of Corrosion Data [CRAIG]:

\section{Nitric Acid}

In nitric acid environments, most AISI 300-series stainless steels (annealed) exhibit good or excellent corrosion resistance up to $65 \% \mathrm{HNO}_{3}$ and $100^{\circ} \mathrm{C}$. Molybdenum alloying additions tend to decrease resistance to nitric acid; thus, $316 \mathrm{~L}(2.5 \mathrm{wt} \% \mathrm{Mo})$ is less resistant to nitric acid than 304L. Sensitization (precipitation of corrosion-inhibiting alloying elements as carbides at grain boundaries, which removes them from the bulk alloy) reduces corrosion resistance and can be avoided by using low or extra-low carbon alloys when welding is necessary and by using the alloy in the solution heat-treated condition.

Nickel alloys are extensively used in the production of nitric acid. Because chromium forms a passive film, higher $\mathrm{Cr}-\mathrm{Ni}$ alloys are more corrosion resistant than higher Mo-Ni alloys (recall the effect of Mo additions in stainless steel as mentioned above).

Commercially pure titanium is often used in nitric acid applications where stainless steels are not suitable. Titanium exhibits excellent corrosion resistance at all concentrations up to $80^{\circ} \mathrm{C}$. Above $80^{\circ} \mathrm{C}$, resistance depends on nitric acid purity; hot, very pure solutions or vapor condensates may cause significant uniform corrosion. Impurities such as $\mathrm{Si}^{+4}, \mathrm{Cr}^{+6}, \mathrm{Fe}^{+3}$, or $\mathrm{Ti}^{+4}$ can inhibit this high-temperature corrosion. Thus, in recirculating process streams where a steady-state level of $\mathrm{Ti}^{+4}$ is achieved, titanium can exhibit excellent corrosion resistance.

\section{Sodium Hydroxide}

All stainless steels resist corrosion by sodium hydroxide in all concentrations up to about $65^{\circ} \mathrm{C}$. Types 304 and 316 exhibit low rates of corrosion in boiling $\mathrm{NaOH}$ up to $\sim 20 \%$ concentration; stress corrosion cracking (SCC) can occur at about $100^{\circ} \mathrm{C}$. The presence of chlorides in an alkaline solution does not appear to have a deleterious effect on the austenitic stainless steels, as long as the solution remains alkaline; a solution of $0.5 \mathrm{~g} / 1 \mathrm{NaOH}(\sim 0.0125 \underline{\mathrm{M}})$ with a $\mathrm{pH}$ of 12 is sufficient. Type $316 \mathrm{~L}$ performs better overall in caustic environments than type $304 \mathrm{~L}$ due to its greater pitting resistance.

Nickel and its alloys exhibit very low corrosion rates in sodium hydroxide. Increasing the nickel content of nickel-base alloys increases resistance to general corrosion and SCC. 
Titanium exhibits low corrosion rates in sodium hydroxide at temperatures below boiling; corrosion increases significantly with increasing concentration and temperature. For alpha and near-alpha alloys hydrogen embrittlement can occur at temperatures greater than $80^{\circ} \mathrm{C}$ and $\mathrm{pH} \geq 12$. Oxidizing species such as chlorate, hypochlorite or nitrate compounds can extend resistance to hydrogen uptake to slightly higher temperatures.

Very little information exists on the corrosion resistance of metals in nitric-hydrofluoric acid mixtures. The data used in Table A-6 of this report indicate that stainless steels are of limited use in such solutions. Nickel-base alloys exhibit considerably better resistance. There are some data which show that increasing $(\mathrm{Ni}+\mathrm{Cr})$ content increases resistance to $\mathrm{HNO}_{3}-\mathrm{HF}$ solutions. Cobalt alloying additions (along with $\mathrm{Ni}+\mathrm{Cr}$ ) could also be helpful in such an environment, since cobalt alloys become more noble with additions of chromium [SMITH]. Titanium is not resistant to dilute hydrofluoric acid solutions.

In general, chromium additions lend improved resistance to oxidizing acids, such as $\mathrm{HNO}_{3}$, while Mo additions do the same for reducing acids. Molybdenum also improves pitting resistance. Carbon, phosphorus, and sulfur levels should be kept as low as possible to prevent precipitation of carbides, phosphides, or sulfides, which could remove corrosion-resistant alloying additions such as chromium from solution.

Materials originally under consideration for corrosion testing included the following: 304L, 316L, AL-6XN, alloys 800, 825, 617, 625, 686, 690, C-276, C-22, G-30, and titanium (Grade 2). Tables A-6 to A-8 lists corrosion rates for the various alloys in $\mathrm{HNO}_{3}, \mathrm{NaOH}$, and $\mathrm{HNO}_{3}-\mathrm{HF}$ environments. Alloy compositions (major components) are given in Table A-9. 
Table A-6. Corrosion Rates in $\mathrm{HNO}_{3}$ Solutions

\begin{tabular}{|c|c|c|c|c|}
\hline \multirow[t]{2}{*}{ Alloy } & \multicolumn{2}{|c|}{ Corrosion Rate } & \multirow[t]{2}{*}{ Test Conditions } & \multirow[t]{2}{*}{ Reference } \\
\hline & $\mathrm{mm} / \mathrm{y}$ & mpy & & \\
\hline $304 \mathrm{~L}$ & 0.25 & 9.6 & $65 \% \mathrm{HNO}_{3}$ boiling & CRAIG \\
\hline $316 \mathrm{~L}$ & 0.9 & 34.3 & $65 \% \mathrm{HNO}_{3}$ boiling & CRAIG \\
\hline AL-6XN & 0.7 & 28.9 & Huey test & ALLEGHENY CORP \\
\hline Alloy 800 & 0.2 & 8.4 & Huey test, $65 \%$ boiling & INCO-1985A \\
\hline \multirow[t]{3}{*}{ Alloy 625} & 0.51 & 20 & $65 \% \mathrm{HNO}_{3}$ boiling & INCO-1994 \\
\hline & 0.8 & 30 & $65 \% \mathrm{HNO}_{3}$ boiling & INCO-1985B \\
\hline & 0.3 & 12.0 & $65 \% \mathrm{HNO}_{3}$ boiling & INCO-1985A \\
\hline Inconel 686 & 5.9 & 231 & $65 \% \mathrm{HNO}_{3}$ boiling & INCO-1985A \\
\hline Inconel 690 & 0.08 & 3.0 & $65 \% \mathrm{HNO}_{3}$ boiling & INCO-1985A \\
\hline Inconel 617 & 0.5 & 20 & $65 \% \mathrm{HNO}_{3}$ boiling & INCO-1979 \\
\hline Hastelloy C-276 & 22.6 & 888 & $65 \% \mathrm{HNO}_{3}$ boiling & HAYNES-1987 \\
\hline Hastelloy C-22 & 3.4 & 134 & $65 \% \mathrm{HNO}_{3}$ boiling & HAYNES-1991 \\
\hline Hastelloy G-30 & 0.1 & 5 & $65 \% \mathrm{HNO}_{3}$ boiling & HAYNES-1989 \\
\hline \multirow[t]{3}{*}{$\mathrm{Ti}^{\mathrm{a}}$} & 0.08 & 3.1 & $70 \%$ boiling & CRAIG \\
\hline & 0.04 & 1.56 & $70 \%, 70^{\circ} \mathrm{C}$, aerated & TIMET \\
\hline & $0.06-0.9$ & $2.5-37$ & $70 \%$ boiling, non-aerated & SMITH \\
\hline
\end{tabular}

aCommercially pure.

bGrade 1. 
Table A-7. Corrosion Rates in $\mathrm{NaOH}$ Solutions

\begin{tabular}{|c|c|c|c|c|}
\hline \multirow[t]{2}{*}{ Alloy } & \multicolumn{2}{|c|}{ Corrosion Rate } & \multirow[t]{2}{*}{ Test Conditions } & \multirow[t]{2}{*}{ Reference } \\
\hline & $\mathrm{mm} / \mathrm{y}$ & mpy & & \\
\hline \multirow[t]{3}{*}{$304 \mathrm{~L}$} & 0.003 & 0.1 & $20 \%,{ }^{\text {a }} 97^{\circ} \mathrm{C}$ & CARLOS \\
\hline & 0.04 & 1.4 & $20 \%, 60^{\circ} \mathrm{C}$ & CRAIG \\
\hline & $1.4-4.7$ & $53-183$ & $50 \%$ boiling & ALLEGHENY TECH \\
\hline 316 & 0.09 & 3.6 & $\begin{array}{l}20 \%, 60^{\circ} \mathrm{C} \text {, rapid agitation, } \\
20 \% \text { suspended crystalline salt }\end{array}$ & CRAIG \\
\hline \multirow[t]{2}{*}{$316 \mathrm{~L}$} & 2.0 & 77.7 & $50 \%$ boiling & ALLEGHENY CORP \\
\hline & 3.1 & 123 & $50 \%$ boiling & CRAIG \\
\hline \multirow[t]{2}{*}{$\mathrm{AL}-6 \mathrm{XN}$} & 0.4 & 16.0 & $50 \%$ boiling & ALLEGHENY CORP \\
\hline & 0.4 & 17.2 & $50 \%$ boiling, welded & CRAIG \\
\hline Alloy 800 & 0.005 & 0.2 & $23 \%, 93^{\circ} \mathrm{C}, \mathrm{NaCl} 7-8 \%$ & CRAIG \\
\hline Alloy 625 & 0.01 & 0.5 & $50 \%$ boiling & CRAIG \\
\hline \multirow[t]{2}{*}{ Alloy 825} & 0.5 & $18.0^{\mathbf{b}}$ & $15 \%, 100^{\circ} \mathrm{C},+2 \% \mathrm{Cl}$-saturated & CRAIG \\
\hline & 0.008 & 0.3 & $74 \%, 129^{\circ} \mathrm{C}$ & INCO-1989 \\
\hline Inconel 686 & -- & - & - & -- \\
\hline \multirow[t]{2}{*}{ Inconel 690} & & c & $20 \%, 320^{\circ} \mathrm{C}$ & INCO-1980 \\
\hline & & d & $\geq 30 \%$ and $\mathrm{T}>260^{\circ} \mathrm{C}$ & INCO-1980 \\
\hline \multirow[t]{2}{*}{ Inconel 617} & 0.01 & 0.4 & $20 \%$ boiling & INCO-1979 \\
\hline & 0.3 & 11 & $48 \%$ boiling & INCO-1979 \\
\hline Hastelloy C-276 & - & -- & -- & -- \\
\hline Hastelloy C-22 & -- & -- & - & -- \\
\hline Hastelloy G-30 & 0.05 & 1.8 & $50 \%$ boiling & HAYNES-1994 \\
\hline $\mathrm{Ti}\left(\right.$ commercially pure) ${ }^{\mathrm{e}}$ & 0.05 & 2.0 & $50 \%$ boiling & CRAIG \\
\hline \multicolumn{5}{|c|}{$\begin{array}{l}{ }^{\mathrm{a}} 6 \mathrm{M} \mathrm{OH} \mathrm{OH}^{-}, 0.20 \mathrm{M} \mathrm{Cl}-0.01 \mathrm{M} \mathrm{F}^{-}, 1.00 \mathrm{M} \mathrm{NO}_{2}^{-}, 2.00 \mathrm{M} \mathrm{NO}_{3}{ }^{-} ; \text {similar composition to Tank } 241-\mathrm{AW}-101 \\
\text { waste listed in Table } 1 .\end{array}$} \\
\hline \multicolumn{5}{|c|}{ bSevere pitting (10 mil depth), crevice attack. } \\
\hline \multicolumn{5}{|c|}{ 'No SCC in $1000 \mathrm{~h}$. } \\
\hline \multicolumn{5}{|l|}{ dSevere general corrosion. } \\
\hline${ }^{e}$ Grade not specified. & & & & \\
\hline
\end{tabular}


Table A-8. Corrosion Rates in $\mathrm{HNO}_{3}$-HF Solutions

\begin{tabular}{|c|c|c|c|c|}
\hline \multirow[t]{2}{*}{ Alloy } & \multicolumn{2}{|c|}{ Corrosion Rate } & \multirow[t]{2}{*}{ Test Conditions } & \multirow[t]{2}{*}{ Reference } \\
\hline & $\mathrm{mm} / \mathrm{y}$ & mpy & & \\
\hline 304L & 94.3 & 3699.0 & $2 \underline{\mathrm{M}} \mathrm{HNO}_{3}-2 \underline{\mathrm{M} \mathrm{NaF}}, 60^{\circ} \mathrm{C}$ & SMITH \\
\hline $316 \mathrm{~L}$ & 224.4-1586.1 & $8800-62,200$ & 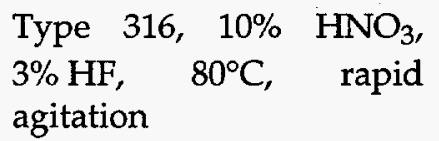 & CLIMAX MOLY \\
\hline AL-6XN & 3.1 & 120 & $10 \% \mathrm{HNO}_{3}, 3 \% \mathrm{HF}, 70^{\circ} \mathrm{C}$ & ALLEGHENY CORP \\
\hline Alloy 800 & - & -- & -- & - \\
\hline Alloy 625 & $\begin{array}{l}0.4 \\
0.7\end{array}$ & $\begin{array}{l}15.6 \\
28.0\end{array}$ & $\begin{array}{l}2 \underline{\mathrm{M} \mathrm{HNO}_{3}}-2 \underline{\mathrm{M}} \mathrm{NaF}, 60^{\circ} \mathrm{C} \\
10 \% \mathrm{HNO}_{3}, 3 \% \mathrm{HF}, 60^{\circ} \mathrm{C}\end{array}$ & $\begin{array}{l}\text { SMITH } \\
\text { INCO-1989 }\end{array}$ \\
\hline Alloy 825 & 0.5 & 19.9 & $2 \underline{\mathrm{M}} \mathrm{HNO}_{3}-2 \underline{\mathrm{M}} \mathrm{NaF}, 60^{\circ} \mathrm{C}$ & SMITH \\
\hline Inconel 686 & -- & - & -- & -- \\
\hline Inconel 690 & $\begin{array}{l}4.1 \\
0.2\end{array}$ & $\begin{array}{c}160 \\
6\end{array}$ & $\begin{array}{l}2 \underline{\mathrm{M} \mathrm{HNO}_{3}-2 \mathrm{M}} \mathrm{NaF}, 60^{\circ} \mathrm{C} \\
10 \% \mathrm{HNO}_{3}, 3 \% \mathrm{HF}, 60^{\circ} \mathrm{C}\end{array}$ & $\begin{array}{l}\text { SMITH } \\
\text { INCO-1985A }\end{array}$ \\
\hline Inconel 617 & 1.2 & 49.0 & $2 \underline{\mathrm{M}} \mathrm{HNO}_{3}-2 \underline{\mathrm{M}} \mathrm{NaF}, 60^{\circ} \mathrm{C}$ & SMITH \\
\hline Hastelloy C-276 & 0.9 & 34.6 & $2 \underline{\mathrm{M}} \mathrm{HNO}_{3}-2 \underline{\mathrm{M} \mathrm{NaF}}, 60^{\circ} \mathrm{C}$ & SMITH \\
\hline Hastelloy C-22 & 0.2 & 6.1 & $2 \underline{\mathrm{M}} \mathrm{HNO}_{3}-2 \underline{\mathrm{M}} \mathrm{NaF}, 60^{\circ} \mathrm{C}$ & SMITH \\
\hline Hastelloy G-30 & 0.2 & 5.7 & $2 \underline{\mathrm{M}} \mathrm{HNO}_{3}-2 \underline{\mathrm{M}} \mathrm{NaF}, 60^{\circ} \mathrm{C}$ & SMITH \\
\hline $\mathrm{Ti}$ (commercially pure) & - & $\begin{array}{l}a \\
b\end{array}$ & $1 \% \mathrm{HF}, 15 \% \mathrm{HNO}_{3}, 25^{\circ} \mathrm{C}$ & $\begin{array}{l}\text { TIMET } \\
\text { SMITH }\end{array}$ \\
\hline
\end{tabular}


Table A-9. Alloy Compositions--Major Components ${ }^{a}$

\begin{tabular}{lccccccccc}
\hline Alloy & Fe & Ni & Cr & Mo & Co & W & Ti & Cu & Other \\
\hline 304L SS & 71 & 10 & 19 & & & & & & \\
316L SS & 68.5 & 12 & 17 & 2.5 & & & & & \\
AL-6XN & 48 & 24 & 21 & 6 & & & & 0.1 & N--0.22 \\
800 & 43 & 33 & 21 & & & 0.37 & 0.75 & 0.37 & \\
825 & 29 & 42 & 21.5 & 3 & & & 0.9 & 2.2 & \\
617 & 3 & 50 & 22 & 9 & 12.5 & & 0.6 & 0.5 & B--0.006 \\
625 & 5 & 59.5 & 21.5 & 9 & 1 & & 0.4 & & Nb+Ta--3.15-4.15 \\
686 & 5 & 59 & 21 & 16 & & 3.7 & 0.13 & & \\
690 & 9 & 60 & 29 & & & & & 0.50 & \\
C-276 & 5.5 & 55 & 15.5 & 16 & 2.5 & 3.75 & & & V--0.35 \\
C-22 & 3 & 56 & 22 & 13 & 2.5 & 3 & & & V--0.35 \\
G-30 & 15 & 37.5 & 30 & 5 & 5 & 2.75 & & 1.7 & Nb+Ta--0.3-1.5 \\
Ti (Grade 2) & 0.3 & & & & & & 99 & & \\
\hline
\end{tabular}

aSelected alloys in bold type.

Inconel 686 and Hastelloy C-276 and C-22 are eliminated from consideration based on their poor performance in boiling concentrated nitric acid. Of the stainless steels $(304 \mathrm{~L}, 316 \mathrm{~L}$, AL-6XN), 304L exhibits the lowest corrosion rate in $\mathrm{HNO}_{3}$ and is comparable to $316 \mathrm{~L}$ in $\mathrm{NaOH}$. However, 316L is more resistant to pitting than 304L. AL-6XN performs better than 316L in $\mathrm{HNO}_{3}$ and better in $50 \%$ boiling $\mathrm{NaOH}$ than either of the others. Type 304L is often used in nitric acid environments, while $316 \mathrm{~L}$ is preferred for caustic environments; AL-6XN could be a compromise between the two. AL-6XN is a "6-Mo stainless"--a high-Ni, high-Cr stainless steel with $\sim 6 \mathrm{wt} \%$ Mo. It is described by the manufacturer as "...fill(ing) the gap between the corrosion performance of conventional 316 stainless steel and nickel-based 625 or Alloy 276" [ALLEGHENY CORP]. Westinghouse Hanford Company has specified 6-Mo alloys for the inner shell construction of new double-shell waste tanks [FRANSON]. Its corrosion resistance is good in $\mathrm{NaOH}$ and $\mathrm{HNO}_{3}-\mathrm{HF}$, and is acceptable (for inclusion in our test program) in nitric acid. Therefore, all three stainless steels will be tested. Alloy 800 is similar to AL-6XN in composition; the $\mathrm{Mo}$ in $\mathrm{Al}-6 \mathrm{XN}$ is replaced with additional $\mathrm{Ni}$ and various trace alloying elements $(\mathrm{W}, \mathrm{Ti}, \mathrm{Cu})$ in alloy 800 . Its corrosion resistance is comparable to that of stainless steels; since we are already testing three stainless alloys, testing of alloy 800 would be redundant. 
The Ni-base alloys under consideration $(825,625,690,617, \mathrm{G}-30)$ perform acceptably in all three environments (except possibly 690 in $\mathrm{NaOH}$, where the only information available simply lists conditions beyond which the alloy does not perform well). The compositional difference between 617 and 625 is due mainly to the replacement of $\sim 10 \mathrm{wt} \% \mathrm{Ni}$ with Co in 617 ; the Co provides solid-solution strengthening and oxidation resistance at temperatures greater than $980^{\circ} \mathrm{C}$. Since the evaporator/concentrator CPU will not approach that temperature, we will test 625 but not 617 . Alloys 825, 625, 690 and G-30 are all various types of Ni-Cr alloys, with a range of $(\mathrm{Ni}+\mathrm{Cr})$ contents and additional alloying elements (see Table A-10). We will test all of these alloys to determine if one of them is clearly superior to the rest in our test environments.

Table A-10. (Nickel+Chromium) Content of Selected Ni-Base Alloys

\begin{tabular}{lcccc}
\hline & \multicolumn{4}{c}{ Alloy } \\
\cline { 2 - 5 } & 825 & 625 & 690 & G-30 \\
\hline & & & & \\
General Type & Ni-Cr-Fe-Mo & Ni-Cr-Mo-Fe & Ni-Cr-Fe & Ni-Cr-Fe-Mo-Co-W \\
(Ni+Cr) wt $\%$ & 63.5 & 81 & 87 & 67.5 \\
\hline
\end{tabular}

Titanium is available in a variety of grades, or compositions. Grades 1-4 are considered commercially pure, Grade 1 being the most pure. Grades 5-12 contain various amounts of intentionally added alloying elements. Grade 2 titanium is currently used for heat exchanger tubes in evaporators and in other industrial applications where good corrosion resistance is required. Titanium is extremely susceptible to corrosion by $\mathrm{HNO}_{3}-\mathrm{HF}$ solutions. However, it is expected to have excellent corrosion resistance in the $\mathrm{HNO}_{3}$ and $\mathrm{NaOH}$ test solutions. Since it may be very well suited to the majority of our processing needs, it ought to be considered as a candidate material. Actual flushing conditions have not yet been determined; it may be possible to adjust the composition of the flushing solution to provide a less corrosive environment for the evaporator.

\section{Candidate Materials}

The alloys which have been selected for corrosion testing are the following:

- Stainless steels:

$304 \mathrm{~L}, 316 \mathrm{~L}, \mathrm{AL}-6 \mathrm{XN}$

- Nickel-base alloys: $\quad 825,625,690$, Hastelloy G-30

- Titanium:

Grade 2

These materials range from the workhorse $304 \mathrm{~L}$ stainless steel to the more exotic G-30. Obtaining information about a variety of alloys will give us greater flexibility in materials selection for the CPU should the usual stainless alloys prove to be inadequate.

\section{REFERENCES}

\section{ALLEGHENY CORP}

"AL-6XN Alloy," Allegheny Ludlum Corporation, Pittsburgh, PA, 1991.

\section{ALLEGHENY TECH}

"General Corrosion of T304 in Acids, Bases and Salts," Allegheny Ludlum Technical Center, 1992. 


\section{CARLOS}

W. C. Carlos, Multi-Function Waste Tank Facility Corrosion Test Report (Phase 1), (WHC-SD-W236A-TRP-001, Rev. 0), December 27, 1993.

CLIMAX MOLY

A Guide to Corrosion Resistance, Climax Molybdenum, 1961.

CRAIG

Handbook of Corrosion Data, B. Craig, ed., ASM International, 1989.

FRANSON

I. Franson, Allegheny Ludlum Technical Center, Personal communication (January 31, 1994).

HAYNES-1987

"Alloy C-276," Publication H-2002B, Haynes International, 1987.

HAYNES-1989

"Alloy G-30," Publication H-2028C, Haynes International, 1989.

HAYNES-1991

"Alloy C-22," Publication H-2019D, Haynes International, 1991.

HAYNES-1994

M. L. Caruso, Haynes International, unpublished data (April 19, 1994).

INCO-1979

"Alloy 617," Huntington Alloys (now Inco Alloys International), 1979.

INCO-1980

"Alloy 690," Huntington Alloys (now Inco Alloys International), 1980.

INCO-1985A

"Resistance to Corrosion," p. 29, Inco Alloys International, 4th ed., 1985.

INCO-1985B

"Alloy 625," Inco Alloys International, 5th ed., 1985.

INCO-1989

"Alloy 622," (Publication IAI-61), Inco Alloys International, 1989.

INCO-1994

L. Shoemaker, Inco Alloys International, unpublished data (March 18, 1994).

MEYER

F. H. Meyer, Jr., Corrosion in a Nitric Acid Concentrator, AECD-3735, 1956.

NACE

Corrosion Data Survey, Metals Section, NACE, 6th ed., p. 11, 1985.

ORME

R. Orme, Westinghouse Hanford Company, personal communication (1994). 
RICHMOND

W. Richmond, "Conceptual Design Report: Cesium Demonstration Unit," EBASCO/BNFL Report E/B-SD-W236B-RPT-008-Rev 0B (1994).

\section{SMITH}

H. D. Smith et al., Corrosion Resistance of Stainless Steels and High Ni-Cr Alloys to Acid-Fluoride Wastes, (PNL-SA-20408), April 1992.

TIMET-1991

"Corrosion Resistance of Titanium," Timet Corp., 1991. 


\section{$\underline{\text { APPENDIX B }}$}

\section{ELECTROCHEMICAL TESTING}

Cyclic potentiodynamic polarization (CPP) tests were performed by CC Technologies on the candidate alloys soon after the long-term exposure tests were started. They were conducted at $80^{\circ} \mathrm{C}$. The results were expected to predict those of the long-term tests, that is, whether the alloys would undergo pitting in the test solution. In this technique, the polarity and magnitude of the current flow between a specimen of the alloy and an inert counter electrode are measured as a function of electrochemical potential. The potential is scanned to a value that exceeds the pitting potential, then reversed and returned to the corrosion potential. The occurrence of hysteresis between the forward and reverse scans is generally indicative of pitting or crevice corrosion on the specimen during the test. The results (see Table B-1 and Figs. B-1 through B-14 b) showed no pitting or crevice attack on any of the samples.

Table B-1. Results from Cyclic Potentiodynamic Polarization Tests

\begin{tabular}{|c|c|c|c|c|c|c|c|}
\hline Alloy & Environment & $\begin{array}{c}\text { Free-Corrosion } \\
\text { Potential, } \\
\text { volts vs. SCE }\end{array}$ & $\begin{array}{c}\text { Free-Corrosion } \\
\text { Current Density, } \\
\mathrm{A} / \mathrm{cm}^{2}\end{array}$ & $\begin{array}{c}\text { Passive Current } \\
\text { Density, } \\
\mathrm{A} / \mathrm{cm}^{2}\end{array}$ & $\begin{array}{c}\text { Anodic Tafel } \\
\text { Slope, } \\
\mathrm{mV} / \mathrm{dec} .\end{array}$ & $\begin{array}{c}\text { Cathodic Tafel } \\
\text { Slope, } \\
\text { mV/dec. }\end{array}$ & $\begin{array}{c}\text { Corrosion Rate, } \\
\text { mpy }\end{array}$ \\
\hline $304 L^{a}$ & Alkaline Waste & -0.275 & $7.00 \mathrm{E}-07$ & $8.00 \mathrm{E}-05$ & 75 & 52 & 0.30 \\
\hline $316 \mathrm{~L}^{\mathrm{a}}$ & Alkaline Waste & -0.310 & $4.50 \mathrm{E}-07$ & $2.00 \mathrm{E}-04$ & 52 & 56 & 0.19 \\
\hline AL6XNa & Alkaline Waste & -0.315 & $8.00 \mathrm{E}-07$ & $4.00 \mathrm{E}-05$ & 33 & 102 & 0.34 \\
\hline $625^{\mathrm{b}}$ & Alkaline Waste & -0.560 & $1.50 \mathrm{E}-07$ & $4.00 \mathrm{E}-05$ & 67 & 67 & 0.06 \\
\hline $825^{\mathrm{C}}$ & Alkaline Waste & -0.308 & $1.80 \mathrm{E}-07$ & $4.00 \mathrm{E}-05$ & 53 & 85 & 0.08 \\
\hline $690^{\mathrm{b}}$ & Alkaline Waste & & & & & & \\
\hline $\mathrm{G} 30^{\mathrm{d}}$ & Alkaline Waste & -0.487 & $1.00 \mathrm{E}-07$ & $4.00 \mathrm{E}-05$ & 83 & 104 & 0.04 \\
\hline Ti Gr2e & Alkaline Waste & -0.885 & $9.00 \mathrm{E}-07$ & $3.50 \mathrm{E}-05$ & 65 & 62 & 0.31 \\
\hline $304 \mathrm{~L}$ & Acid Waste & 0.915 & $8.00 \mathrm{E}-06$ & & 75 & 63 & 3.33 \\
\hline $316 \mathrm{~L}$ & Acid Waste & 0.880 & $1.70 \mathrm{E}-05$ & $1.60 \mathrm{E}-04$ & 54 & 44 & 7.25 \\
\hline AL6XN & Acid Waste & 0.902 & $2.00 \mathrm{E}-06$ & & 47 & 36 & 0.85 \\
\hline 625 & Acid Waste & 0.886 & $4.00 \mathrm{E}-06$ & & 67 & 42 & 1.64 \\
\hline 825 & Acid Waste & 0.692 & $7.00 \mathrm{E}-06$ & $1.20 \mathrm{E}-04$ & 33 & 43 & 2.93 \\
\hline 690 & Acid Waste & & & & & & \\
\hline G30 & Acid Waste & 0.785 & 2.00E-06 & $2.00 \mathrm{E}-05$ & 47 & 52 & 0.83 \\
\hline TiGr2 & Acid Waste & 0.738 & $1.00 \mathrm{E}-0.5$ & $6.90 \mathrm{E}-05$ & 67 & 55 & 3.46 \\
\hline
\end{tabular}

aStainless steel alloys.

$\mathbf{b}_{\text {Inconel nickel-based alloys. }}$

CIncoloy nickel-based alloy.

$\mathrm{d}_{\text {Hastelloy nickel-based alloy. }}$

eTitanium Grade 2. 


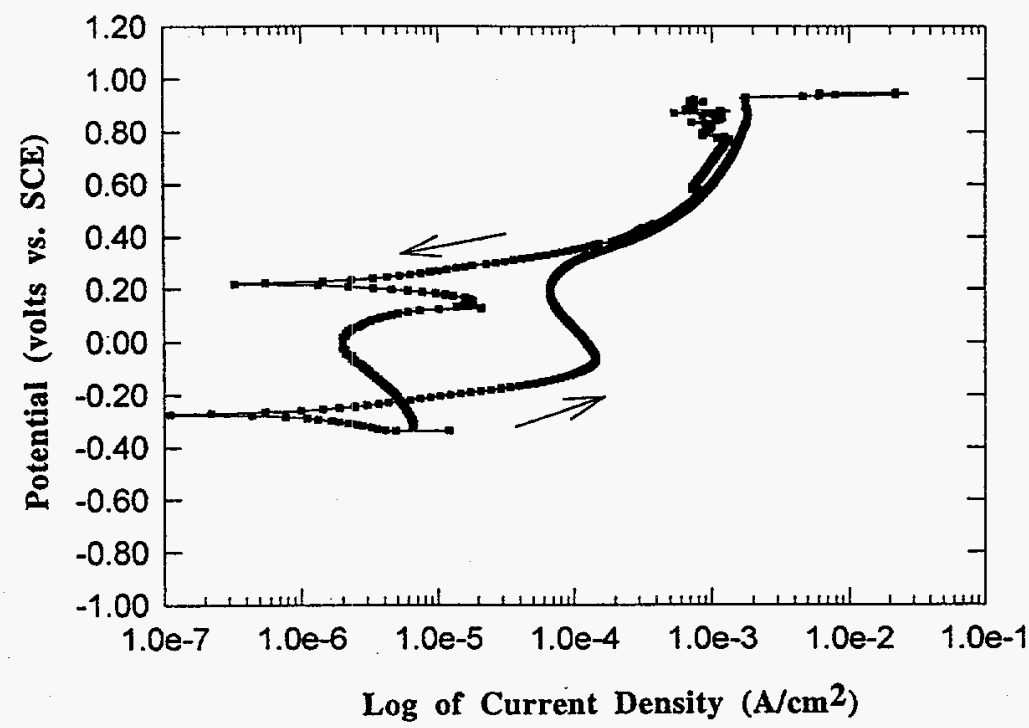

Fig. B-1. Cyclic Potentiodynamic Polarization Test Results of 304L Stainless Steel in Alkaline Solution

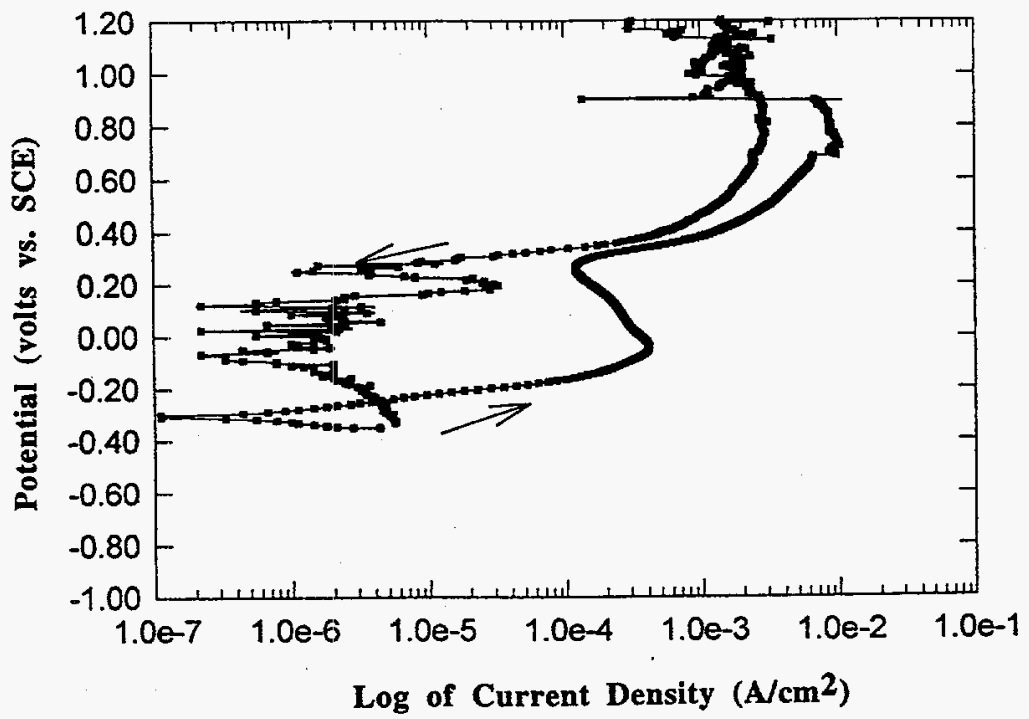

Fig. B-2. Cyclic Potentiodynamic Polarization Test Results of 316L Stainless Steel in Alkaline Solution 


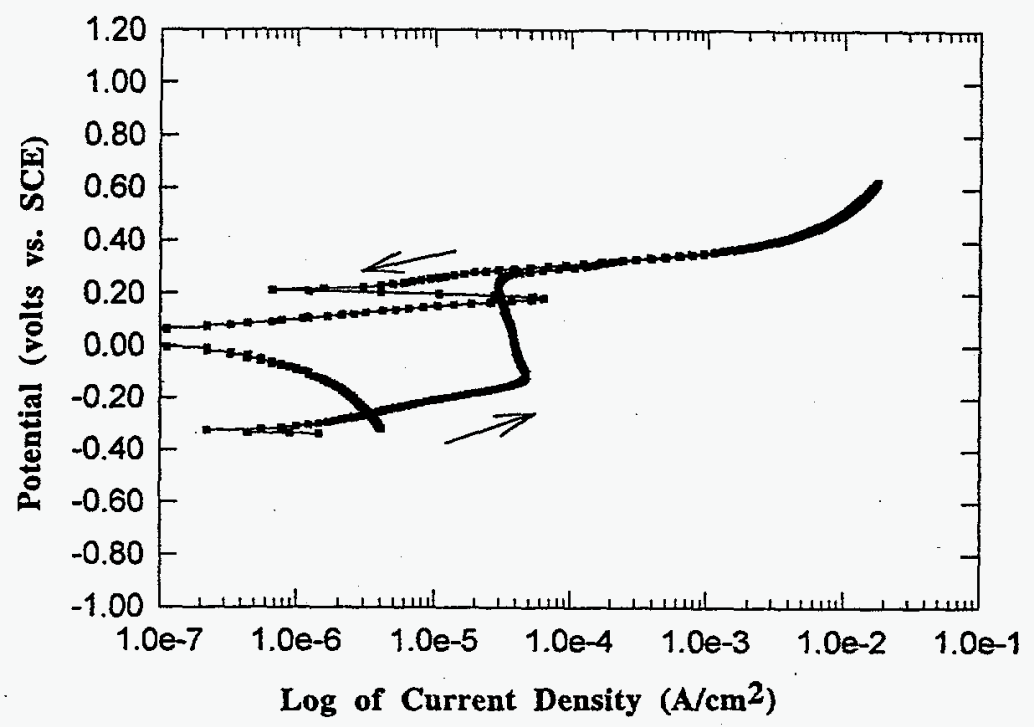

Fig. B-3. Cyclic Potentiodynamic Polarization Test Results of AL-6XN Stainless Steel in Alkaline Solution

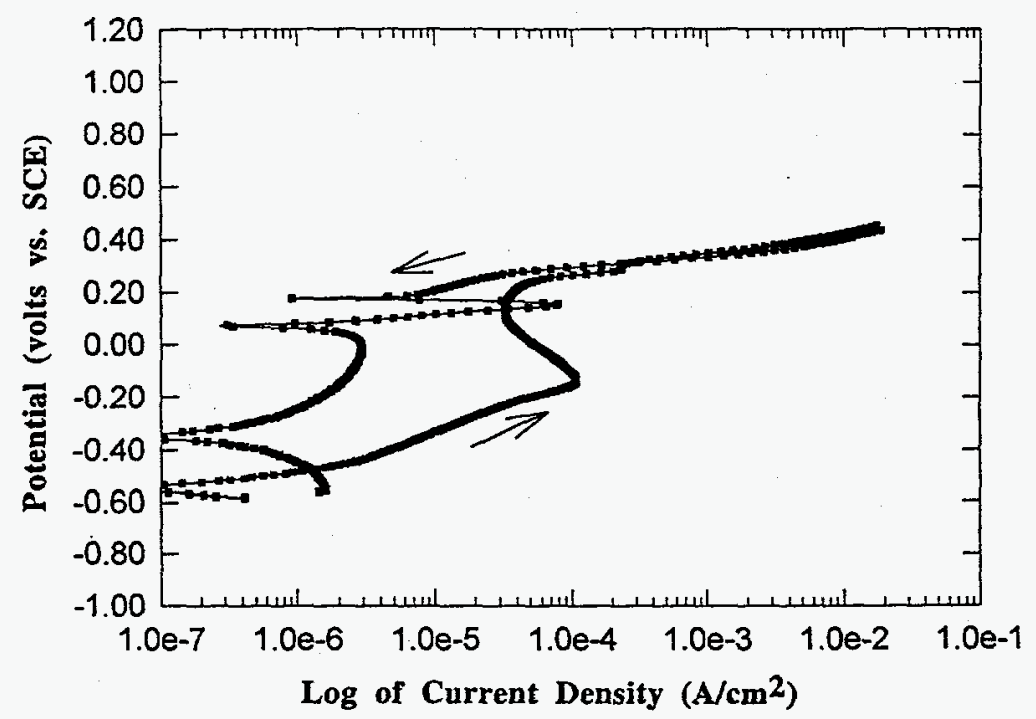

Fig. B-4. Cyclic Potentiodynamic Polarization Test Results of Inconel 625 in Alkaline Solution 


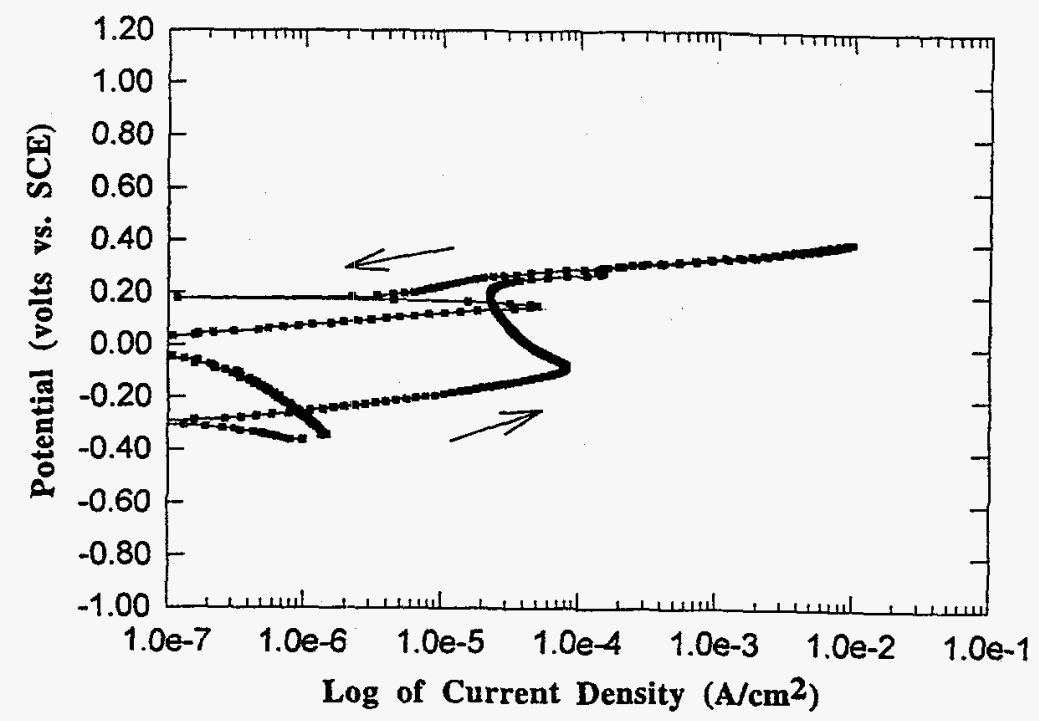

Fig. B-5. Cyclic Potentiodynamic Polarization Test Results of Incoloy 825 in Alkaline Solution

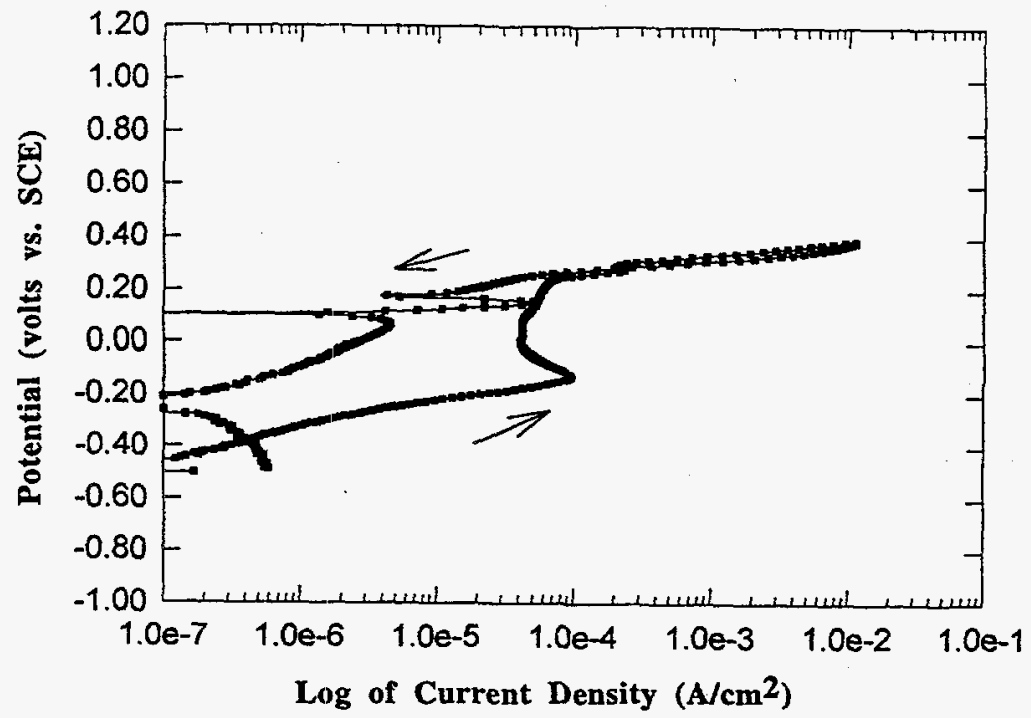

Fig. B-6. Cyclic Potentiodynamic Polarization Test Results of Hastelloy G-30 in Alkaline Solution 


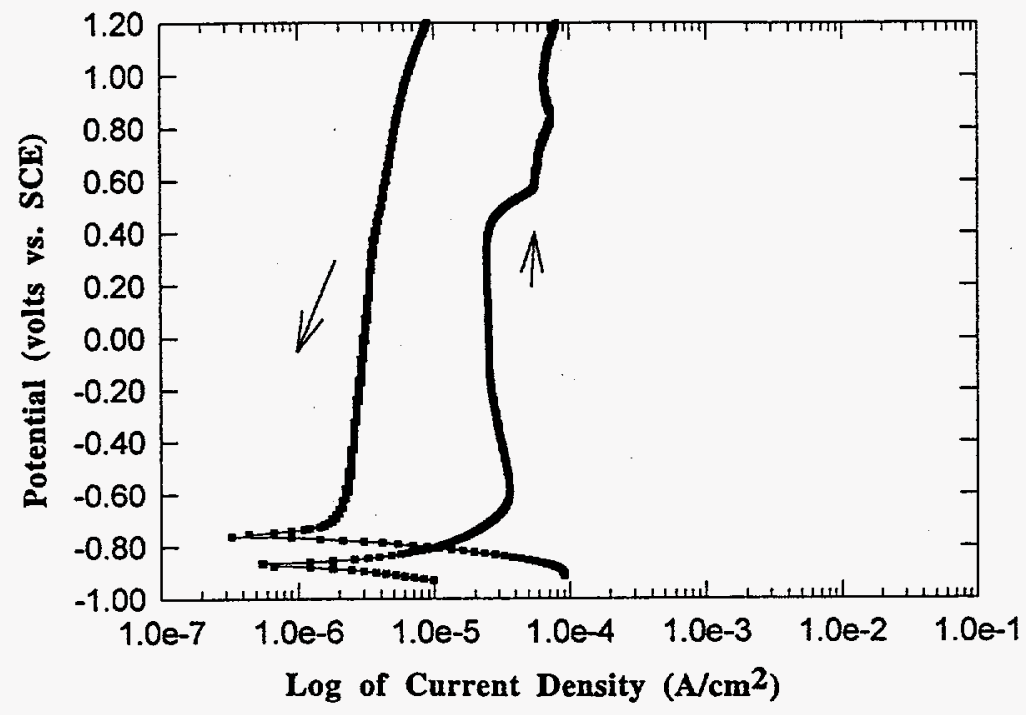

Fig. B-7a. Cyclic Potentiodynamic Polarization Test Results of Titanium Grade 2 in Alkaline Solution at Regular Scale

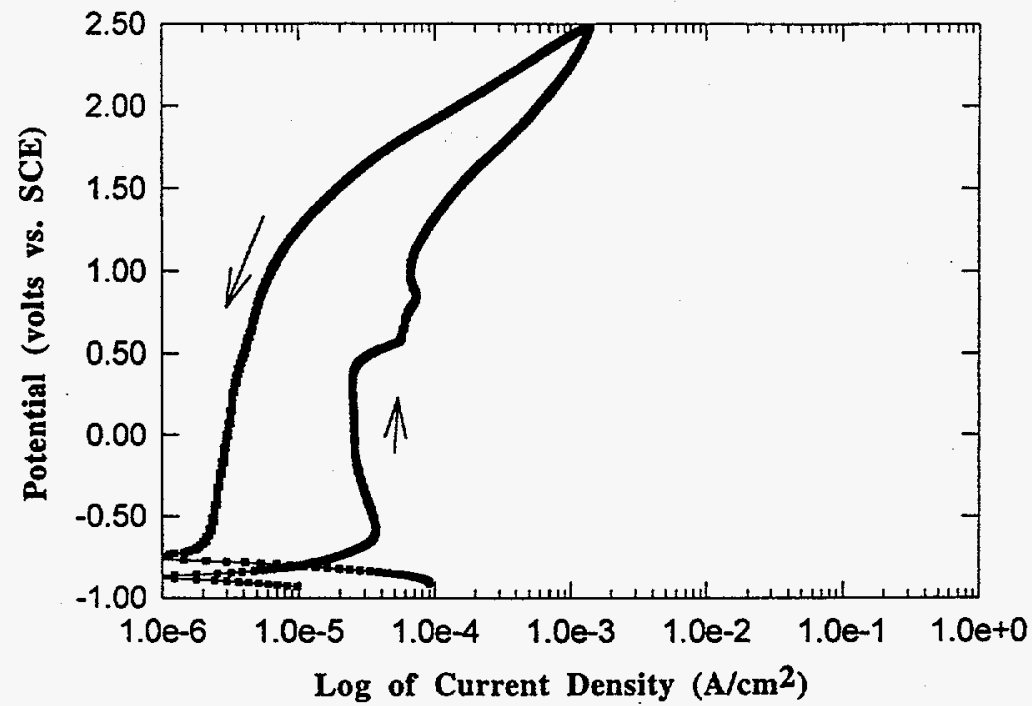

Fig. B-7b. Cyclic Potentiodynamic Polarization Test Results of Titanium Grade 2 in Alkaline Solution at Expanded Scale 


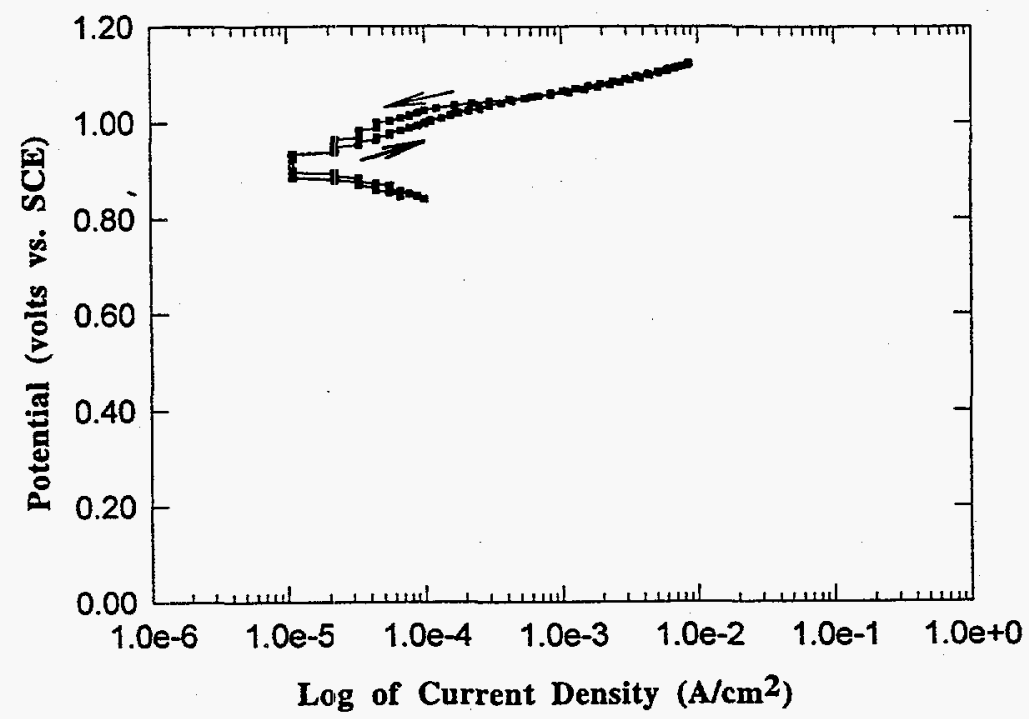

Fig. B-8. Cyclic Potentiodynamic Polarization Test Results of $304 \mathrm{~L}$ Stainless Steel in Nitric Acid Solution

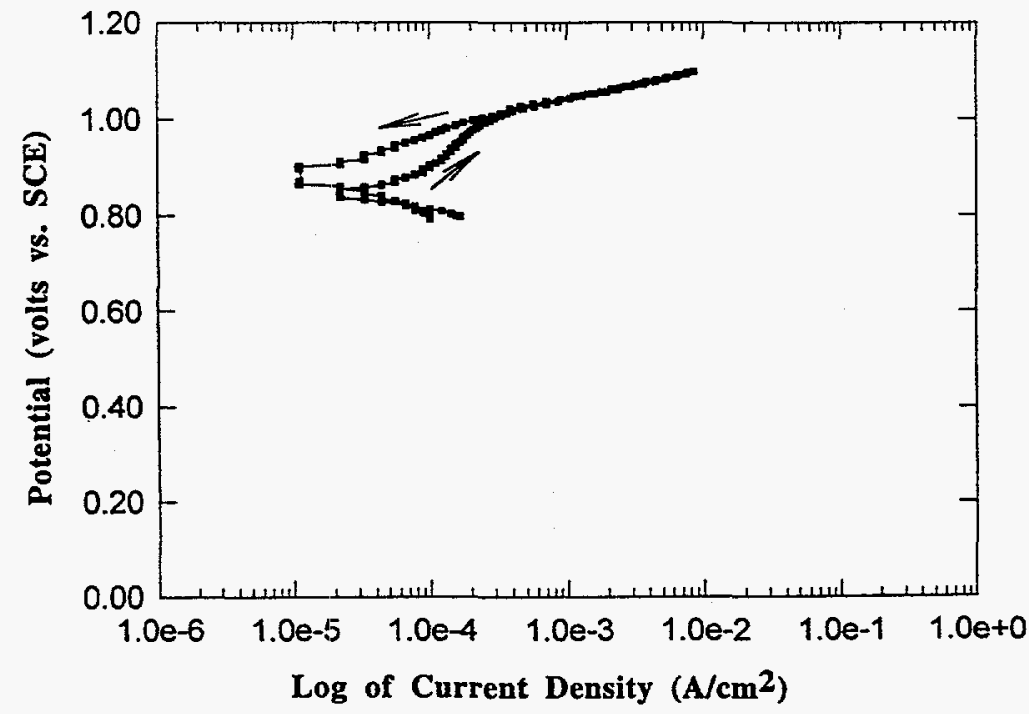

Fig. B-9. Cyclic Potentiodynamic Polarization Test Results of $316 \mathrm{~L}$ Stainless Steel in Nitric Acid Solution 


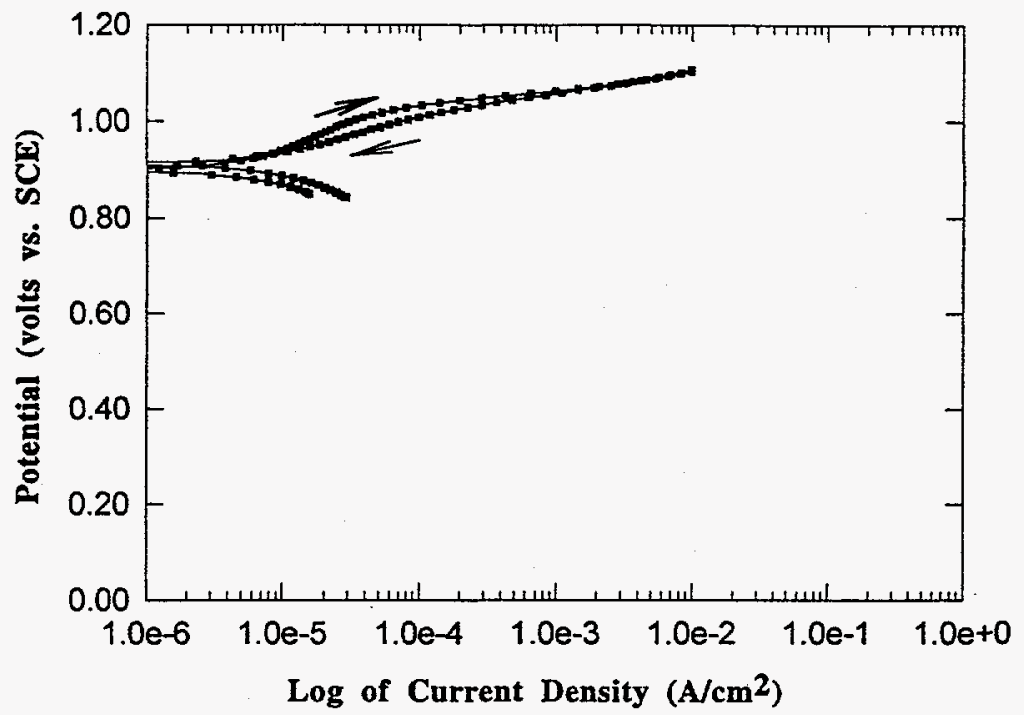

Fig. B-10. Cyclic Potentiodynamic Polarization Test Results of AL6XN Stainless Steel in Nitric Acid Solution

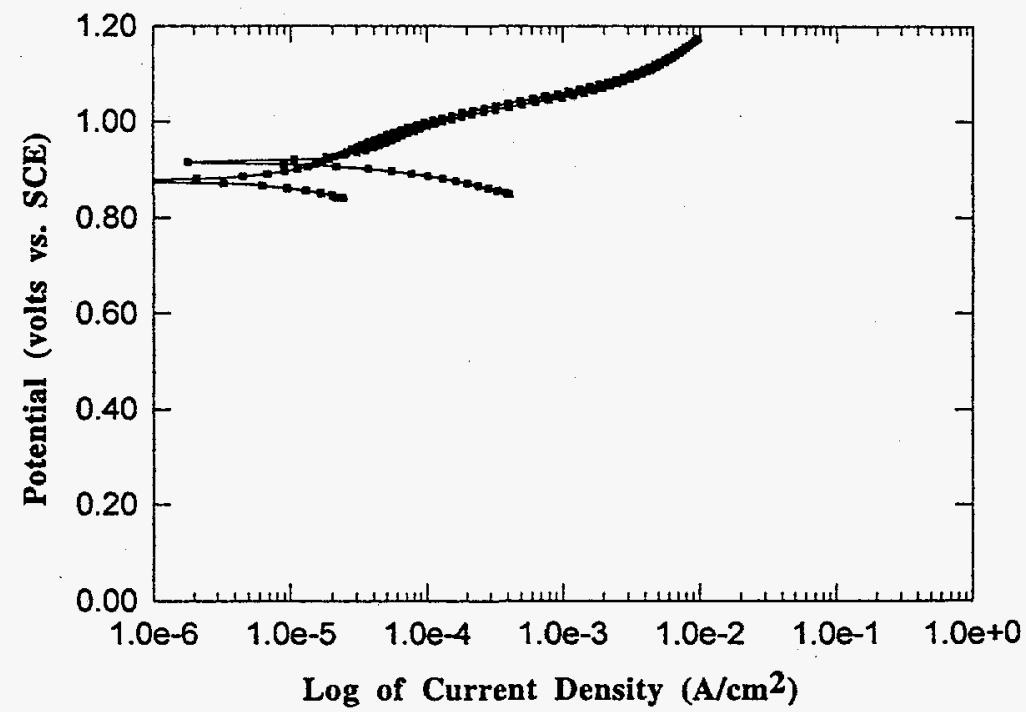

Fig. B-11. Cyclic Potentiodynamic Polarization Test Results of Inconel 625 in Nitric Acid Solution 


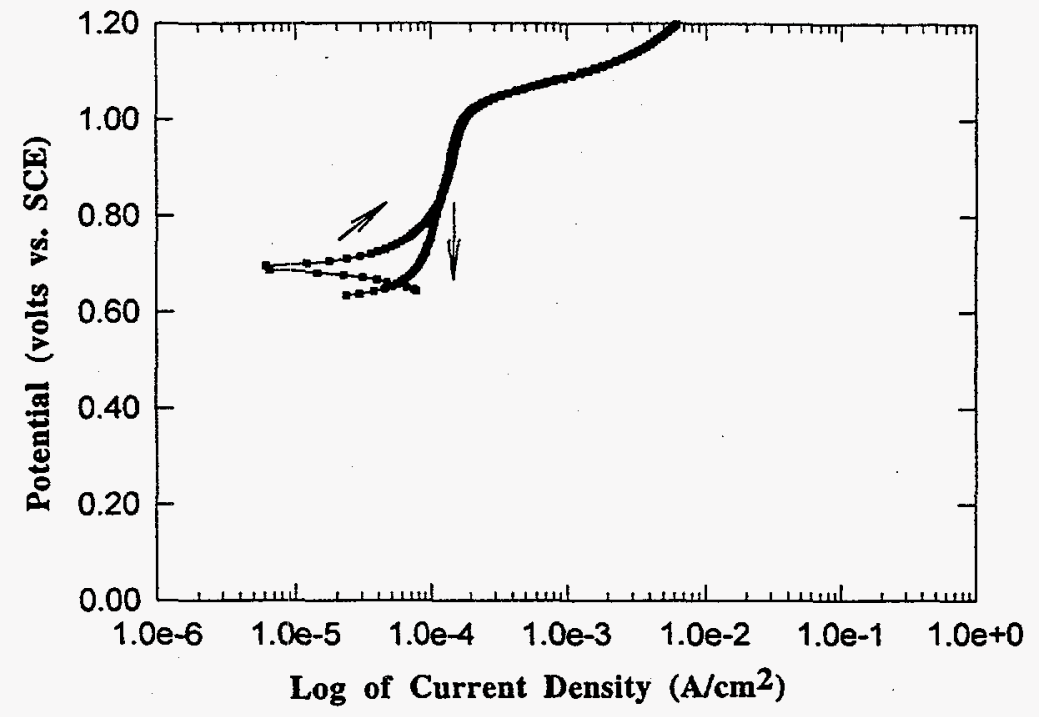

Fig. B-12. Cyclic Potentiodynamic Polarization Test Results of Incoloy 825 in Nitric Acid Solution

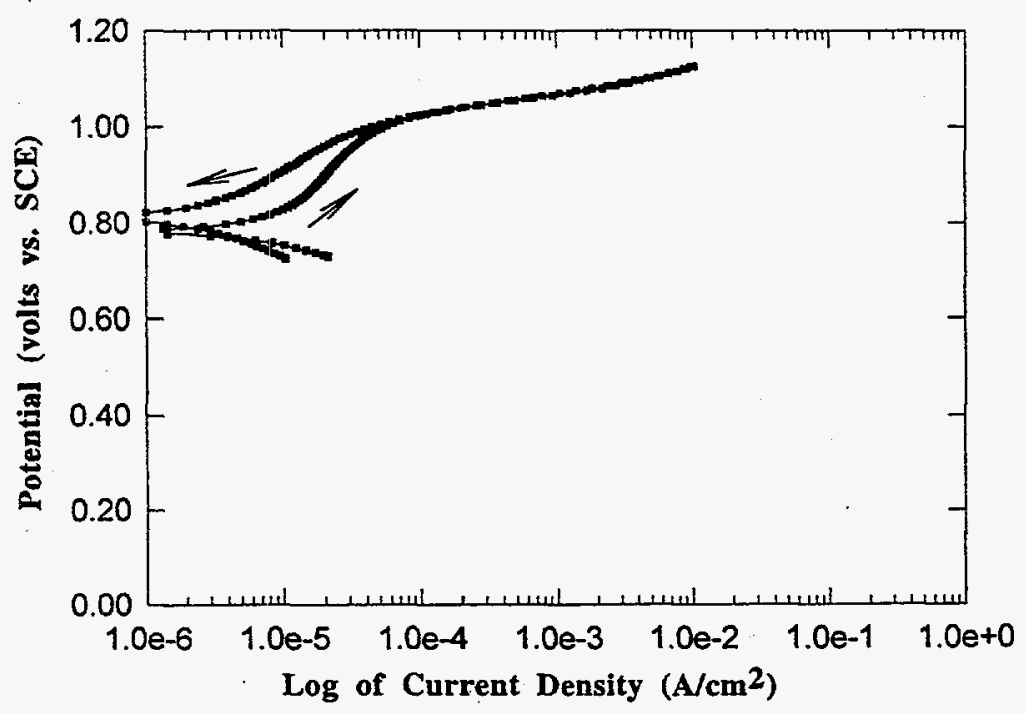

Fig. B-13. Cyclic Potentiodynamic Polarization Test Results of Hastelloy G-30 in Nitric Acid Solution 


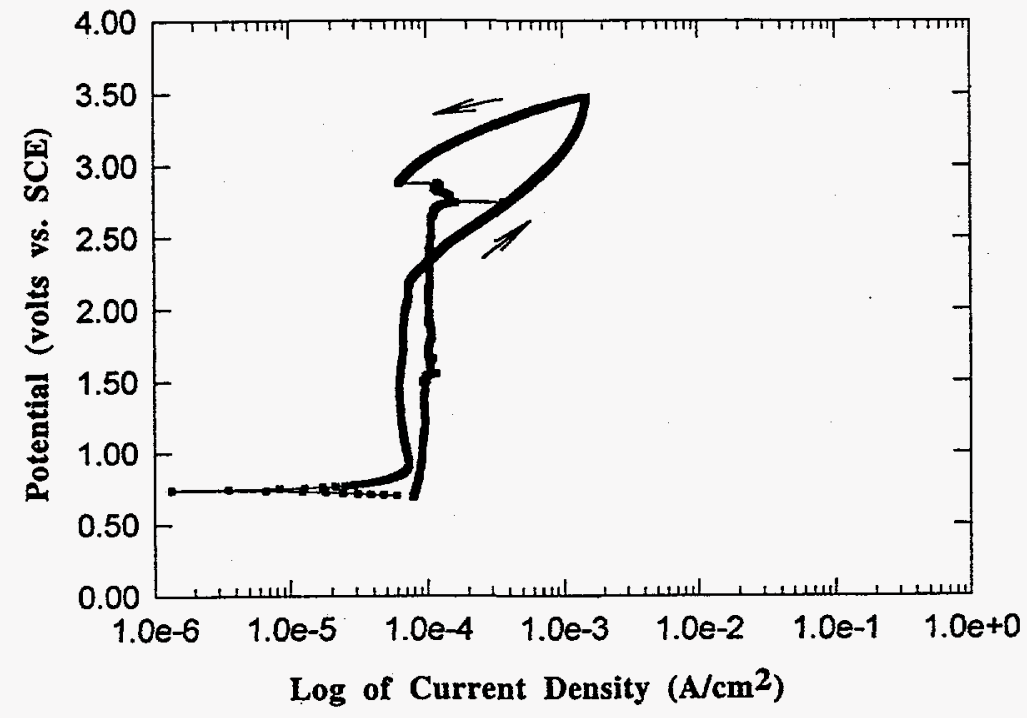

Fig. B-14a. Cyclic Potentiodynamic Polarization Test Results of Titanium Grade 2 in Nitric Acid Solution at Regular Scale

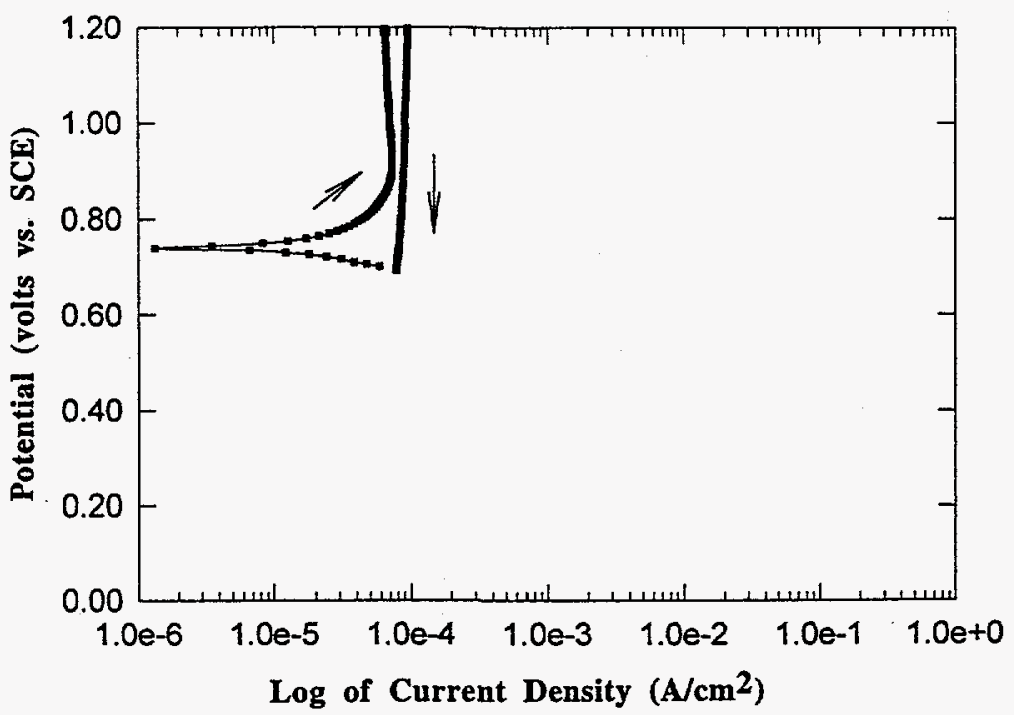

Fig. B-14b. Cyclic Potentiodynamic Polarization Test Results of Titanium Grade 2 in Nitric Acid Solution at Expanded Scale 
APPENDIXC

FINAL REPORT T 004-01

CC TECHNOLOGIES

MOBILE EVAPORATOR/CONCENTRATOR

CANDIDATE ALLOY CORROSION EVALUATION 


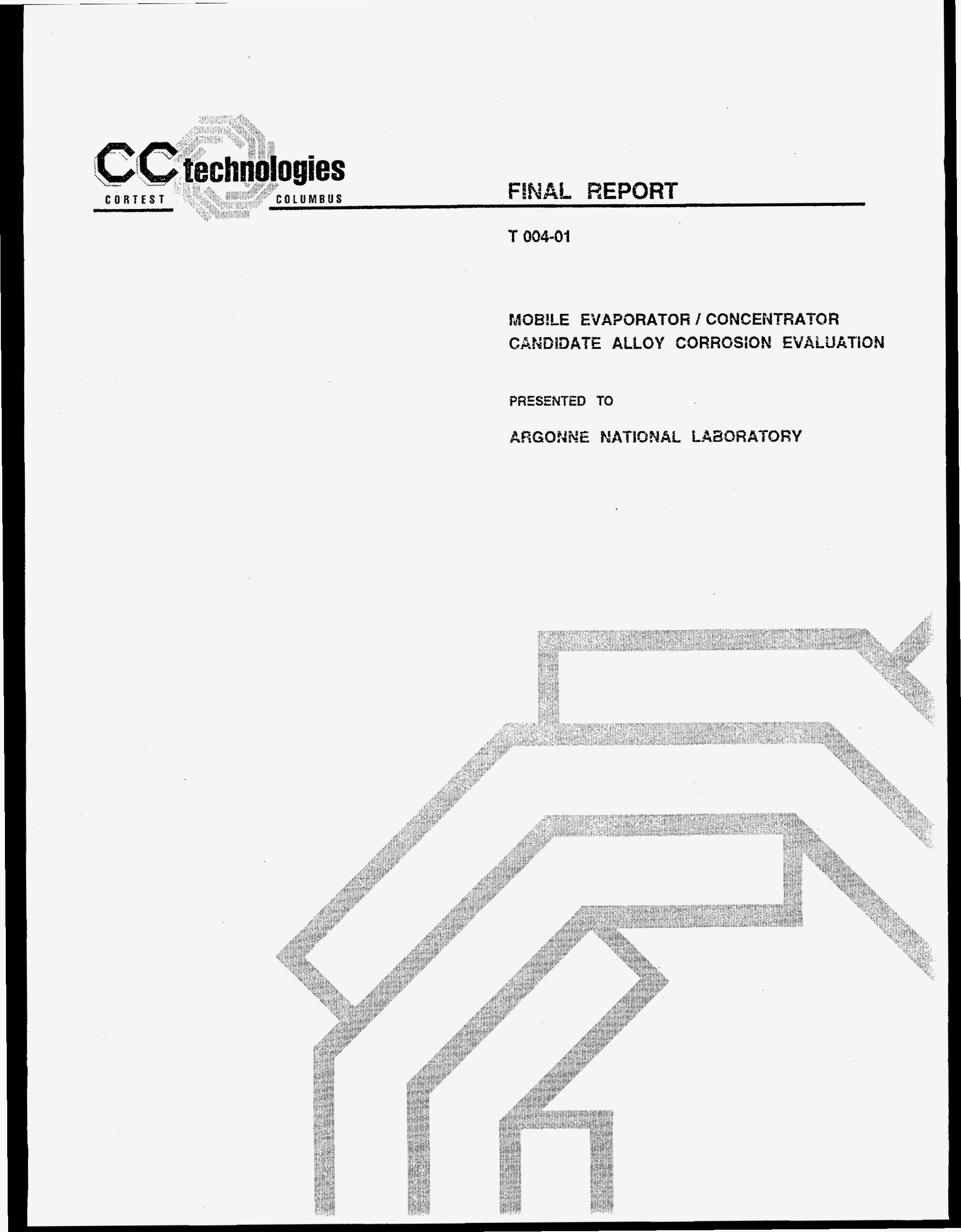


FINAL REPORT

T 004-01

\section{MOBILE EVAPORATOR / CONCENTRATOR \\ CANDIDATE ALLOY CORROSION EVALUATION}

To

ARGONNE NATIONAL LABORATORY

BY

KURT M. LAWSON

CC TeChnologies Laboratories, INC. 2704 SAWBURY BOULEVARD

Columbus, OHIO 43235

JANUARY 26, 1995 


\section{DISCLAIMER}

This report documents the work performed by CC Technologies Laboratories, Inc. for Argonne National Laboratory. Neither CC Technologies Laboratories, Inc. or any person acting on behalf of CC Technologies Laboratories, Inc.:

(1) assumes any liabilities with respect to the use of any information contained in this report or that the use of any information, apparatus, method, or process disclosed in this report, and

(2) makes any warranty or representations that the use of any information, apparatus, method, or process disclosed in this report may not infringe on privately-owned rights. 


\section{EXECUTIVE SUMMARY}

This report summarizes the results of a laboratory corrosion testing program performed by CC Technologies Laboratories, Inc. for Argonne National Laboratory. The objective of the project was to screen possible materials of construction for the mobile evaporator/concentrator Compact Processing Unit for processing wastes removed from underground storage tanks at Department of Energy (DOE) sites. The unit is designed to recover water from alkaline wastes and nitric acid from acidic wastes. Therefore, the materials of construction must be corrosion resistant to both the acidic and alkaline environments at the units operating temperature of $80^{\circ} \mathrm{C}$.

The following eight alloys were included in the testing: $304 \mathrm{~L}, 316 \mathrm{~L}$, and AL-6XN stainless steels; Incoloy 825, Inconel 625, Inconel 690, and Hastelloy G-30 nickel-base alloys; and titanium - Grade 2. The testing included exposure of standard weight-loss samples as well as welded samples to the liquid, vapor, and liquid/vapor interface of the simulated environments. In addition, standard and welded samples with crevice-forming washers were evaluated in the liquid phase of the environments.

The solution compositions and mixing instructions were supplied by Argonne and consisted of a fuming nitric acid solution and a sodium hydroxide alkaline waste solution. The testing was conducted in four-liter resin kettles at a temperature of $80^{\circ} \mathrm{C}$, under a slight vacuum (100 Torr), for forty-five days. Solution level changes due to loss of solution from evaporation were adjusted by the addition of additional test solution. Corrosion rates within the test solutions were monitored using the linear polarization resistance (LPR) method to determine if dramatic solution compositional changes were occurring.

The results of the testing indicated that none of the alloys tested showed significant corrosion in the alkaline environment. The stainless steels (304L, 316L, and AL-6XN) exposed to the nitric acid environment showed the highest corrosion rates (up to 23 mils per year), predominantly in the liquid and vapor/liquid interface phase of the solution. These rates were accompanied by a very thin, tenacious deposit (similar to bluing) on the samples. No localized attack (pitting or crevice) was observed in either solution for any of the materials. Some of the samples exposed to the liquid phase of the nitric acid solution showed obvious etching of the base metal and the weld, although no preferential attack of the welds or heat affected zones was observed. The attack observed in the nitric acid test solution was characterized as intergranular attack with varying degrees of grain loss. 


\section{TABLE OF CONTENTS}

Page

BACKGROUND $\ldots \ldots \ldots \ldots \ldots \ldots \ldots \ldots \ldots \ldots \ldots \ldots \ldots \ldots \ldots \ldots \ldots$

APPROACH ............................... 1

Task 1 - Sample Selection, Acquisition, And Preparation .......... 1

Task 2 -Immersion Testing . . . . . . . . . . . . . . . . . 2

Task 3 - Specimen Evaluation $\ldots \ldots \ldots \ldots \ldots \ldots \ldots \ldots \ldots$

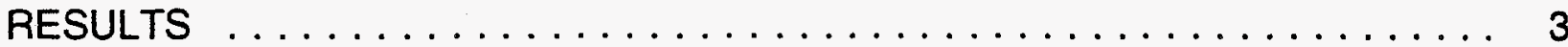

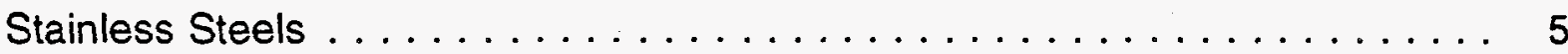

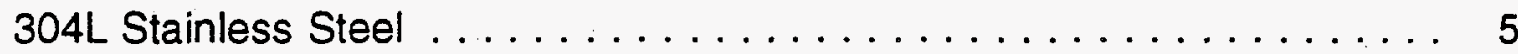

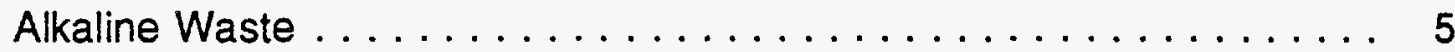

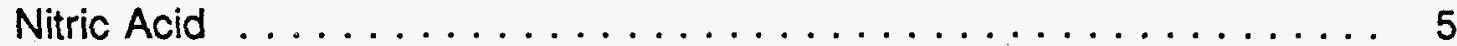

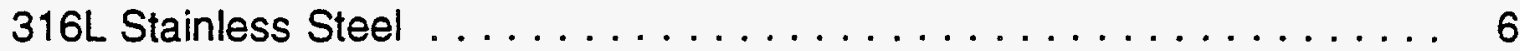

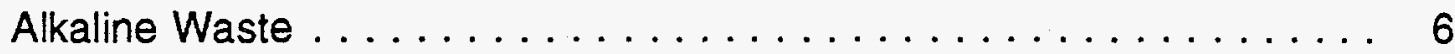

Nitric Acid ......................... 6

AL-6XN Stainless Steel $\ldots \ldots \ldots \ldots \ldots \ldots \ldots \ldots \ldots \ldots \ldots \ldots$

Alkaline Waste ...................... 7

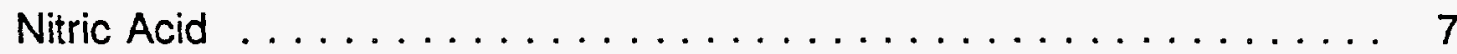

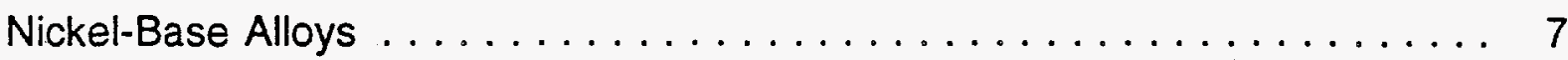

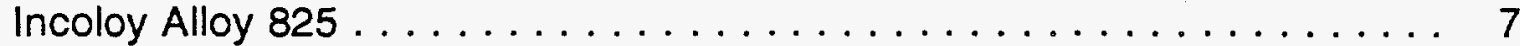

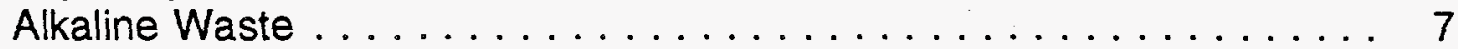

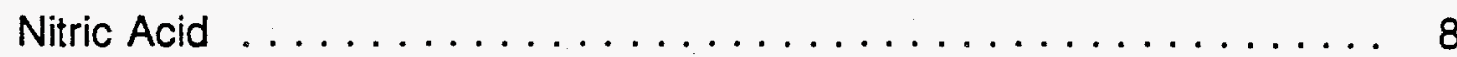

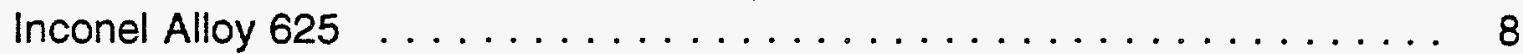

Alkaline Waste ......................... 8

Nitric Acid .......................... 8

Inconel Alloy $690 \ldots \ldots \ldots \ldots \ldots \ldots \ldots \ldots \ldots \ldots$

Alkaline Waste ......................... 9

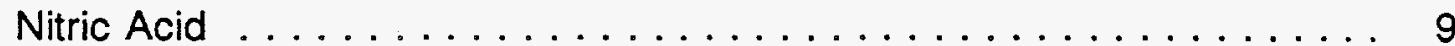

Hastelloy Alloy G-30 . . . . . . . . . . . . . . . . . . . 9

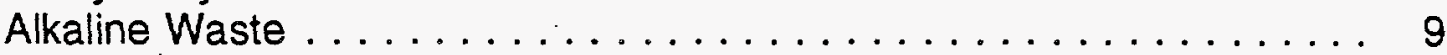

Nitric Acid . . . . . . . . . . . . . . . . 10

Titanium ............................... 10

Titanium Grade $-2 \ldots \ldots \ldots \ldots \ldots \ldots \ldots \ldots \ldots \ldots \ldots$

Alkaline Waste . . . . . . . . . . . . . . . . 10

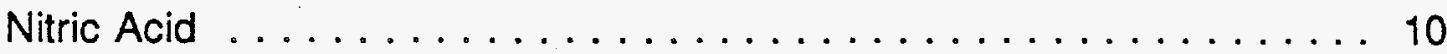

CONCLUSIONS ............................. 11

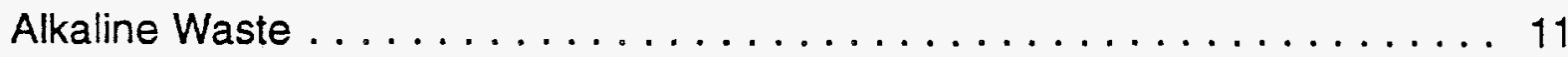

Nitric Acid Waste . . . . . . . . . . . . . . . . . . 11

APPENDIX A Mixing Instructions For The Alkaline Waste Test Solution APPENDIX B Corrosion Rate Data 


\section{LIST OF FIGURES}

Page

Figure 1a. Schematic Diagram Of Standard Sample $\ldots \ldots \ldots \ldots \ldots \ldots$

Figure 1b. Schematic Diagram Of Weided Sample. .............. 12

Figure 2. Resin Kettle And Associated Test Apparatus . . . . . . . . . 13

Figure 3. Corrosion Test Matrix $\ldots \ldots \ldots \ldots \ldots \ldots \ldots \ldots \ldots \ldots$

Figure 4a. Sample "Tree. ${ }^{n} \ldots \ldots \ldots \ldots \ldots \ldots \ldots \ldots \ldots \ldots \ldots \ldots$

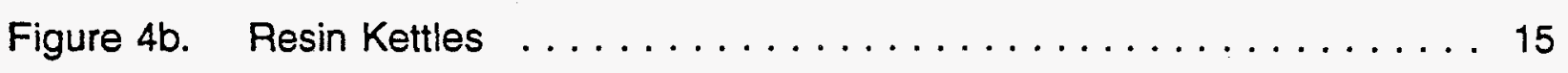

\section{LIST OF TABLES}

Table 1. Chemical Composition Of Alloys Used In Testing .......... 16

Table 2. Composition Of Test Solutions (a) Nitric Acid Test Solution

Composition (b) Alkaline Waste Test Solution Composition . . . . . 17 


\section{BACKGROUND}

This report summarizes the results of a laboratory corrosion testing program performed by CC Technologies Laboratories, Inc. for Argonne National Laboratory. The objective of the project was to screen possible materials of construction for the mobile evaporator/concentrator Compact Processing Unit for processing wastes removed from underground storage tanks at Department of Energy (DOE) sites. The unit is designed to recover water from alkaline wastes and nitric acid from acidic wastes. Therefore, the materials of construction must be corrosion resistant to both the acidic and alkaline environments at the units operating conditions of a temperature of $80^{\circ} \mathrm{C}$ and a slight (100 Torr) vacuum.

\section{APPROACH}

The corrosion testing of a selection of alloys was necessary to determine which alloys were capable of handling the extreme environments present in the Compact Processing Unit (CPU). For the initial phase of testing, the work was divided into three tasks: Task 1 - Sample Selection, Acquisition, and Preparation; Task 2 - Immersion Testing, and Task 3 - Specimen Evaluation. The details of each task are given below.

\section{Task 1 - Sample Selection, Acquisition, And Preparation}

The purpose of Task 1 was to obtain the required samples of the materials identified by Argonne as being candidate materials for CPU construction. The alloys identified as such were the following:

- Stainless Steels: $304 \mathrm{~L}, 316 \mathrm{~L}, \mathrm{AL}-6 \mathrm{XN}$,

- Nickel-base Alloys: Incoloy alloy 825, Inconel alloy 625, Inconel alloy 690, and

- Titanium: Hastelloy alloy G-30, and Grade 2.

Sixteen plain samples and sixteen welded samples of each alloy were obtained. The sample configurations and dimensions of each sample type are shown in Figure 1. All samples of each alloy were from the same heat and oriented parallel to the rolling direction. The chemical composition of each of the alloys are given in Table 1. Surface finish on all samples was 120 grit. Once received, the samples were cleaned, degreased, and weighed. 


\section{Task 2 - Immersion Testing}

The purpose of Task 2 was to perform the actual corrosion exposures under the environmental conditions supplied by Argonne. The exposures were performed in fourliter resin kettles designed to maintain the environmental conditions required. Figure 2 shows the resin kettle test apparatus. The kettles incorporate a heating mantle and thermocouple controlled by a proportion temperature controller. The reflux condenser was used to help minimize evaporation of the solutions while a slight (100 Torr) vacuum was pulled through the kettles. Also, as shown in Figure 2, samples were exposed to the liquid, the vapor, and the liquid/vapor interface portions of the test solutions.

Figure 3 shows the actual corrosion test matrix for a single alloy. Duplicate samples of each condition shown in the matrix were tested. A single kettle included two similar alloys for a total of 32 specimens. The samples were supported within the kettle by a rigid Teflon 'tree' which incorporated Hastelloy C276 hardware isolated from the samples by Teflon washers and tubes. The crevice samples indicated in the test matrix were formed by standard (ASTM G78) radially grooved Teflon crevice formers bolted to either side of the test sample. A typical sample 'tree' and kettle are shown in Figure 4. One alkaline waste kettle and one nitric acid kettle also included a cylindrical test probe incorporating a $304 \mathrm{~L}$ stainless steel probe and two platinum wires for conducting periodic linear polarization resistance (LPR) measurements to assure that the corrosiveness of the solutions did not undergo any significant changes (which may have indicated a dramatic change in the chemistry of the test solution) over the course of the testing.

Once the sample 'trees' were assembled and placed in the kettles, the tops were seated and sealed with Teflon tape. Solutions were then added to the kettles to the level required to immerse one half of the samples exposed at the vapor/liquid interface. The temperature was then adjusted to $80^{\circ} \mathrm{C}$ and cooling water to the condensers and the vacuum source were started. Throughout the forty-five day exposure period, the solution level was carefully monitored and adjustments were made by the addition of test solution when required. Deviations or upset conditions to the normal operation of the test kettles are outlined in detail in the Results Section below.

The solution chemistries for the nitric acid test solution and the sodium hydroxide test solution were supplied by Argonne and are given in Tables 2 and 3 . In addition, the mixing instructions for the alkaline waste test solution were supplied by Argonne and is reproduced in Appendix A. All chemicals used in the preparation of the test solutions 
were reagent grade and the water used was deionized water with a conductivity of greater than 5 Mega-Ohms.

\section{Task 3 - Specimen Evaluation}

Following the forty-five day exposure, the samples were removed from the test apparatus, rinsed, dried, and evaluated as per ASTM G1-90 and ASTM G31-72. The evaluation included visual evaluation prior to sample cleaning, mechanical and chemical cleaning, visual evaluation after cleaning, and weight-loss measurements and calculations.

Visual observations prior to sample cleaning included notation of staining, deposits, or corrosion products. Mechanical cleaning to remove loose deposits (on those samples which required it) consisted of brushing the samples with a soft bristled nylon brush under running warm water followed by DI water and acetone rinse. The nature and extent of the chemical cleaning (again, of those samples which required it) was dependent upon the alloy being cleaned and tenacity of the corrosion/chemical deposits. A weighed blank (unexposed) specimen of each material being cleaned was included in the cleaning operations to assure any weight loss associated with the cleaning process was accounted for in the weight-loss calculations. Following the cleaning, the samples were weighed and visually evaluated for pitting, crevice attack, or weld/heat affected zone (HAZ) attack. The weight loss was converted to a general corrosion rate, in mils per year. The results of these evaluations and calculations are presented in the Results section below.

\section{RESULTS}

The results of the testing conducted are organized by alloy and environment in the paragraphs following the brief general comments below. Tables B-1 through B-16 discussed in association with each alloy and environment can be found in Appendix B.

Several problems associated with the application of the vacuum to the test cells were encountered during the course of the testing. The original design of the test kettles did not incorporate facilities to apply, maintain and monitor the vacuum. During the set-up of the alkaline waste kettles, several attempts were made at sealing the kettles and various vacuum sources were tried. The final system design for the alkaline waste kettles consisted of sealing the various orifices of the resin kettles with rubber or ground glass stoppers sealed with Teflon tape. The lid of the kettles were sealed with a neoprene 
o-ring. Various vacuum sources were explored and an aspirator attached to a faucet was found to be the most suitable and cost effective means of generating and controlling the 100 Torr vacuum level. Each of the four alkaline test kettles were plumbed to a common manifold which was plumbed to a trap designed to condense and collect any vapor pulled through the manifold. The trap was then evacuated and the vacuum maintained via the aspirator. The vacuum level was monitored by a vacuum gauge which was installed at the trap. These vacuum design and implementation problems resulted in variations in the vacuum level for the initial eleven days of exposure for the alkaline waste samples.

During the testing, the alkaline waste kettles were observed to be lightly boiling under the temperature and vacuum conditions $\left(80^{\circ} \mathrm{C}, 100 \mathrm{Torr}\right)$. Following the testing, some etching and attack of the glass resin kettles exposed to the liquid phase of the alkaline waste was observed. It is not believed that the condition variations noted in the paragraphs above (vacuum deviations and glass attack) effected the results of the alkaline waste tests.

Following the initiation of the alkaline waste tests, a similar kettle/vacuum set-up was attempted for the nitric acid tests. The concentrated/fuming nitric acid, however, attacked the rubber stoppers and the neoprene o-rings of the kettles. The resulting attack contaminated the test solution in the kettles overnight and the tests were shut down for a two day period (weekend). Rather than possibly compromise the test results (due to the sample contamination and solution) the samples were removed from the kettles, cleaned, and re-weighed. New solutions were also prepared. The kettles were also thoroughly cleaned and re-designed with the wetted portions of the system being either glass or Teflon. The new system materials and vacuum system performed adequately, although twice during the forty-five day exposures the vacuum was lost for a short period ( $<24$ hours) due to the vacuum line becoming blocked by debris. It is not believed that these excursions from the desired test conditions effected the results of the nitric acid tests.

Corrosion rates monitored during the course of the testing by the LPR technique for $304 \mathrm{~L}$ material did not exceed $0.07 \mathrm{mpy}$ for the alkaline solution after approximately forty-eight hours of exposure. No effect on the rate was observed when the vacuum was applied to the test kettle. No effect of solution additions (to maintain solution level) were observed in the measured corrosion rates once the temperature of the system had returned to $80^{\circ} \mathrm{C}$ following the addition. The rate was relatively stable in the alkaline solution, although rates that low are often difficult to accurately measure. Corrosion rates 
monitored in the nitric acid solution for 304L material did not exceed $4.2 \mathrm{mpy}$ after approximately ninety-six hours of exposure, although the initial rates observed were in excess of $50.0 \mathrm{mpy}$. Individual measurements of the corrosion rate within the nitric acid solutions did vary up to $+/-2$ mpy on measurements repeated during a single day; however, the rates averaged for that day never differed from the previous average by more than twenty percent. No effect of the vacuum was seen in the measured corrosion rate during the vacuum losses over the course of the forty-five day exposure. No effect of solution additions (to maintain solution level) were observed in the measured corrosion rates once the temperature of the system had returned to $80^{\circ} \mathrm{C}$ following the addition.

\section{Stainless Steels}

\section{L Stainless Steel}

\section{Alkaline Waste}

The results for the $304 \mathrm{~L}$ stainless steel exposed to the alkaline waste environment can be found in Table B-1. No pitting, crevice, or preferential attack of the welds was observed on any of the samples. Some slight discoloration (tinting) was observed beneath the crevice formers and sample mounting hardware of the liquid and vapor/liquid exposed samples. An average corrosion rate of $0.03 \mathrm{mpy}$ was observed for all samples exposed to the liquid phase. An average corrosion rate of $0.02 \mathrm{mpy}$ was observed for the samples exposed to the vapor/liquid interface. An average corrosion rate of $0.02 \mathrm{mpy}$ was observed for the samples exposed to the vapor phase.

\section{Nitric Acid}

The results for the $304 \mathrm{~L}$ stainless steel exposed to the nitric acid environment can be found in Table B-2. No pitting or crevice attack was observed on any of the samples. All of the samples exhibited a deep blue/black tinting (bluing) which was impervious to standard cleaning methods. The luminescent appearance of the tinting indicates that it is a very thin film and its presence will not effect the corrosion rate calculation. The observed films were heavier for the samples exposed to the liquid and vapor/liquid interface regions than those observed for the vapor phase. The nature of the attack was characterized as severe uniform intergranular attack with uniform grain loss. Although the weld structures were revealed (and also exhibited intergranular attack) on those samples exposed to the liquid and vapor liquid interface regions, no preferential attack 
of the weld metal or HAZ was observed. An average corrosion rate of 5.37 mpy was observed for all samples exposed to the liquid phase. An average corrosion rate of 4.54 mpy was observed for the samples exposed to the vapor/liquid interface. An average corrosion rate of 0.09 mpy was observed for the samples exposed to the vapor phase.

\section{L Stainless Steel}

\section{Alkaline Waste}

The results for the $316 \mathrm{~L}$ stainless steel exposed to the alkaline waste environment can be found in Table B-3. No pitting, crevice, or preferential attack of the welds was observed on any of the samples. Some slight discoloration (tinting) was observed beneath the crevice formers and sample mounting hardware of the liquid and vapor/liquid exposed samples. Tinting was also observed on the vapor side of the liquid/vapor exposed samples. An average corrosion rate of 0.03 mpy was observed for all samples exposed to the liquid phase. An average corrosion rate of $0.01 \mathrm{mpy}$ was observed for the samples exposed to the vapor/liquid interface. An average corrosion rate of $0.02 \mathrm{mpy}$ was observed for the samples exposed to the vapor phase.

\section{Nitric Acid}

The results for the $316 \mathrm{~L}$ stainless steel exposed to the nitric acid environment can be found in Table B-4. No pitting or crevice attack was observed on any of the samples: Those samples exposed to the liquid and vapor/liquid interface region were heavily etched. All of the samples exhibited a deep blue/brown tinting (bluing) which was impervious to standard cleaning methods. The luminescent appearance of the tinting indicates that it is a very thin film and its presence will not effect the corrosion rate calculation. The observed films were heavier for the samples exposed to the liquid and vapor/liquid interface regions. The nature of the attack was characterized as severe uniform intergranular corrosion with uniform grain loss. The weld structures were also revealed on those samples exposed to the liquid and vapor liquid interface regions, but no preferential attack was observed. An average corrosion rate of 17.28 mpy was observed for all samples exposed to the liquid phase. An average corrosion rate of 17.00 mpy was observed for the samples exposed to the vapor/liquid interface. An average corrosion rate of 0.06 mpy was observed for the samples exposed to the vapor phase. 


\section{AL-6XN Stainless Steel}

\section{Alkaline Waste}

The results for the AL-6XN stainless steel exposed to the alkaline waste environment can be found in Table B-5. No pitting, crevice, or preferential attack of the welds was observed on any of the samples. An average corrosion rate of 0.05 mpy was observed for all samples exposed to the liquid phase. An average corrosion rate of 0.04 mpy was observed for the samples exposed to the vapor/liquid interface. An average corrosion rate of $0.03 \mathrm{mpy}$ was observed for the samples exposed to the vapor phase.

\section{Nitric Acid}

The results for the AL-6XN stainless steel exposed to the nitric acid environment can be found in Table B-6. No pitting or crevice attack was observed on any of the samples. The nature of the attack observed on those samples exposed to the liquid and vapor/liquid interface regions was characterized as uniform intergranular attack with some intermittent grain loss. The extent of the attack was not as severe as that observed on the $04 \mathrm{~L}$ and $316 \mathrm{~L}$. The weld structures were clearly revealed on those samples exposed to the liquid and vapor liquid interface regions, but no preferential attack was observed. The welds were just barely visible on the samples exposed to the vapor phase. The sample exposed to the interface region showed a very light etching resulting from the intergranular attack. An average corrosion rate of 1.31 mpy was observed for all samples exposed to the liquid phase. An average corrosion rate of $2.38 \mathrm{mpy}$ was observed for the samples exposed to the vapor/liquid interface. An average corrosion rate of $0.09 \mathrm{mpy}$ was observed for the samples exposed to the vapor phase.

\section{Nickel-Base Alloys}

\section{Incoloy Alloy 825}

\section{Alkaline Waste}

The results for the Incoloy Alloy 825 (1825) samples exposed to the alkaline waste environment can be found in Table B-7. No pitting, crevice, or preferential attack of the welds was observed on any of the samples. Although the pre-clean visual evaluation indicated a possibility of light etching, the observed corrosion rates were all quite low. An 
average corrosion rate of 0.02 mpy was observed for all samples exposed to the liquid phase. The average corrosion rate for the samples exposed to the interface region was $0.01 \mathrm{mpy}$. The average corrosion rate for those samples exposed to the vapor phase was also $0.01 \mathrm{mpy}$.

\section{Nitric Acid}

The results for the 1825 samples exposed to the nitric acid environment can be found in Table B-8. No pitting or crevice attack was observed on any of the samples. The attack was characterized as uniform intergranular attack with some grain loss. The weld structures were revealed on those samples exposed to the liquid and vapor liquid interface regions, but no preferential attack was observed. An average corrosion rate of $3.55 \mathrm{mpy}$ was observed for all samples exposed to the liquid phase. An average corrosion rate of $1.51 \mathrm{mpy}$ was observed for the samples exposed to the vapor/liquid interface. An average corrosion rate of 0.02 mpy was observed for the samples exposed to the vapor phase.

\section{Inconel Alloy 625}

\section{Alkaline Waste}

The results for the Inconel Alloy 625 (1625) samples exposed to the alkaline waste environment can be found in Table B-9. No pitting, crevice, or preferential attack of the welds was observed on any of the samples. An average corrosion rate of $0.02 \mathrm{mpy}$ was observed for all samples exposed to the liquid phase. The average corrosion rate for the samples exposed to the interface region was $0.02 \mathrm{mpy}$. The average corrosion rate for those samples exposed to the vapor phase was also $0.02 \mathrm{mpy}$.

\section{Nitric Acid}

The results for the 1625 samples exposed to the nitric acid environment can be found in Table B-10. No pitting or crevice attack was observed on any of the samples. The attack was characterized as uniform intergranular attack with no grain loss. The weld structures were clearly revealed on both sides of the samples exposed to the liquid and vapor liquid interface regions, but no preferential attack was observed. An average corrosion rate of $2.65 \mathrm{mpy}$ was observed for all samples exposed to the liquid phase. An average corrosion rate of $2.71 \mathrm{mpy}$ was observed for the samples exposed to the 
vapor/liquid interface. An average corrosion rate of 0.07 mpy was observed for the samples exposed to the vapor phase.

\section{Inconel Alloy 690}

\section{Alkaline Waste}

The results for the Inconel Alloy 690 (1690) samples exposed to the alkaline waste environment can be found in Table B-11. No pitting, crevice, or preferential attack of the welds was observed on any of the samples. An average corrosion rate of 0.03 mpy was observed for all samples exposed to the liquid phase. The average corrosion rate for the samples exposed to the interface region was $0.02 \mathrm{mpy}$. The average corrosion rate for those samples exposed to the vapor phase was also $0.04 \mathrm{mpy}$.

\section{Nitric Acid}

The results for the 1690 samples exposed to the nitric acid environment can be found in Table B-12. No pitting or crevice attack was observed on any of the samples. The attack was characterized as light intergranular attack with some slight grain loss. The weld structures were revealed on the samples exposed to the liquid and vapor liquid interface regions, but no preferential attack was observed. All samples exposed to the liquid or the interface regions showed very light tinting (brown) and very slight etching. An average corrosion rate of 1.52 mpy was observed for all samples exposed to the liquid phase. An average corrosion rate of 0.58 mpy was observed for the samples exposed to the vapor/liquid interface. An average corrosion rate of 0.02 mpy was observed for the samples exposed to the vapor phase.

\section{Hastelloy Alloy G-30}

\section{Alkaline Waste}

The results for the Hastelloy Alloy G-30 samples exposed to the alkaline waste environment can be found in Table B-13. No pitting, crevice, or preferential attack of the welds was observed on any of the samples. An average corrosion rate of $0.01 \mathrm{mpy}$ was observed for all samples exposed to the liquid phase. The average corrosion rate for the samples exposed to the interface region was $0.01 \mathrm{mpy}$. The average corrosion rate for those samples exposed to the vapor phase was also $0.01 \mathrm{mpy}$. 


\section{Nitric Acid}

The results for the Hastelloy Alloy G-30 samples exposed to the nitric acid environment can be found in Table B-14. No pitting or crevice attack was observed on any of the samples. The attack was characterized as light etching which revealed the microstructure of the alloy, however, no significant intergranular attack was noted. The weld structures were revealed on the samples exposed to the liquid and vapor liquid interface regions, but no preferential attack was observed. All samples exposed to the liquid or the interface regions showed very light tinting (brown). An average corrosion rate of 0.76 mpy was observed for all samples exposed to the liquid phase. An average corrosion rate of $0.75 \mathrm{mpy}$ was observed for the samples exposed to the vapor/liquid interface. An average corrosion rate of 0.03 mpy was observed for the samples exposed to the vapor phase.

\section{Titanium}

\section{Titanium Grade - 2}

\section{Alkaline Waste}

The results for the Titanium Grade - 2 (Ti-2) samples exposed to the alkaline waste environment can be found in Table B-15. No pitting, crevice, or preferential attack of the welds was observed on any of the samples. All samples were discolored/tinted (blue/brown). The discoloration/tinting was darker in the liquid phase exposures. An average corrosion rate of 0.09 mils per year (mpy) was observed for all samples exposed to the liquid phase. The average corrosion rate for the samples exposed to the interface region was $0.14 \mathrm{mpy}$. The average corrosion rate for those samples exposed to the vapor phase was also 0.07 mpy.

\section{Nitric Acid}

The results for the Ti-2 samples exposed to the nitric acid environment can be found in Table B-16. No pitting or crevice attack was observed on any of the samples. All samples exposed to the liquid or the interface regions showed very light tinting (blue/brown). An average corrosion rate of $0.11 \mathrm{mpy}$ was observed for all samples exposed to the liquid phase. An average corrosion rate of $0.03 \mathrm{mpy}$ was observed for 
the samples exposed to the vapor/liquid interface. An average corrosion rate of $0.03 \mathrm{mpy}$ was observed for the samples exposed to the vapor phase.

\section{CONCLUSIONS}

\section{Alkaline Waste}

The results of the exposures performed indicate that from both a general and localized corrosion standpoint any of the alloys evaluated would be acceptable in the alkaline waste environment under the conditions of these tests. However, other concerns not addressed in this study may dramatically effect the performance of these alloys in this environment. Some of these concerns include the effect of solution flow or velocity and the effect of solution chemical changes/concentration during the recovery process. Also, acceptable corrosion resistance in the alkaline waste environment does not preclude the potential for other failure modes such as stress corrosion cracking (SCC).

\section{Nitric Acid Waste}

The results of the nitric acid exposures performed indicate that the lower stainless steels (304L and $316 \mathrm{~L}$ ) evaluated showed the highest general corrosion rates (up to 23 mpy). The rates observed on the other alloys were on the average all less than $3 \mathrm{mpy}$. Corrosion rates of this magnitude can be managed through proper design; however, as was the case with the alkaline waste tests, other concerns not addressed by this study (flow, chemistry, etc.) need to be carefully considered. No evidence of localized corrosion (pitting or crevice) or preferential attack of the welds was observed for any of the alloys. However, intergranular corrosion was observed on many of the alloys. The extent of the intergranular attack could be well characterized and reported through the metallographic examination of representative samples of each alloy. The susceptibility of an alloy to intergranular corrosion is often an indication of the alloys susceptibility to SCC (particularly in stainless steels and copper alloys). This possibility should be thoroughly explored before an alloy is chosen for use. 


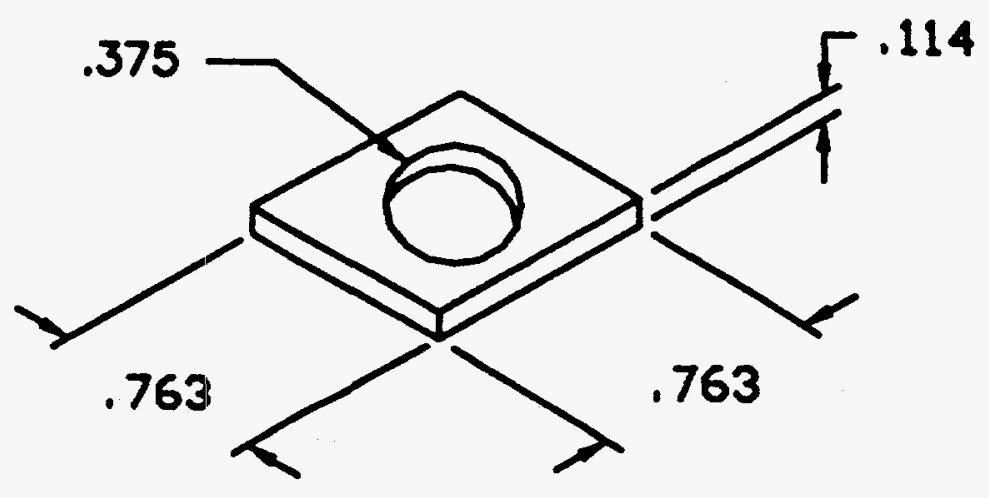

Figure 1a. Schematic Diagram Of Standard Sample.

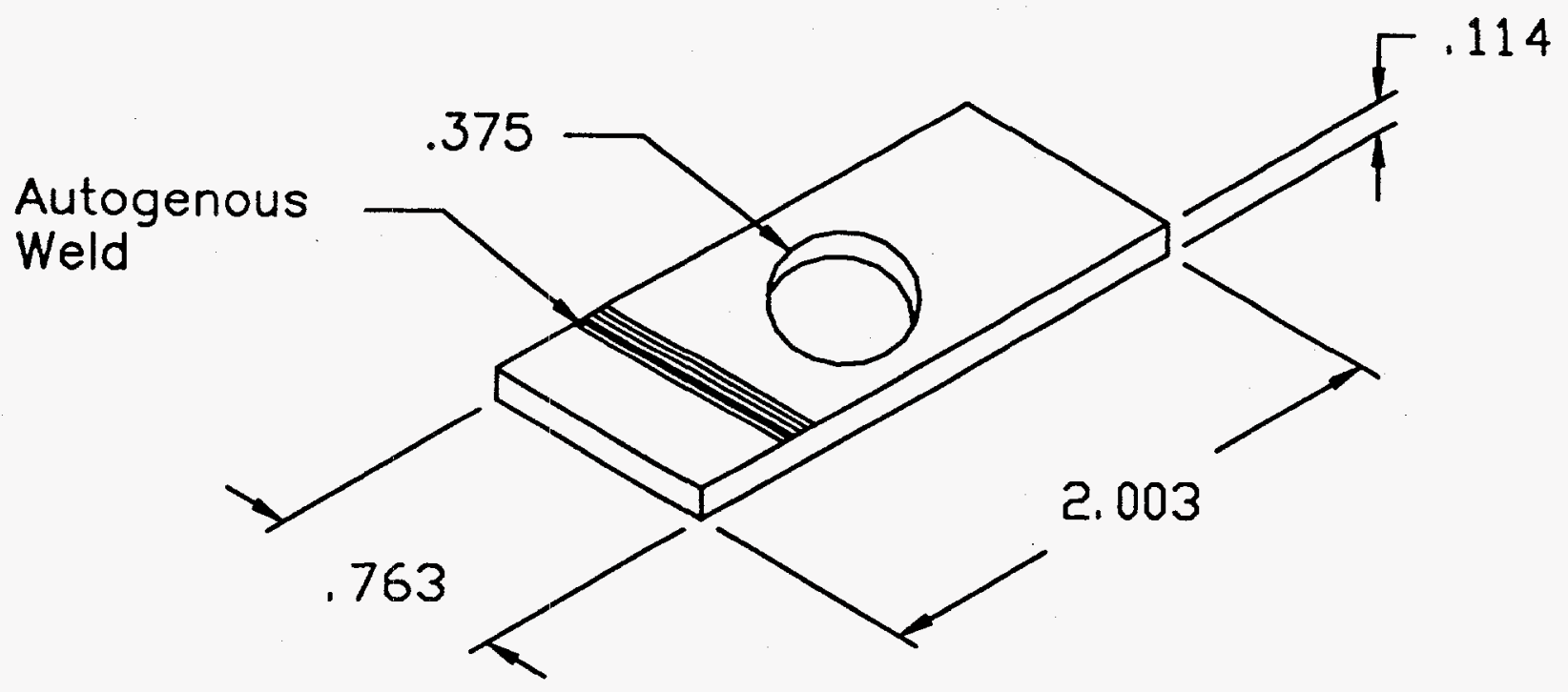

Figure 1b. Schematic Diagram Of Welded Sample. 


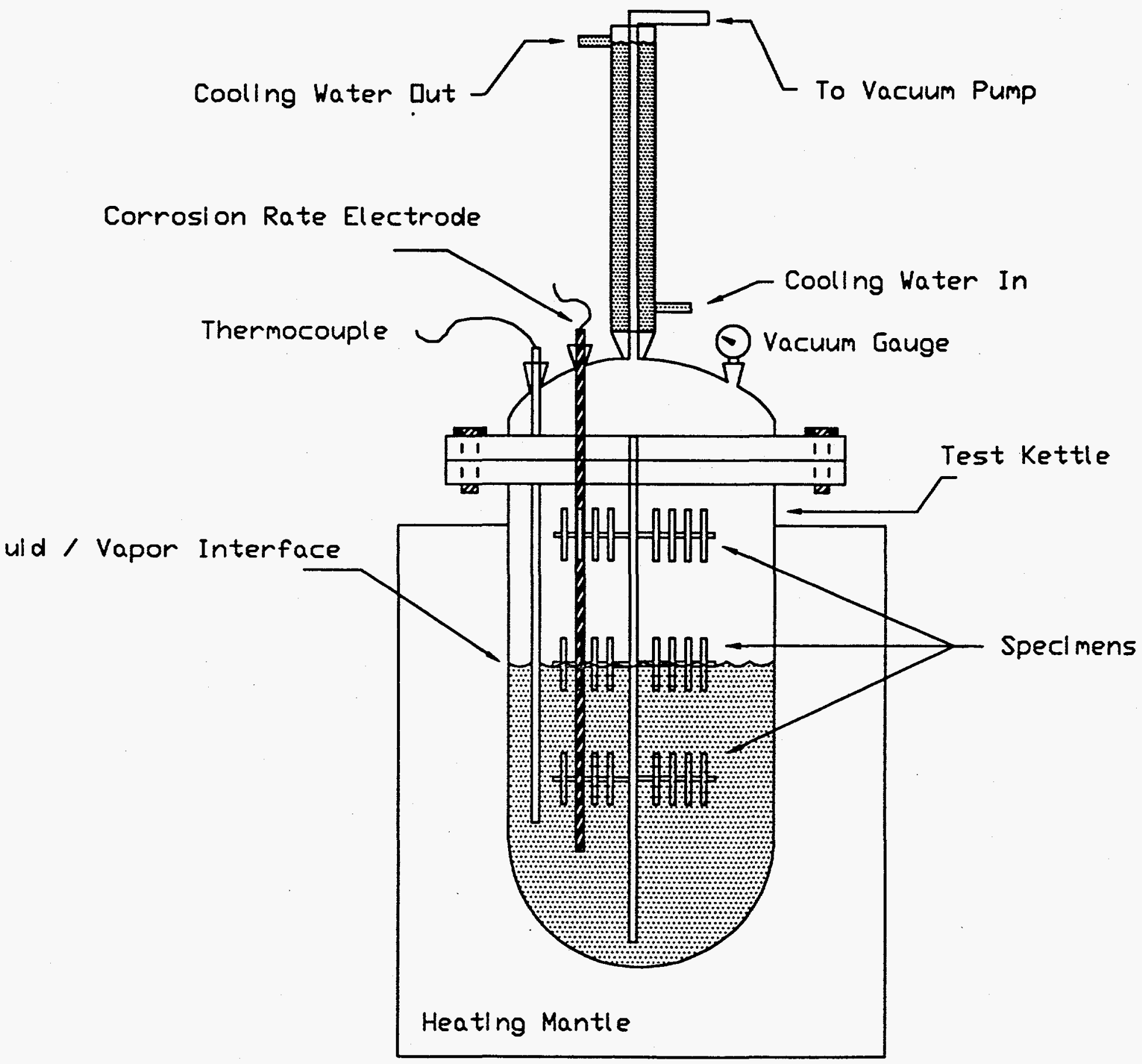

Figure 2. Resin Kettle And Associated Test Apparatus. 


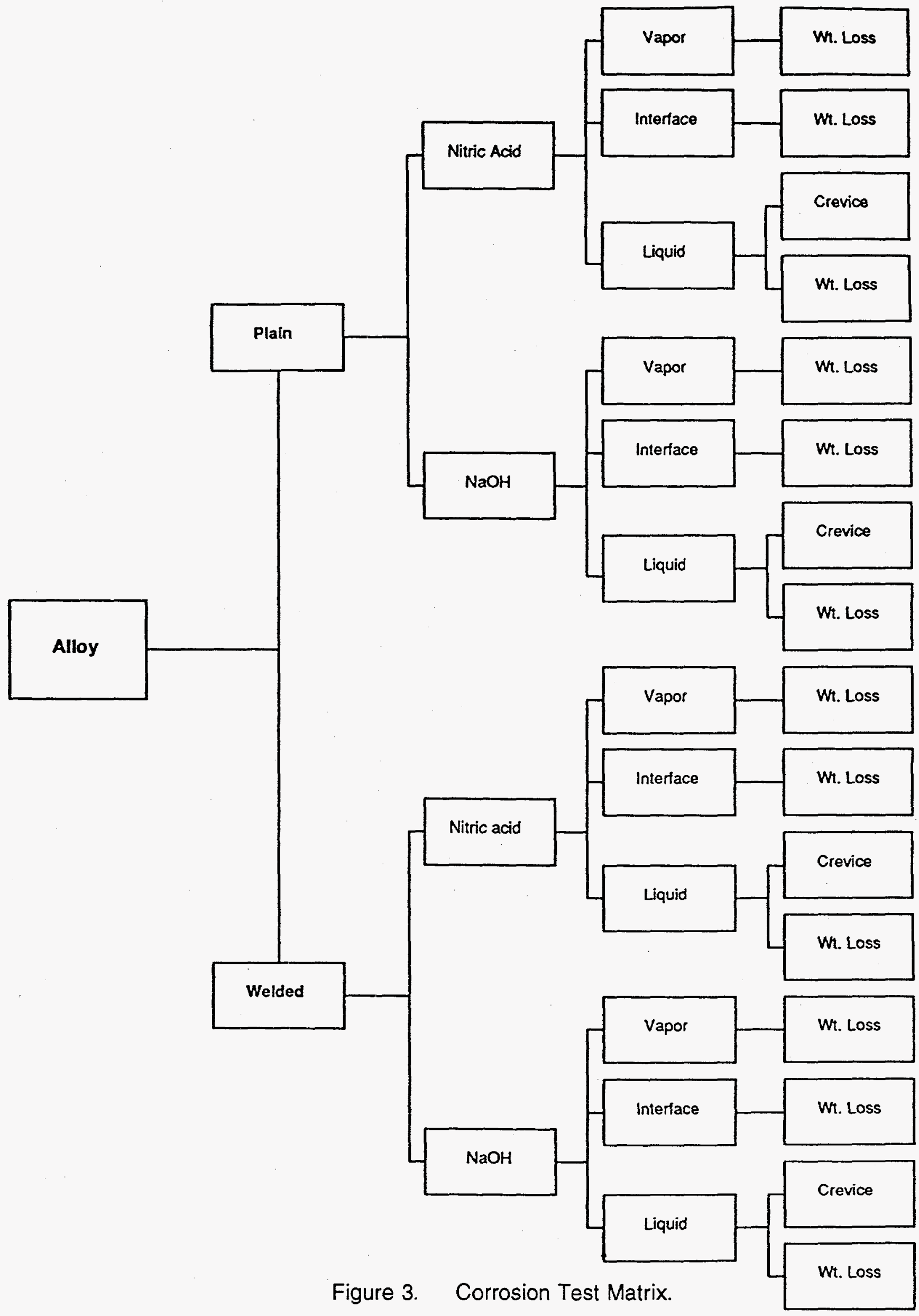




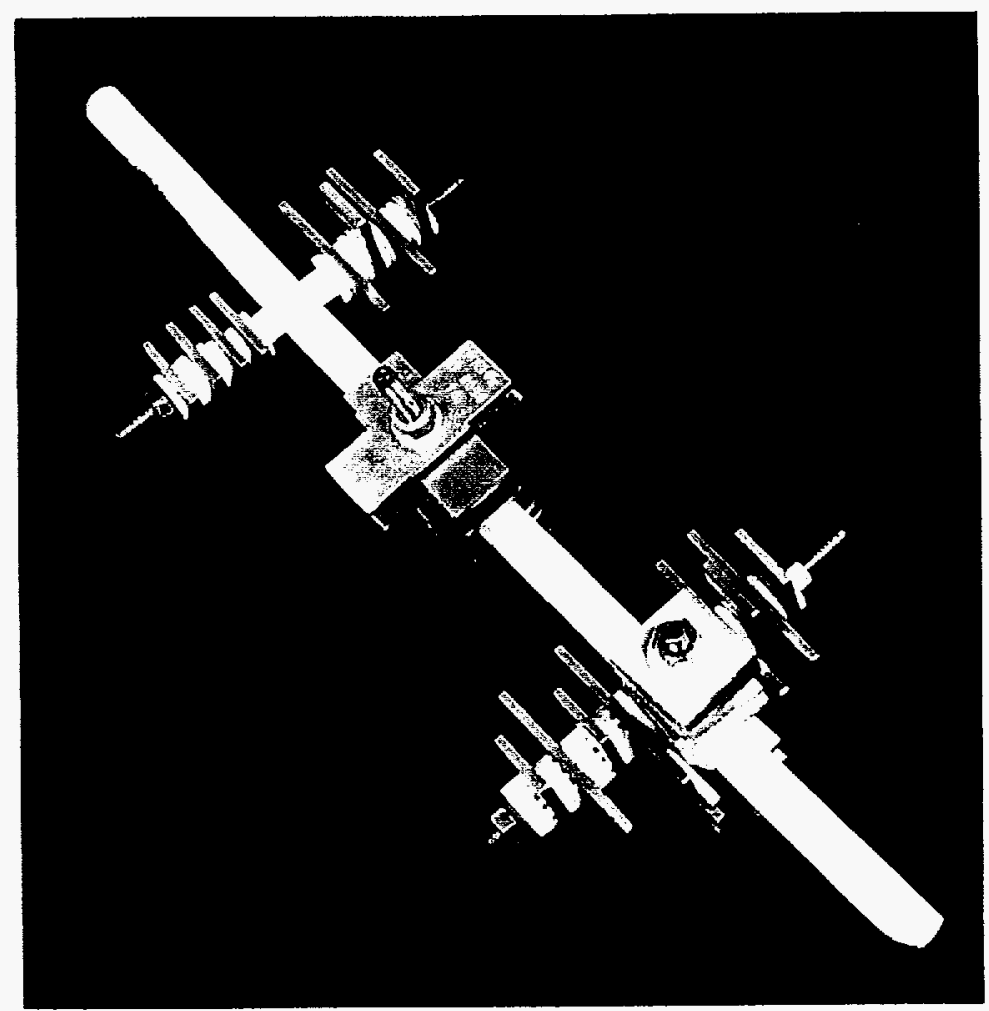

Figure 4a. Sample "Tree."

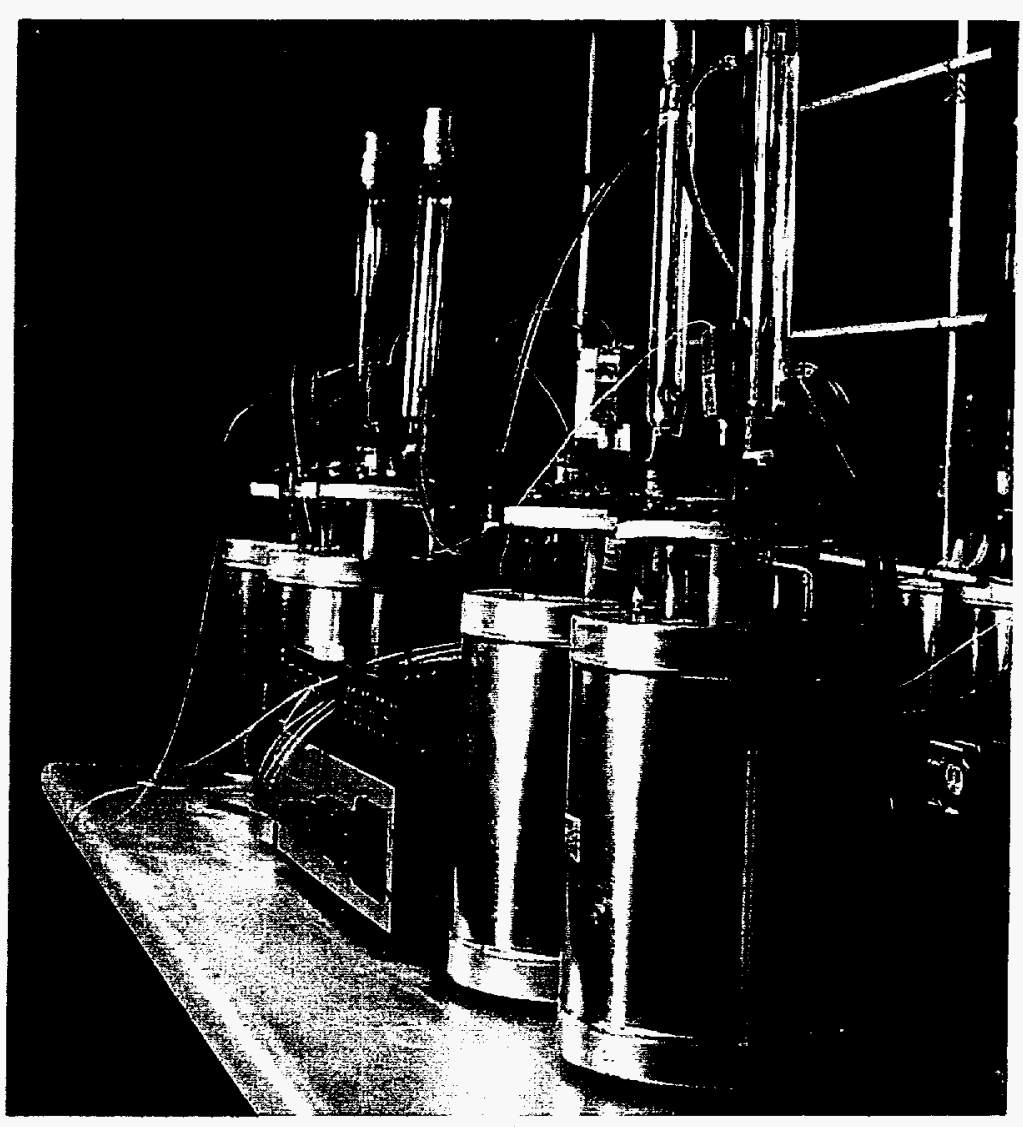

Figure 4b. Resin Kettles. 
Tabie 1. Chemical Composition of Alioys Usêd in Testing.

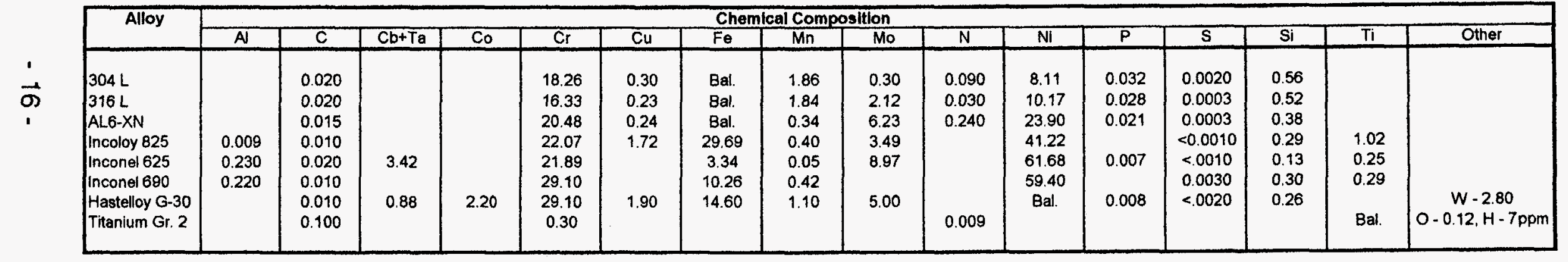




\section{Table 2. Composition of Test Solutions.}

a. Nitric Acid Test Solution Composition.

\begin{tabular}{|c|c|}
\hline Constituent & Concentration (M) \\
\hline $\mathrm{H}^{+}$ & 15.9 \\
$\mathrm{Na}^{+}$ & 2.5 \\
$\mathrm{NO}_{3}{ }^{-}$ & 18.4 \\
\hline
\end{tabular}

b. Alkaline Waste Test Solution Composition

\begin{tabular}{|c|c|}
\hline Constituent & Concentration (M) \\
\hline & $9.5 \mathrm{E}-01$ \\
Aluminum & $1.5 \mathrm{E}-02$ \\
Ammonia & $2.1 \mathrm{E}-01$ \\
Bicarbonate & $1.5 \mathrm{E}-01$ \\
Chloride & $3.1 \mathrm{E}-03$ \\
Chromium & $5.7 \mathrm{E}+00$ \\
Hydroxide & $7.9 \mathrm{E}-04$ \\
Iron & $4.0 \mathrm{E}-03$ \\
Fluoride & $2.0 \mathrm{E}-03$ \\
Manganese & $3.8 \mathrm{E}+00$ \\
Nitrate & $2.8 \mathrm{E}+00$ \\
Nitrite & $2.2 \mathrm{E}-02$ \\
Phosphate & $1.1 \mathrm{E}+00$ \\
Potassium & $9.0 \mathrm{E}+00$ \\
Sodium & $1.1 \mathrm{E}-02$ \\
Sulfate & \\
\hline
\end{tabular}


APPENDIX A

MIXING INSTRUCTIONS FOR

THE ALKALINE WASTE TEST SOLUTION 


\section{ARCONNE NATIONAL LABORATORY}

Chemical Tedhnology Division Building 205

9700 Sourt Cass Avenue, Arconne, Illinaí 60439-4837

Mr. Kurt Lawson

Cortest Columbus Technologies, Inc.

2704 Sawbury Boulevard

Columbus, $\mathrm{OH} 43235$

Dear Kurt:

Regarding our conversation on June 9, 1994 concerning the recipe for the sodium hydroxide test solution--I have outlined the compound amounts and proper mixing sequence below.

\begin{tabular}{cc}
\hline Compound & $\mathrm{g} / \mathrm{L}$ \\
\hline $\mathrm{Na}_{2} \mathrm{CO}_{3}$ & 22.26 \\
$\mathrm{Na}_{2} \mathrm{SO}_{4}$ & 1.56 \\
$\mathrm{NaCl}$ & 8.77 \\
$\mathrm{NaF}$ & 0.1680 \\
$\mathrm{NaNO}_{2}$ & 193.21 \\
$\mathrm{NaNO}_{3}$ & 78.97 \\
$\mathrm{NaOH}$ & 184.03 \\
$\mathrm{Al}\left(\mathrm{NO}_{3}\right)_{3} \bullet 9 \mathrm{H}_{2} \mathrm{O}$ & 356.35 \\
$\mathrm{Mg}\left(\mathrm{NO}_{3}\right)_{2} \cdot 6 \mathrm{H}_{2} \mathrm{O}$ & 0.5126 \\
$\mathrm{Fe}\left(\mathrm{NO}_{3}\right)_{3} \bullet 9 \mathrm{H}_{2} \mathrm{O}$ & 0.3192 \\
$\mathrm{Na}_{2} \mathrm{CrO}_{4}$ & 0.5022 \\
$\mathrm{Na} \mathrm{PO}_{4} \bullet 10 \mathrm{H}_{2} \mathrm{O}$ & 8.36 \\
$\mathrm{KOH}$ & 61.72 \\
$\mathrm{NH}_{4} \mathrm{NO}_{3}$ & 1.200 \\
\hline
\end{tabular}

1. Dissolve $\mathrm{KOH}$ and $\mathrm{NaOH}$ in $\mathrm{H}_{2} \mathrm{O}$. Start with about $50 \%$ of the required volume. Add more as necessary.

2. After $\mathrm{KOH}$ and $\mathrm{NaOH}$ have dissolved, add $\mathrm{Al}\left(\mathrm{NO}_{3}\right)_{3} \bullet 9 \mathrm{H}_{2} \mathrm{O}$ slowly until all has dissolved.

3. Add $\mathrm{Na}_{2} \mathrm{CrO}_{4}$ after $\mathrm{Al}$ has dissolved.

4. Add other salts at random except $\mathrm{NH}_{4} \mathrm{NO}_{3}$ and $\mathrm{NaNO}_{2}$. 
5. Add $\mathrm{NH}_{4} \mathrm{NO}_{3}$ and $\mathrm{NaNO}_{2}$ last.

6. Dilute to final volume.

This recipe will produce a test solution with the following concentrations:

\begin{tabular}{|c|c|c|c|}
\hline Constituent & Concentration (M) & Constituent & Concentration (M) \\
\hline Aluminum & 9.5 E-01 & Chloride & $1.5 \mathrm{E}-01$ \\
\hline Dichromate & 3.1 E-03 & Hydroxide & $5.7 \mathrm{E}+00$ \\
\hline Iron & 7.9 E-04 & Fluoride & 4.0 E-03 \\
\hline Magnesium $^{\mathrm{a}}$ & $2: 0$ E-03 & Nitrite & $2.8 \mathrm{E}+00$ \\
\hline Potassium & $1.1 \mathrm{E}+00$ & Nitrate & $3.8 \mathrm{E}+00$ \\
\hline Sodium & $9.0 \mathrm{E}+00$ & Phosphate & 2.2 E-02 \\
\hline \multirow[t]{2}{*}{ Ammonia } & 1.5 E-02 & Sulfate & 1.1 E-02 \\
\hline & & Carbonate & 2.1 E-01 \\
\hline
\end{tabular}

an the original Statement of Work, this element was incorrectly labeled as "Manganese".

I hope this is helpful. If you have any other questions, please give me a call.

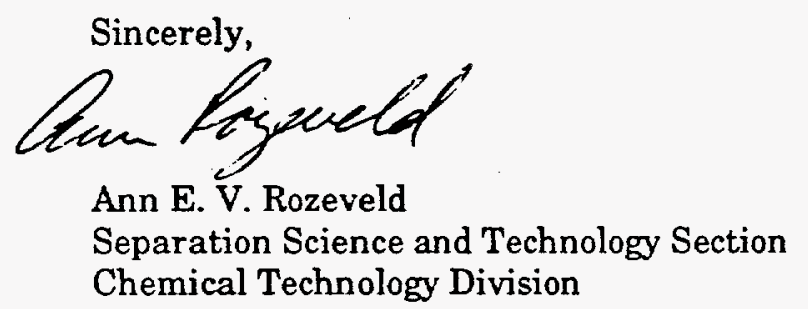

$\mathrm{AEVR} / \mathrm{dkt}$ 
APPENDIX B CORROSION RATE DATA 
Table B-1. Exposure Results - 304L Stainless Steel - Alkaline Waste, 80 C, 45 Days

\begin{tabular}{|c|c|c|c|c|c|c|}
\hline Sample ID & Condition & $\begin{array}{c}\text { Initial Weight } \\
\text { (g) }\end{array}$ & $\begin{array}{c}\text { Final Weight } \\
(\mathrm{g})\end{array}$ & $\begin{array}{c}\text { Weight Loss } \\
\text { (g) }\end{array}$ & $\begin{array}{c}\text { Corrosion Rate } \\
\text { (mpy) }\end{array}$ & $\begin{array}{c}\text { Average } \\
\text { Comosion Rate } \\
\text { (mpy) }\end{array}$ \\
\hline 1 & Wt. Loss - Liquid & 12.4311 & 12.4299 & 0.0012 & 0.04 & \\
\hline 2 & Wt. Loss - Liquid & 12.3566 & 12.3545 & 0.0021 & 0.07 & 0.06 \\
\hline 7 & Crevice - Liquid & 12.4646 & 12.4639 & 0.0007 & 0.02 & \\
\hline 8 & Crevice - Liquid & 12.5774 & 12.5765 & 0.0009 & 0.03 & 0.03 \\
\hline 9 & Wt. Loss - Interface & 12.5131 & 12.5123 & 0.0008 & 0.03 & \\
\hline 10 & Wt. Loss - Interface & 12.3460 & 12.3452 & 0.0008 & 0.03 & 0.03 \\
\hline 13 & Wt. Loss - Vapor & 12.2619 & 12.2611 & 0.0008 & 0.03 & \\
\hline 14 & Wt. Loss - Vapor & 12.5741 & 12.5733 & 0.0008 & 0.03 & 0.03 \\
\hline 631 & Weld - Wt. Loss - Liquid & 18.1673 & 18.1663 & 0.0010 & 0.02 & \\
\hline 632 & Weld - Wt. Loss - Liquid & 18.4738 & 18.4730 & 0.0008 & 0.01 & 0.02 \\
\hline 637 & Weld - Crevice - Liquid & 17.7660 & 17.7651 & 0.0009 & 0.02 & \\
\hline 638 & Weld - Crevice - Liquid & 17.5638 & 17.5628 & 0.0010 & 0.02 & 0.02 \\
\hline 639 & Weld - Wt. Loss - Interface & 17.2323 & 17.2320 & 0.0003 & 0.01 & \\
\hline 640 & Weld - Wt. Loss - Interface & 17.7362 & 17.7359 & 0.0003 & 0.01 & 0.01 \\
\hline 673 & Weld - Wt. Loss - Vapor & 17.5033 & 17.5031 & 0.0002 & 0.00 & \\
\hline 674 & Weld - Wt. Loss - Vapor & 17.9803 & 17.9800 & 0.0003 & 0.01 & 0.00 \\
\hline \multicolumn{4}{|c|}{ Average: } & \multicolumn{3}{|c|}{0.02} \\
\hline \multicolumn{3}{|c|}{ Standard Deviation: } & & \multicolumn{3}{|c|}{0.02} \\
\hline
\end{tabular}


Table B-2. Exposure Results - 304L Stainless Steel - Nitric Acid, 80 C, 45 Days

\begin{tabular}{|c|c|c|c|c|c|c|}
\hline Sample ID & Condition & $\begin{array}{c}\text { Initial Weight } \\
(\mathrm{g})\end{array}$ & $\begin{array}{c}\text { Final Weight } \\
(\mathrm{g})\end{array}$ & $\begin{array}{c}\text { Weight Loss } \\
\text { (g) }\end{array}$ & $\begin{array}{c}\text { Corrosion Rate } \\
\text { (mpy) }\end{array}$ & $\begin{array}{c}\text { Average } \\
\text { Corrosion Rate } \\
\text { (mpy) }\end{array}$ \\
\hline 3 & Wt. Loss - Liquid & 12.4053 & 12.2250 & 0.1803 & 6.35 & \\
\hline 4 & Wt. Loss - Liquid & 12.3422 & 12.1948 & 0.1474 & 5.19 & 5.77 \\
\hline 5 & Crevice - Liquid & 12.5159 & 12.3643 & 0.1516 & 5.34 & \\
\hline 6 & Crevice - Liquid & 12.4635 & 12.3245 & 0.1390 & 4.90 & 3.29 \\
\hline 11 & Wt. Loss - Interface & 12.4611 & 12.3283 & 0.1328 & 4.68 & \\
\hline 12 & Wt. Loss - Interface & 12.5189 & 12.3880 & 0.1309 & 4.61 & 4.65 \\
\hline 15 & Wt. Loss - Vapor & 12.5331 & 12.5297 & 0.0034 & 0.12 & 0.10 \\
\hline 16 & Wt. Loss - Vapor & 12.4360 & 12.4336 & 0.0024 & 0.08 & $3.04-$ \\
\hline 633 & Weld - Wt. Loss - Liquid & 17.2816 & 16.9540 & 0.3276 & 5.77 & \\
\hline 634 & Weld - Wt. Loss - Liquid & 18.7333 & 18.4750 & 0.2583 & 4.55 & 5.16 \\
\hline 635 & Weld - Crevice - Liquid & 17.4758 & 17.1780 & 0.2978 & 5.25 & \\
\hline 636 & Weld - Crevice - Liquid & 16.8980 & 16.5801 & 0.3179 & 5.60 & 5.43 \\
\hline 671 & Weld - Wt. Loss - Interface & 17.6361 & 17.3767 & 0.2594 & 4.57 & \\
\hline 672 & Weld - Wt. Loss - Interface & 17.8265 & 17.5833 & 0.2432 & 4.29 & 4.43 \\
\hline 675 & Weld - Wt. Loss - Vapor & 16.0238 & 16.0190 & 0.0048 & 0.08 & \\
\hline 676 & Weld - Wt Loss - Vapor & 17.5240 & 17.5203 & 0.0037 & 0.07 & 0.07 \\
\hline
\end{tabular}


Table B-3. Exposure Results - 316L Stainless Steel - Alkaline Waste, 80 C, 45 Days

\begin{tabular}{|c|c|c|c|c|c|c|}
\hline Sample ID & Condition & $\begin{array}{c}\text { Initial Weight } \\
\text { (g) }\end{array}$ & $\begin{array}{c}\text { Final Weight } \\
\text { (g) }\end{array}$ & $\begin{array}{c}\text { Weight Loss } \\
\text { (g) }\end{array}$ & $\begin{array}{c}\text { Corrosion Rate } \\
\text { (mpy) }\end{array}$ & $\begin{array}{c}\text { Average } \\
\text { Corrosion Rate } \\
\text { (mpy) }\end{array}$ \\
\hline 1 & Wt. Loss - Liquid & 12.7285 & 12.7275 & 0.0010 & 0.04 & \\
\hline 2 & Wt. Loss - Liquid & 12.6590 & 12.6582 & 0.0008 & 0.03 & 0.03 \\
\hline 7 & Crevice - Liquid & 12.7124 & 12.7115 & 0.0009 & 0.03 & \\
\hline 8 & Crevice - Liquid & 12.7147 & 12.7134 & 0.0013 & 0.05 & 0.04 \\
\hline 9 & Wt. Loss - Interface & 12.6205 & 12.6204 & 0.0001 & 0.00 & \\
\hline 10 & Wt. Loss - Interface & 12.4933 & 12.4922 & 0.0011 & 0.04 & 0.02 \\
\hline 13 & Wt. Loss - Vapor & 12.3405 & 12.3400 & 0.0005 & 0.02 & \\
\hline 14 & Wt. Loss - Vapor & 12.6700 & 12.6694 & 0.0006 & 0.02 & 0.02 \\
\hline 9 & Weld - Wt. Loss - Liquid & 20.2809 & 20.2790 & 0.0019 & 0.03 & \\
\hline 10 & Weld - Wt. Loss - Liquid & 20.3018 & 20.3005 & 0.0013 & 0.02 & 0.03 \\
\hline 11 & Weld - Crevice - Liquid & 20.2740 & 20.2723 & 0.0017 & 0.03 & \\
\hline 12 & Weld - Crevice - Liquid & 20.3798 & 20.3785 & 0.0013 & 0.02 & 0.03 \\
\hline 13 & Weld - Wt. Loss - Interface & 20.4488 & 20.4499 & -0.0011 & 0.00 & \\
\hline 14 & Weld - Wt. Loss - Interface & 20.2992 & 20.2992 & 0.0000 & 0.00 & 0.00 \\
\hline 15 & Weld - Wt. Loss - Vapor & 20.0904 & 20.0900 & 0.0004 & 0.01 & \\
\hline 16 & Weld - Wt. Loss - Vapor & 20.3734 & 20.3723 & 0.0011 & 0.02 & 0.01 \\
\hline \multicolumn{4}{|c|}{ Average: } & \multicolumn{3}{|c|}{0.02} \\
\hline \multicolumn{3}{|c|}{ Standard Deviation: } & & \multicolumn{3}{|c|}{0.01} \\
\hline
\end{tabular}


Table B-4. Exposure Results - 316L Stainless Steel - Nitric Acid, 80 C, 45 Days

\begin{tabular}{|c|c|c|c|c|c|c|}
\hline Sample ID & Condition & $\begin{array}{c}\text { Initial Weight } \\
\text { (g) }\end{array}$ & $\begin{array}{c}\text { Final Weight } \\
(g)\end{array}$ & $\begin{array}{l}\text { Weight Loss } \\
\text { (g) }\end{array}$ & $\begin{array}{c}\text { Corrosion Rate } \\
\text { (mpy) }\end{array}$ & $\begin{array}{c}\text { Average } \\
\text { Corrosion Rate } \\
\text { (mpy) }\end{array}$ \\
\hline 3 & Wt. Loss - Liquid & 10.6853 & 10.2901 & 0.3952 & 13.93 & \\
\hline 4 & Wt. Loss - Liquid & 12.7403 & 12.3171 & 0.4232 & 14.91 & 14.42 \\
\hline 5 & Crevice - Liquid & 12.5270 & 12.0689 & 0.4581 & 16.14 & \\
\hline 6 & Crevice - Liquid & 12.5154 & 12.0472 & 0.4682 & 16.50 & 16.32 \\
\hline 11 & Wt. Loss - Interface & 12.6331 & 12.3192 & 0.3139 & 11.06 & \\
\hline 12 & Wt. Loss - Interface & 12.4620 & 12.1077 & 0.3543 & 12.48 & 11.77 \\
\hline 15 & Wt. Loss - Vapor & 12.5574 & 12.5534 & 0.0040 & 0.14 & \\
\hline 16 & Wt. Loss - Vapor & 11.8711 & 11.8664 & 0.0047 & 0.17 & 0.15 \\
\hline 1 & Weld - Wt. Loss - Liquid & 20.1985 & 19.2662 & 0.9323 & 16.43 & \\
\hline 2 & Weld - Wt. Loss - Liquid & 20.6226 & 19.6660 & 0.9566 & 16.86 & 16.65 \\
\hline 3 & Weld - Crevice - Liquid & 20.2954 & 19.0792 & 1.2162 & 21.44 & \\
\hline 4 & Weld - Crevice - Liquid & 20.4636 & 19.2117 & 1.2519 & 22.07 & 21.75 \\
\hline 5 & Weld - Wt. Loss - Interface & 20.4969 & 19.3309 & 1.1660 & 20.55 & \\
\hline 6 & Weld - Wt. Loss - Interface & 19.7417 & 18.3842 & 1.3575 & 23.93 & 22.24 \\
\hline 7 & Weld - Wt Loss - Vapor & 202433 & 202377 & 0.0056 & 0.10 & \\
\hline 8 & Weld - Wt. Loss - Vapor & 20.1558 & 20.1511 & 0.0047 & 0.08 & 0.09 \\
\hline
\end{tabular}

Average:

12.92

Standard Deviation:

8.37 
Table B-5. Exposure Results - AL6XN Stainless Steel - Alkaline Waste, 80 C, 45 Days

\begin{tabular}{|c|c|c|c|c|c|c|}
\hline Sample ID & Condition & $\begin{array}{c}\text { Initial Weight } \\
\text { (g) }\end{array}$ & $\begin{array}{c}\text { Final Weight } \\
\text { (g) }\end{array}$ & $\begin{array}{c}\text { Weight Loss } \\
\text { (g) }\end{array}$ & $\begin{array}{c}\text { Corrosion Rate } \\
\text { (mpy) }\end{array}$ & $\begin{array}{c}\text { Average } \\
\text { Corrosion Rate } \\
\text { (mpy) }\end{array}$ \\
\hline 9 & Wt. Loss - Liquid & 12.5306 & 12.5294 & 0.0012 & 0.04 & \\
\hline 10 & Wt. Loss - Liquid & 12.8889 & 12.8872 & 0.0017 & 0.06 & 0.05 \\
\hline 11 & Crevice - Liquid & 12.7853 & 12.7842 & 0.0011 & 0.04 & \\
\hline 12 & Crevice - Liquid & 11.8396 & 11.8386 & 0.0010 & 0.03 & 0.04 \\
\hline 13 & Wt. Loss - Interface & 12.9104 & 12.9086 & 0.0018 & 0.06 & \\
\hline 14 & Wt. Loss - Interface & 12.5320 & 12.5310 & 0.0010 & 0.03 & 0.05 \\
\hline 15 & Wt. Loss - Vapor & 12.9423 & 12.9409 & 0.0014 & 0.05 & \\
\hline 16 & Wt. Loss - Vapor & 13.3706 & 13.3698 & 0.0008 & 0.03 & 0.04 \\
\hline 9 & Weld - Wt. Loss - Liquid & 21.3128 & 21.3104 & 0.0024 & 0.04 & \\
\hline 10 & Weld - Wt. Loss - Liquid & 21.5713 & 21.5664 & 0.0049 & 0.08 & 0.06 \\
\hline 11 & Weld - Crevice - Liquid & 21.7320 & 21.7289 & 0.0031 & 0.05 & \\
\hline 12 & Weld - Crevice - Liquid & 21.7030 & 21.7016 & 0.0014 & 0.02 & 0.04 \\
\hline 13 & Weld - Wt. Loss - Interface & 21.5300 & 21.5281 & 0.0019 & 0.03 & \\
\hline 14 & Weld - Wt. Loss - Interface & 21.6392 & 21.6361 & 0.0031 & 0.05 & 0.04 \\
\hline 15 & Weld - Wt. Loss - Vapor & 20.9858 & 20.9845 & 0.0013 & 0.02 & \\
\hline 16 & Weld - Wt. Loss - Vapor & 21.2347 & 21.2340 & 0.0007 & 0.01 & 0.02 \\
\hline \multicolumn{4}{|c|}{ Average: } & \multicolumn{3}{|c|}{0.04} \\
\hline \multicolumn{3}{|c|}{ Standard Deviation: } & & \multicolumn{3}{|c|}{0.02} \\
\hline
\end{tabular}


Table B-6. Exposure Results - AL6XN Stainless Steel - Nitric Acid, 80 C, 45 Days

\begin{tabular}{|c|c|c|c|c|c|c|}
\hline Sample ID & Condition & $\begin{array}{c}\text { Initial Weight } \\
(\mathrm{g})\end{array}$ & $\begin{array}{c}\text { Final Weight } \\
(\mathrm{g})\end{array}$ & $\begin{array}{c}\text { Weight Loss } \\
(\mathrm{g})\end{array}$ & $\begin{array}{c}\text { Corrosion Rate } \\
\text { (mpy) }\end{array}$ & $\begin{array}{c}\text { Average } \\
\text { Corrosion Rate } \\
\text { (mpy) }\end{array}$ \\
\hline 1 & Wt. Loss - Liquid & 12.7376 & 12.6996 & 0.0380 & 1.31 & \\
2 & Wt. Loss - Liquid & 12.6770 & 12.6414 & 0.0356 & 1.22 & 1.26 \\
3 & Crevice - Liquid & 12.6904 & 12.6185 & 0.0719 & 2.47 & \\
4 & Crevice - Liquid & 12.9028 & 12.8552 & 0.0476 & 1.64 & 2.05 \\
5 & Wt. Loss - Interface & 12.9360 & 12.8520 & 0.0840 & 2.89 & \\
6 & Wt. Loss - Interface & 12.8665 & 12.8265 & 0.0400 & 1.37 & 2.13 \\
7 & Wt. Loss - Vapor & 12.8663 & 12.8629 & 0.0034 & 0.12 & \\
8 & Wt. Loss - Vapor & 12.8371 & 12.8345 & 0.0026 & 0.09 & 0.10 \\
1 & Weld - Wt. Loss - Liquid & 21.6136 & 21.5368 & 0.0768 & 1.32 & \\
2 & Weld - Wt. Loss - Liquid & 21.7366 & 21.6879 & 0.0487 & 0.84 & 1.08 \\
3 & Weld - Crevice - Liquid & 21.8340 & 21.7819 & 0.0521 & 0.90 & \\
4 & Weld - Crevice - Liquid & 21.5543 & 21.5071 & 0.0472 & 0.81 & 0.85 \\
5 & Weld - Wt. Loss - Interface & 21.6803 & 21.5137 & 0.1666 & 2.86 & \\
6 & Weld - Wt. Loss - Interface & 21.6155 & 21.4760 & 0.1395 & 2.40 & 2.63 \\
7 & Weld - Wt. Loss - Vapor & 21.4596 & 21.4554 & 0.0042 & 0.07 & 0.07 \\
8 & Weld - Wt. Loss - Vapor & 21.5115 & 21.5071 & 0.0044 & 0.08 & 0.07 \\
\hline
\end{tabular}

Average: 
Table B-7. Exposure Results - Incoloy 825 - Alkaline Waste, 80 C, 45 Days

\begin{tabular}{|c|c|c|c|c|c|c|}
\hline Sample ID & Condition & $\begin{array}{c}\text { Initial Weight } \\
\text { (g) }\end{array}$ & $\begin{array}{c}\text { Final Weight } \\
(\mathrm{g})\end{array}$ & $\begin{array}{c}\text { Weight Loss } \\
\text { (g) }\end{array}$ & $\begin{array}{c}\text { Corrosion Rate } \\
\text { (mpy) }\end{array}$ & $\begin{array}{c}\text { Average } \\
\text { Corrosion Rate } \\
\text { (mpy) }\end{array}$ \\
\hline 9 & Wt. Loss - Liquid & 13.2024 & 13.2020 & 0.0004 & 0.01 & \\
\hline 10 & Wt. Loss - Liquid & 12.8122 & 12.8117 & 0.0005 & 0.02 & 0.02 \\
\hline 11 & Crevice - Liquid & 13.3003 & 13.2992 & 0.0011 & 0.04 & \\
\hline 12 & Crevice - Liquid & 13.2837 & 13.2832 & 0.0005 & 0.02 & 0.03 \\
\hline 13 & Wt. Loss - Interface & 13.2264 & 13.2255 & 0.0009 & 0.03 & \\
\hline 14 & Wt. Loss - Interface & 13.3308 & 13.3305 & 0.0003 & 0.01 & 0.02 \\
\hline 15 & Wt. Loss - Vapor & 13.1913 & 13.1910 & 0.0003 & 0.01 & \\
\hline 16 & Wt. Loss - Vapor & 13.0744 & 13.0738 & 0.0006 & 0.02 & 0.02 \\
\hline 109 & Weld - Wt. Loss - Liquid & 21.8268 & 21.8263 & 0.0005 & 0.01 & \\
\hline 110 & Weld - Wt. Loss - Liquid & 19.9539 & 19.9533 & 0.0006 & 0.01 & 0.01 \\
\hline 111 & Weld - Crevice - Liquid & 21.1550 & 21.1545 & 0.0005 & 0.01 & \\
\hline 112 & Weld - Crevice - Liquid & 21.3082 & 21.3076 & 0.0006 & 0.01 & 0.01 \\
\hline 113 & Weld - Wt. Loss - Interface & 20.7956 & 20.7955 & 0.0001 & 0.00 & \\
\hline 114 & Weld - Wt. Loss - Interface & 21.1859 & 21.1860 & -0.0001 & 0.00 & 0.00 \\
\hline 115 & Weld - Wt. Loss - Vapor & 21.2805 & 21.2805 & 0.0000 & 0.00 & \\
\hline 116 & Weld - Wt. Loss - Vapor & 20.9935 & 20.9935 & 0.0000 & 0.00 & 0.00 \\
\hline \multicolumn{4}{|c|}{ Average: } & \multicolumn{3}{|c|}{0.01} \\
\hline \multicolumn{4}{|c|}{ Standard Deviation: } & \multicolumn{3}{|c|}{0.01} \\
\hline
\end{tabular}


Table B-8. Exposure Results - Incoloy 825 - Nitric Acid, 80 C, 45 Days

\begin{tabular}{|c|c|c|c|c|c|c|}
\hline Sample ID & Condition & $\begin{array}{c}\text { Initial Weight } \\
(\mathrm{g})\end{array}$ & $\begin{array}{c}\text { Final Weight } \\
(\mathrm{g})\end{array}$ & $\begin{array}{c}\text { Weight Loss } \\
(\mathrm{g})\end{array}$ & $\begin{array}{c}\text { Corrosion Rate } \\
\text { (mpy) }\end{array}$ & $\begin{array}{c}\text { Average } \\
\text { Corrosion Rate } \\
(\mathrm{mpy})\end{array}$ \\
\hline 1 & Wt. Loss - Liquid & 13.3319 & 13.2160 & 0.1159 & 3.96 & \\
2 & Wt. Loss - Liquid & 13.4186 & 13.2723 & 0.1463 & 5.00 & 4.48 \\
3 & Crevice - Liquid & 13.0887 & 12.9485 & 0.1402 & 4.79 & \\
4 & Crevice - Liquid & 13.2610 & 13.1331 & 0.1279 & 4.37 & 4.58 \\
5 & Wt. Loss - Interface & 12.9922 & 12.9362 & 0.0560 & 1.92 & \\
6 & Wt. Loss - Interface & 13.2345 & 13.1828 & 0.0517 & 1.77 & 1.84 \\
7 & Wt. Loss - Vapor & 13.1588 & 13.1580 & 0.0008 & 0.03 & \\
8 & Wt. Loss - Vapor & 12.9519 & 12.9508 & 0.0011 & 0.04 & 0.03 \\
101 & Weld - Wt. Loss - Liquid & 21.0876 & 20.9474 & 0.1402 & 2.40 & \\
102 & Weld - Wt. Loss - Liquid & 21.0159 & 20.8421 & 0.1738 & 2.97 & 2.69 \\
103 & Weld - Crevice - Liquid & 21.1230 & 21.0137 & 0.1093 & 1.87 & \\
104 & Weld - Crevice - Liquid & 21.2443 & 21.0649 & 0.1794 & 3.07 & 2.47 \\
105 & Weld - Wt. Loss - Interface & 21.4018 & 21.3337 & 0.0681 & 1.16 & \\
106 & Weld - Wt. Loss - Interface & 21.1333 & 21.0648 & 0.0685 & 1.17 & 1.17 \\
107 & Weld - Wt. Loss - Vapor & 19.5562 & 19.5554 & 0.0008 & 0.01 & \\
108 & Weld - Wt. Loss - Vapor & 21.0260 & 21.0252 & 0.0008 & 0.01 & 0.01 \\
\hline
\end{tabular}

Average:

2.16

Standard Deviation:

1.74 
Table B-9. Exposure Results - Inconel 625 - Alkaline Waste, 80 C, 45 Days

\begin{tabular}{|c|c|c|c|c|c|c|}
\hline Sample ID & Condition & $\begin{array}{c}\text { Initial Weight } \\
\text { (g) }\end{array}$ & $\begin{array}{c}\text { Final Weight } \\
\text { (g) }\end{array}$ & $\begin{array}{c}\text { Weight Loss } \\
\text { (g) }\end{array}$ & $\begin{array}{c}\text { Corrosion Rate } \\
\text { (mpy) }\end{array}$ & $\begin{array}{c}\text { Average } \\
\text { Comosion Rate } \\
\text { (mpy) }\end{array}$ \\
\hline 9 & Wt. Loss - Liquid & 14.5993 & 14.5984 & 0.0009 & 0.03 & \\
\hline 10. & Wt. Loss - Liquid & 14.7592 & 14.7582 & 0.0010 & 0.03 & 0.03 \\
\hline 11 & Crevice - Liquid & 14.6116 & 14.6107 & 0.0009 & 0.03 & \\
\hline 12 & Crevice - Liquid & 14.4641 & 14.4628 & 0.0013 & 0.04 & 0.04 \\
\hline 13 & Wt. Loss - Interface & 14.7749 & 14.7739 & 0.0010 & 0.03 & \\
\hline 14 & Wt: Loss - Interface & 14.5583 & 14.5572 & 0.0011 & 0.04 & 0.03 \\
\hline 15 & Wt. Loss - Vapor & 14.6107 & 14.6096 & 0.0011 & 0.04 & \\
\hline 16 & Wt. Loss - Vapor & 14.6560 & 14.6553 & 0.0007 & 0.02 & 0.03 \\
\hline 9 & Weld - Wt. Loss - Liquid & 22.1036 & 22.1027 & 0.0009 & 0.01 & \\
\hline 10 & Weld - Wt Loss - Liquid & 22.1837 & 22.1832 & 0.0005 & 0.01 & 0.01 \\
\hline 11 & Weld - Crevice - Liquid & 22.1328 & 22.1323 & 0.0005 & 0.01 & \\
\hline 12 & Weld - Crevice - Liquid & 21.4931 & 21.4926 & 0.0005 & 0.01 & 0.01 \\
\hline 13 & Weld - Wt. Loss - Interface & 21.5755 & 21.5749 & 0.0006 & 0.01 & \\
\hline 14 & Weld - Wt. Loss - Interface & 22.0848 & 22.0843 & 0.0005 & 0.01 & 0.01 \\
\hline 15 & Weld - Wt. Loss - Vapor & 21.7762 & 21.7755 & 0.0007 & 0.01 & \\
\hline 16 & Weld - Wt Loss - Vapor & 22.1780 & 22.1775 & 0.0005 & 0.01 & 0.01 \\
\hline \multicolumn{4}{|c|}{ Average: } & \multicolumn{3}{|c|}{0.02} \\
\hline \multicolumn{3}{|c|}{ Standard Deviation: } & & \multicolumn{3}{|c|}{0.01} \\
\hline
\end{tabular}


Table B-10. Exposure Results - Inconel 625 - Nitric Acid, 80 C, 45 Days

\begin{tabular}{|c|c|c|c|c|c|c|}
\hline Sample ID & Condition & $\begin{array}{c}\text { Initial Weight } \\
\text { (g) }\end{array}$ & $\begin{array}{c}\text { Final Weight } \\
(\mathrm{g})\end{array}$ & $\begin{array}{l}\text { Weight Loss } \\
\text { (g) }\end{array}$ & $\begin{array}{c}\text { Corrosion Rate } \\
\text { (mpy) }\end{array}$ & $\begin{array}{c}\text { Average } \\
\text { Corrosion Rate } \\
\text { (mpy) }\end{array}$ \\
\hline 1 & Wt. Loss - Liquid & 14.5689 & 14.4845 & 0.0844 & 2.78 & \\
\hline 2 & Wt. Loss - Liquid & 14.6193 & 14.5099 & 0.1094 & 3.61 & 3.20 \\
\hline 3 & Crevice - Liquid & 14.6357 & 14.5270 & 0.1087 & 3.59 & \\
\hline 4 & Crevice - Liquid & 14.5411 & 14.4256 & 0.1155 & 3.81 & 3.70 \\
\hline 5 & Wt. Loss - Interface & 14.4630 & 14.3684 & 0.0946 & 3.12 & \\
\hline 6 & Wt. Loss - Interface & 14.4717 & 14.3987 & 0.0730 & 2.41 & 2.76 \\
\hline 7 & Wt. Loss - Vapor & 14.6685 & 14.6664 & 0.0021 & 0.07 & \\
\hline 8 & Wt. Loss - Vapor & 14.7600 & 14.7576 & 0.0024 & 0.08 & 0.07 \\
\hline 1 & Weld - Wt. Loss - Liquid & 21.8308 & 21.6932 & 0.1376 & 2.27 & \\
\hline 2 & Weld - Wt. Loss - Liquid & 21.8507 & 21.7245 & 0.1262 & 2.08 & 2.18 \\
\hline 3 & Weld - Crevice - Liquid & 22.2019 & 22.0973 & 0.1046 & 1.73 & \\
\hline 4 & Weld - Crevice - Liquid & 21.7327 & 21.6532 & 0.0795 & 1.31 & 1.52 \\
\hline 5 & Weld - Wt. Loss - Interface & 22.1684 & 22.0106 & 0.1578 & 2.60 & \\
\hline 6 & Weld - Wt. Loss - Interface & 22.2569 & 22.0936 & 0.1633 & 2.69 & 2.65 \\
\hline 7 & Weld - Wt. Loss - Vapor & 22.0491 & 22.0443 & 0.0048 & 0.08 & \\
\hline 8 & Weld - Wt. Loss - Vapor & 22.2296 & 22.2259 & 0.0037 & 0.06 & 0.07 \\
\hline
\end{tabular}


Table B-11. Exposure Results - Inconel 690 - Alkaline Waste, 80 C, 45 Days

\begin{tabular}{|c|c|c|c|c|c|c|}
\hline Sample ID & Condition & $\begin{array}{l}\text { Initial Weight } \\
\text { (g) }\end{array}$ & $\begin{array}{c}\text { Final Weight } \\
(g)\end{array}$ & $\begin{array}{c}\text { Weight Loss } \\
\text { (g) }\end{array}$ & $\begin{array}{c}\text { Corrosion Rate } \\
\text { (mpy) }\end{array}$ & $\begin{array}{c}\text { Average } \\
\text { Comosion Rate } \\
\text { (mpy) }\end{array}$ \\
\hline 9 & Wt. Loss - Liquid & 14.0474 & 14.0446 & 0.0028 & 0.10 & \\
\hline 10 & Wt: Loss - Liquid & 14.1820 & 14.1807 & 0.0013 & 0.04 & 0.07 \\
\hline 11 & Crevice - Liquid & 13.9978 & 13.9959 & 0.0019 & 0.06 & \\
\hline 12 & Crevice - Liquid & 14.1568 & 14.1550 & 0.0018 & 0.06 & 0.06 \\
\hline 13 & Wt. Loss - Interface & 14.2447 & 14.2439 & 0.0008 & 0.03 & \\
\hline 14 & Wt. Loss - Interface & 13.9695 & 13.9688 & 0.0007 & 0.02 & 0.03 \\
\hline 15 & Wt. Loss - Vapor & 14.2477 & 14.2458 & 0.0019 & 0.06 & \\
\hline 16 & Wt. Loss - Vapor & 13.2145 & 13.2123 & 0.0022 & 0.07 & 0.07 \\
\hline 9 & Weld - Wt. Loss - Liquid & 21.7252 & 21.7248 & 0.0004 & 0.01 & \\
\hline 10 & Weld - Wt. Loss - Liquid & 21.6447 & 21.6441 & 0.0006 & 0.01 & 0.01 \\
\hline 11 & Weld - Crevice - Liquid & 21.8455 & 21.8453 & 0.0002 & 0.00 & \\
\hline 12 & Weld - Crevice - Liquid & 22.0687 & 22.0686 & 0.0001 & 0.00 & 0.00 \\
\hline 13 & Weld - Wt. Loss - Interface & 22.1099 & 22.1096 & 0.0003 & 0.01 & \\
\hline 14 & Weld - Wt. Loss - Interface & 22.1055 & 22.1059 & -0.0004 & -0.01 & 0.00 \\
\hline 15 & Weld - Wt Loss - Vapor & 22.1788 & 22.1784 & 0.0004 & 0.01 & \\
\hline 16 & Weld - Wt. Loss - Vapor & 22.2409 & 22.2409 & 0.0000 & 0.00 & 0.00 \\
\hline
\end{tabular}

Average:

0.03

Standard Deviation:

0.03 
Table B-12. Exposure Results - Inconel 690 - Nitric Acid, 80 C, 45 Days

\begin{tabular}{|c|c|c|c|c|c|c|}
\hline Sample ID & Condition & $\begin{array}{c}\text { Initial Weight } \\
\text { (g) }\end{array}$ & $\begin{array}{c}\text { Final Weight } \\
\text { (g) }\end{array}$ & $\begin{array}{c}\text { Weight Loss } \\
\text { (g) }\end{array}$ & $\begin{array}{c}\text { Comosion Rate } \\
\text { (mpy) }\end{array}$ & $\begin{array}{c}\text { Average } \\
\begin{array}{c}\text { Corrosion Rate } \\
\text { (mpy) }\end{array}\end{array}$ \\
\hline 1 & Wt. Loss - Liquid & 14.0705 & 14.0229 & 0.0476 & 1.62 & \\
\hline 2 & Wt. Loss - Liquid & 14.1730 & 14.1221 & 0.0509 & 1.73 & 1.67 \\
\hline 3 & Crevice - Liquid & 13.3507 & 13.3069 & 0.0438 & 1.49 & \\
\hline 4 & Crevice - Liquid & 13.0137 & 12.9687 & 0.0450 & 1.53 & 1.51 \\
\hline 5 & Wt. Loss - Interface & 13.6287 & 13.6049 & 0.0238 & 0.81 & \\
\hline 6 & Wt. Loss - Interface & 14.0710 & 14.0567 & 0.0143 & 0.49 & 0.65 \\
\hline 7 & Wt. Loss - Vapor & 13.9528 & 13.9520 & 0.0008 & 0.03 & \\
\hline 8 & Wt. Loss - Vapor & 13.5860 & 13.5852 & 0.0008 & 0.03 & 0.03 \\
\hline 1 & Weld - Wt. Loss - Liquid & 21.4776 & 21.3971 & 0.0805 & 1.37 & \\
\hline 2 & Weld - Wt Loss - Liquid & 21.7257 & 21.6295 & 0.0962 & 1.64 & 1.50 \\
\hline 3 & Weld - Crevice - Liquid & 22.2794 & 22.2062 & 0.0732 & 1.24 & \\
\hline 4 & Weld - Crevice - Liquid & 21.9229 & 21.8342 & 0.0887 & 1.51 & 1.38 \\
\hline 5 & Weld - Wt. Loss - Interface & 21.9297 & 21.8994 & 0.0303 & 0.52 & \\
\hline 6 & Weld - Wt. Loss - Interface & 21.9927 & 21.9634 & 0.0293 & 0.50 & 0.51 \\
\hline 7 & Weld - Wt. Loss - Vapor & 22.0750 & 22.0746 & 0.0004 & 0.01 & \\
\hline 8 & Weld - Wt. Loss - Vapor & 22.0857 & 22.0846 & 0.0011 & 0.02 & 0.01 \\
\hline
\end{tabular}


Table B-13. Exposure Results - Hastelloy G-30 - Alkaline Waste, 80 C, 45 Days

\begin{tabular}{|c|c|c|c|c|c|c|}
\hline Sample ID & Condition & $\begin{array}{l}\text { Initial Weight } \\
\text { (g) }\end{array}$ & $\begin{array}{c}\text { Final Weight } \\
(\mathrm{g})\end{array}$ & $\begin{array}{c}\text { Weight Loss } \\
(\mathrm{g})\end{array}$ & $\begin{array}{c}\text { Corrosion Rate } \\
\text { (mpy) }\end{array}$ & $\begin{array}{c}\text { Average } \\
\text { Corrosion Rate } \\
\text { (mpy) }\end{array}$ \\
\hline 1 & Wt. Loss - Liquid & 14.4937 & 14.4936 & 0.0001 & 0.00 & \\
\hline 2 & Wt. Loss - Liquid & 14.4341 & 14.4337 & 0.0004 & 0.01 & 0.01 \\
\hline 3 & Crevice - Liquid & 14.4916 & 14.4914 & 0.0002 & 0.01 & \\
\hline 4 & Crevice - Liquid & 14.5846 & 14.5837 & 0.0009 & 0.03 & 0.02 \\
\hline 5 & Wt. Loss - Interface & 14.2514 & 14.2510 & 0.0004 & 0.01 & \\
\hline 6 & Wt. Loss - Interface & 14.5476 & 14.5474 & 0.0002 & 0.01 & 0.01 \\
\hline 7 & Wt. Loss - Vapor & 14.3813 & 14.3811 & 0.0002 & 0.01 & \\
\hline 8 & Wt. Loss - Vapor & 14.5407 & 14.5404 & 0.0003 & 0.01 & 0.01 \\
\hline 101 & Weld - Wt. Loss - Liquid & 20.7638 & 20.7633 & 0.0005 & 0.01 & \\
\hline 102 & Weld - Wt. Loss - Liquid & 20.2044 & 20.2047 & -0.0003 & 0.00 & 0.00 \\
\hline 103 & Weld - Crevice - Liquid & 21.4097 & 21.4103 & -0.0006 & 0.00 & \\
\hline 104 & Weld - Crevice - Liquid & 21.6047 & 21.6052 & -0.0005 & 0.00 & 0.00 \\
\hline 105 & Weld - Wt. Loss - Interface & 21.2474 & 21.2482 & -0.0008 & 0.00 & \\
\hline 106 & Weld - Wt Loss - Interface & 21.5521 & 21.5524 & -0.0003 & 0.00 & 0.00 \\
\hline 107 & Weld - Wt. Loss - Vapor & 21.3956 & 21.3960 & -0.0004 & 0.00 & \\
\hline 108 & Weld - Wt. Loss - Vapor & 21.4382 & 21.4390 & -0.0008 & 0.00 & 0.00 \\
\hline
\end{tabular}

Average:

0.01

Standard Deviation:

0.01 
Table B-14. Exposure Results - Hastelloy G-30 - Nitric Acid, 80 C, 45 Days

\begin{tabular}{|c|c|c|c|c|c|c|}
\hline Sample ID & Condition & $\begin{array}{c}\text { Initial Weight } \\
(\mathrm{g})\end{array}$ & $\begin{array}{c}\text { Final Weight } \\
(\mathrm{g})\end{array}$ & $\begin{array}{c}\text { Weight Loss } \\
(\mathrm{g})\end{array}$ & $\begin{array}{c}\text { Corrosion Rate } \\
\text { (mpy) }\end{array}$ & $\begin{array}{c}\text { Corrosion Rate } \\
\text { (mpy) }\end{array}$ \\
\hline 9 & Wt. Loss - Liquid & 14.2112 & 14.1896 & 0.0216 & 0.72 & \\
10 & Wt. Loss - Liquid & 14.3810 & 14.3560 & 0.0250 & 0.84 & 0.78 \\
11 & Crevice - Liquid & 14.4856 & 14.4577 & 0.0279 & 0.93 & \\
12 & Crevice - Liquid & 14.6124 & 14.5787 & 0.0337 & 1.13 & 1.03 \\
13 & Wt. Loss - Interface & 14.4856 & 14.4607 & 0.0249 & 0.83 & \\
14 & Wt. Loss - Interface & 14.3135 & 14.2848 & 0.0287 & 0.96 & 0.90 \\
15 & Wt. Loss - Vapor & 14.6053 & 14.6040 & 0.0013 & 0.04 & \\
16 & Wt. Loss - Vapor & 14.6308 & 14.6299 & 0.0009 & 0.03 & 0.04 \\
109 & Weld - Wt. Loss - Liquid & 21.2571 & 21.2250 & 0.0321 & 0.54 & \\
110 & Weld - Wt. Loss - Liquid & 21.6100 & 21.5764 & 0.0336 & 0.56 & 0.55 \\
111 & Weld - Crevice - Liquid & 21.2915 & 21.2511 & 0.0404 & 0.68 & \\
112 & Weld - Crevice - Liquid & 21.5520 & 21.5098 & 0.0422 & 0.71 & 0.69 \\
113 & Weld - Wt. Loss - Interface & 21.3955 & 21.3608 & 0.0347 & 0.58 & \\
114 & Weld - Wt. Loss - Interface & 21.4694 & 21.4330 & 0.0364 & 0.61 & 0.60 \\
115 & Weld - Wt. Loss - Vapor & 21.4588 & 21.4568 & 0.0020 & 0.03 & \\
116 & Weld - Wt. Loss - Vapor & 21.4183 & 21.4165 & 0.0018 & 0.03 & 0.03 \\
\hline
\end{tabular}

Average: $\quad 0.58$

Standard Deviation: $\quad 0.36$ 
Table B-15. Exposure Results - Titanium 2 - Alkaline Waste, 80 C, 45 Days

\begin{tabular}{|c|c|c|c|c|c|c|}
\hline Sample ID & Condition & $\begin{array}{c}\text { Initial Weight } \\
\text { (g) }\end{array}$ & $\begin{array}{c}\text { Final Weight } \\
\text { (g) }\end{array}$ & $\begin{array}{c}\text { Weight Loss } \\
\text { (g) }\end{array}$ & $\begin{array}{c}\text { Corrosion Rate } \\
\text { (mpy) }\end{array}$ & $\begin{array}{c}\text { Average } \\
\text { Corrosion Rate } \\
\text { (mpy) }\end{array}$ \\
\hline 1 & Wt. Loss - Liquid & 7.3417 & 7.3401 & 0.0016 & 0.10 & \\
\hline 2 & Wt. Loss - Liquid & 7.3750 & 7.3736 & 0.0014 & 0.09 & 0.09 \\
\hline 3 & Crevice - Liquid & 7.4744 & 7.4729 & 0.0015 & 0.09 & \\
\hline 4 & Crevice - Liquid & 7.4681 & 7.4668 & 0.0013 & 0.08 & 0.09 \\
\hline 5 & Wt. Loss - Interface & 7.5158 & 7.5139 & 0.0019 & 0.12 & \\
\hline 6 & Wt. Loss - interface & 7.5703 & 7.5682 & 0.0021 & 0.13 & 0.12 \\
\hline 7 & Wt. Loss - Vapor & 7.4863 & 7.4852 & 0.0011 & 0.07 & \\
\hline 8 & Wt. Loss - Vapor & 7.4128 & 7.4116 & 0.0012 & 0.07 & 0.07 \\
\hline 1 & Weld - Wt. Loss - Liquid & 11.6762 & 11.6749 & 0.0013 & 0.08 & \\
\hline 2 & Weld - Wt. Loss - Liquid & 11.7261 & 11.7242 & 0.0019 & 0.12 & 0.10 \\
\hline 3 & Weld - Crevice - Liquid & 11.5776 & 11.5758 & 0.0018 & 0.11 & \\
\hline 4 & Weld - Crevice - Liquid & 11.6418 & 11.6398 & 0.0020 & 0.12 & 0.12 \\
\hline 5 & Weld - Wt. Loss - Interface & 11.4370 & 11.4345 & 0.0025 & 0.15 & \\
\hline 6 & Weld - Wt. Loss - Interface & 11.8120 & 11.8095 & 0.0025 & 0.15 & 0.15 \\
\hline 7 & Weld - Wt. Loss - Vapor & 11.6877 & 11.6868 & 0.0009 & 0.06 & \\
\hline 8 & Weld - Wt. Loss - Vapor & 11.8014 & 11.8002 & 0.0012 & 0.07 & 0.06 \\
\hline
\end{tabular}

Average:

0.10

Standard Deviation: 
Table B-16. Exposure Results - Titanium 2 - Nitric Acid, 80 C, 45 Days

\begin{tabular}{|c|c|c|c|c|c|c|}
\hline Sample ID & Condition & $\begin{array}{c}\text { Initial Weight } \\
(9)\end{array}$ & $\begin{array}{c}\text { Final Weight } \\
(g)\end{array}$ & $\begin{array}{c}\text { Weight Loss } \\
(g)\end{array}$ & $\begin{array}{c}\text { Corrosion Rate } \\
\text { (mpy) }\end{array}$ & $\begin{array}{c}\text { Average } \\
\text { Corrosion Rate } \\
\text { (mpy) }\end{array}$ \\
\hline 9 & Wt. Loss - Liquid & 7.7239 & 7.7115 & 0.0124 & 0.77 & \\
\hline 10 & Wt. Loss - Liquid & 7.5176 & 7.5172 & 0.0004 & 0.02 & 0.40 \\
\hline 11 & Crevice - Liquid & 7.5567 & 7.5565 & 0.0002 & 0.01 & \\
\hline 12 & Crevice-Liquid & 7.6266 & 7.6263 & 0.0003 & 0.02 & 0.02 \\
\hline 13 & Wt. Loss - Interface & 7.5806 & 7.5803 & 0.0003 & 0.02 & \\
\hline 14 & Wt. Loss - Interface & 7.3855 & 7.3851 & 0.0004 & 0.02 & 0.02 \\
\hline 15 & Wt. Loss - Vapor & 7.6163 & 7.6155 & 0.0008 & 0.05 & \\
\hline 16 & Wt. Loss - Vapor & 7.3702 & 7.3700 & 0.0002 & 0.01 & 0.03 \\
\hline 9 & Weld - Wt. Loss - Liquid & 11.7715 & 11.7711 & 0.0004 & 0.02 & \\
\hline 10 & Weld - Wt. Loss - Liquid & 11.8157 & 11.8155 & 0.0002 & 0.01 & 0.02 \\
\hline 11 & Weld - Crevice - Liquid & 11.7916 & 11.7914 & 0.0002 & 0.01 & \\
\hline 12 & Weld - Crevice - Liquid & 11.5847 & 11.5844 & 0.0003 & 0.02 & 0.02 \\
\hline 13 & Weld - Wt. Loss - Interface & 11.6036 & 11.6029 & 0.0007 & 0.04 & \\
\hline 14 & Weld - Wt. Loss - Interface & 11.4668 & 11.4660 & 0.0008 & 0.05 & 0.05 \\
\hline 15 & Weld - Wt. Loss - Vapor & 11.7683 & 11.7677 & 0.0006 & 0.04 & \\
\hline 16 & Weld - Wt. Loss - Vapor & 10.7186 & 10.7182 & 0.0004 & 0.02 & 0.03 \\
\hline
\end{tabular}

Average:

0.07

Standard Deviation:

0.19 